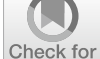

Check for

updates

Cite as

Nano-Micro Lett.

(2021) 13:49

Received: 25 September 2020

Accepted: 19 November 2020

Published online: 4 January 2021

(C) The Author(s) 2021

\section{Laser Synthesis and Microfabrication of Micro/ Nanostructured Materials Toward Energy Conversion and Storage}

\author{
Lili Zhao ${ }^{1}$, Zhen Liu ${ }^{1}$, Duo Chen ${ }^{1}$, Fan $\mathrm{Liu}^{1}$, Zhiyuan Yang ${ }^{3}$, Xiao $\mathrm{Li}^{1}$, Haohai $\mathrm{Yu}^{2}$, \\ Hong Liu ${ }^{1,2}$, Weijia Zhou ${ }^{1}$ 凶
}

\title{
HIGHLIGHTS
}

- The current understanding and advances on laser synthesis of nanomaterials are summarized.

- The laser microfabrication-enabled energy conversion and storage devices are reviewed.

- The limitations and solutions for current laser processing of nanomaterials and other more potential development directions for laser processing are proposed.

\begin{abstract}
Nanomaterials are known to exhibit a number of interesting physical and chemical properties for various applications, including energy conversion and storage, nanoscale electronics, sensors and actuators, photonics devices and even for biomedical purposes. In the past decade, laser as a synthetic technique and laser as a microfabrication technique facilitated nanomaterial preparation and nanostructure construction, including the laser processing-induced carbon and non-carbon nanomaterials, hierarchical structure construction, patterning, heteroatom doping, sputtering etching, and so on. The laser-induced nanomaterials and nanostructures have extended broad applications in electronic devices, such as light-thermal conversion, batteries, supercapacitors, sensor devices, actuators and electrocatalytic electrodes. Here, the recent developments in the laser synthesis of carbon-based and non-carbon-based nanomaterials are comprehensively summarized. An extensive overview on laser-enabled electronic devices for various applications is depicted. With the rapid progress made in the research on nanomaterial preparation through laser synthesis and laser microfabrication technologies, laser synthesis and microfabrication toward energy conversion and storage will undergo fast development.
\end{abstract}

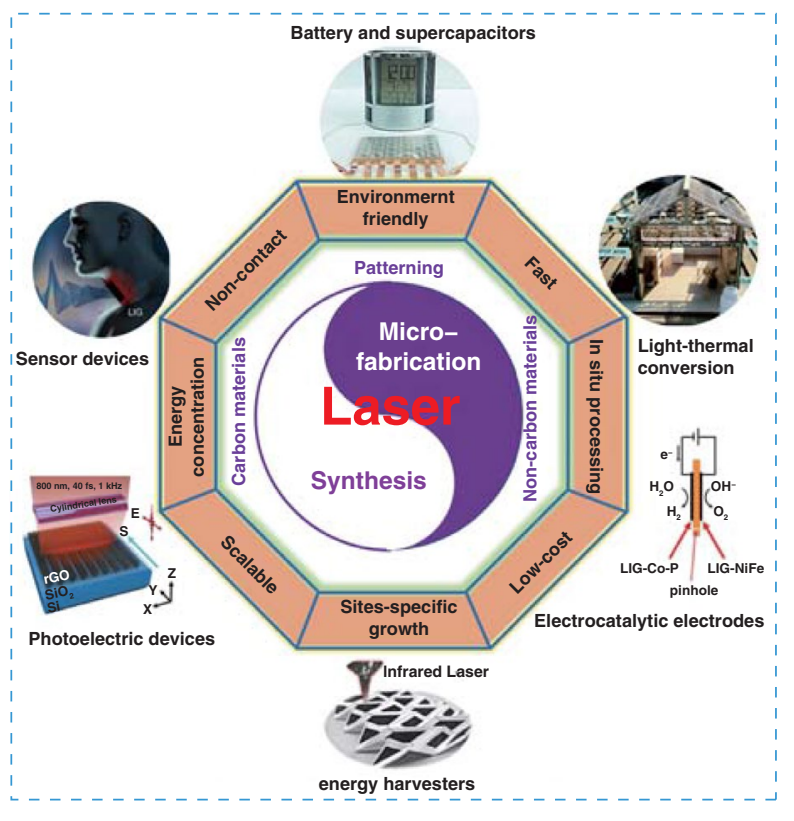

KEYWORDS Laser synthesis; Laser microfabrication; Micro/nanostructured materials; Energy conversion and storage

Lili Zhao, Zhen Liu and Duo Chen have contributed equally to this work

$\triangle$ Hong Liu, hongliu@sdu.edu.cn; Weijia Zhou, ifc_zhouwj@ujn.edu.cn

1 Collaborative Innovation Center of Technology and Equipment for Biological Diagnosis and Therapy in Universities of Shandong, Institute for Advanced Interdisciplinary Research (iAIR), University of Jinan, Jinan 250022, People's Republic of China

2 State Key Laboratory of Crystal Materials, Shandong University, Jinan 250100, People's Republic of China

3 School of Information Science and Engineering, Shandong University, 72 Binhai Road, Qingdao 266237, People's Republic of China 


\begin{tabular}{|c|c|}
\hline Abbreviatio & \\
\hline GO & Graphene oxide \\
\hline rGO & Reduced graphene oxide \\
\hline $\mathrm{G}$ & Graphene \\
\hline GF & Graphene foam \\
\hline DVD & Digital video disk \\
\hline TE & Transverse electric \\
\hline DP & Dielectric permittivity \\
\hline TE-SPs & Transverse electric mode surface plasmons \\
\hline Nd-YAG & $\begin{array}{l}\text { Neodymium-doped yttrium aluminum } \\
\text { garnet }\end{array}$ \\
\hline PI & Polyimide \\
\hline LIG & Laser-induced graphene \\
\hline LIGP & Laser-induced graphene paper \\
\hline LSG & Laser-scribed graphene \\
\hline LOM & Laminated object manufacturing \\
\hline $3 \mathrm{D}$ & Three dimensional \\
\hline PTFE & Polytetrafluoroethylene \\
\hline $\mathrm{CNS}$ & Carbon nanospheres \\
\hline CVD & Chemical vapor deposition \\
\hline EG & Epitaxial growth \\
\hline $\mathrm{SiC}$ & Silicon carbide \\
\hline DLC & Diamond-like carbon \\
\hline PLD & Pulsed laser deposition \\
\hline OES & Optical emission spectroscopy \\
\hline LIF & Laser-induced fluorescence \\
\hline PET & Polyethylene terephthalate \\
\hline PBI & Polybenzimidazole \\
\hline DMSO & Dimethyl sulfoxide \\
\hline ITO & Indium tin oxide \\
\hline FTO & F-doped tin oxide \\
\hline LIBs & Lithium-ion batteries \\
\hline MOFs & Metal-organic frameworks \\
\hline ZIF-67 & Zeolitic imidazolate frameworks \\
\hline MNPs & Metal nanoparticles \\
\hline nano-LaMP & Nanoscale laser metallurgy and patterning \\
\hline TMCs & Transition metal carbide nanoparticles \\
\hline MCG & Molybdenum carbide-graphene \\
\hline TMDs & Transition metal dichalcogenides \\
\hline LIAS & Laser irradiation-assisted selenization \\
\hline PSCs & Perovskite solar cells \\
\hline LAL & Laser ablation in liquids \\
\hline LFL & Laser fragmentation in liquids \\
\hline LML & Laser melting in liquids \\
\hline PLAL & $\begin{array}{l}\text { Pulsed laser ablation of a solid target in } \\
\text { liquids }\end{array}$ \\
\hline PLICN & $\begin{array}{l}\text { Pulsed laser irradiation of colloidal nano- } \\
\text { particles in liquids }\end{array}$ \\
\hline AuNPs & Gold nanoparticles \\
\hline & Femtosecond \\
\hline
\end{tabular}

$\begin{array}{ll}\text { LDHs } & \text { Layered double hydroxides } \\ \text { TONs } & \text { Ternary oxide nanocrystals } \\ \text { SAAs } & \text { Single-atom alloys } \\ \text { Cl-CDs } & \text { Cl-functionalized carbon dots } \\ \text { CB } & \text { Conduction band } \\ \text { N-CNTs } & \text { N-doped carbon nanotubes } \\ \text { MWCNT } & \text { Multi-walled carbon nanotube } \\ \text { UV } & \text { Ultraviolet } \\ \text { Vis } & \text { Visible } \\ \text { NIR } & \text { Near infrared } \\ \text { CW } & \text { Continuous wave } \\ \text { SSG } & \text { Solar steam generation } \\ \text { OPN } & \text { Optothermally gated photon nudging } \\ \text { HOPGF } & \text { Highly vertically ordered pillar array of } \\ & \text { graphene framework } \\ \text { EES } & \text { Electrochemical energy storage } \\ \text { SCs } & \text { Supercapacitors } \\ \text { MSCs } & \text { Micro-supercapacitors } \\ \text { PANI } & \text { Polyaniline } \\ \text { LaCVP } & \text { Laser-assisted chemical vapor pyrolysis } \\ \text { LDW } & \text { Laser direct writing } \\ \text { RH } & \text { Relative humidity } \\ \text { TENG } & \text { Triboelectric nanogenerator } \\ \text { OLED } & \text { Organic light-emitting device } \\ \text { BJTs } & \text { Bipolar junction transistors } \\ \text { OTNL } & \text { Optothermoplasmonic nanolithography } \\ \text { HER } & \text { Hydrogen evolution reaction } \\ \text { OER } & \text { Oxygen evolution reaction } \\ \text { ORR } & \text { Oxygen reduction reaction } \\ \text { LIG-O } & \text { Oxidized laser-induced graphene } \\ \text { LIG-A } & \text { Annealed laser-induced graphene } \\ \text { GC electrode } & \text { Glassy carbon electrode } \\ & \end{array}$

\section{Introduction}

Nanomaterials have presented a number of interesting physical and chemical properties for various applications, including energy storage and conversion [1], nanoscale electronics [2], sensors and actuators [3], photonics devices [4], and even for biomedical purposes [5]. The researches on nanomaterial synthesis have a long history, and a large number of different synthesis approaches have been performed up until now, including the wet chemical method in solution conducting environment and the thermal treatment process in gas conducting environment. However, uniform and largescale production of nanomaterials remains a challenge, and the nanomaterials synthesized through these conventional approaches are non-site specific in general. Thus, new 
technologies for large-scale production and position controllability are necessary.

The laser as a synthetic technique and laser as a microfabrication technique provide the alternative choice, which has the advantages of fast, scalable, environment friendly, costeffective and permitting in situ processing [6,7]. Compared with the traditional synthesis and microfabrication techniques, laser-assisted processing techniques enable direct synthesis of nanomaterials in both gas environment and liquid environment with environment friendliness and less energy loss; especially, the suitability for processing of thermally sensitive substrates has more advantages. On the other hand, recent advances in laser microfabrication incorporate mask unemployment for more advanced patterns of nanomaterials. Specially, as the synthetic technique, the traditional wet chemical methods are capable of producing nanomaterials with unique morphologies, but toxic or environmentally unfriendly reagents were frequently used. On the contrary, laser synthesis methods in solution conducting environment commonly used the target as precursor, avoiding the use of toxic reagents, and nanomaterials with smaller particle sizes can be obtained through regulation of the laser power, laser wavelength, laser focal length, laser pulse width and laser frequency [8]. Thermal treatment or annealing process is also frequently used methods for nanomaterial synthesis, which is conducted in the furnace at a high temperature by depending on the material formation thermodynamics. But this procedure undergoes some issues of time consuming, high thermal power and energy loss with sample dimensions considerably smaller than the heated volume. In addition, such methods are not suitable for thermally sensitive substrates such as ITO glass or polymers, where microstructural changes and thermal-expansion mismatch will occur under high temperatures. Alternatively, the laser synthesis technique with a focused irradiation beam enables a site-specific growth of nanomaterials based on the local photo-thermochemical reaction, which possesses the general advantages of spatially confined reaction, non-contact, fast processing speeds by direct writing and 3D compatibility [9]. The advantage of spatially confined reaction for laser synthesis technology means that the laser-induced photothermal effect or photochemical effect through synthesis of the purpose materials at a localized position to construct the patterned nanostructures. This can be called the spatially confined reaction by laser, which is strongly dependent on the laser process parameters, especially the pulse width. In addition, additional selectivity and unique properties of nanomaterials for some special applications can be conveyed by regulating the applied laser parameters [10]. As the microfabrication technique, employing masks for the definition of patterns on substrates and lithographic techniques are essential for the conventional fabrication method, which are awkward and expensive for constructing various devices for applications. The laser microfabrication technique obviates the need for masks and lithography, thereby enhancing the production yield of devices and promoting flexibility in the design of device geometry [11]. In conclusion, the laser provides not only an effective alternative to the conventional synthesis and microfabrication processes, but also innovative selective synthesis and microfabrication strategies for efficient usage of nanomaterials with minimized environmental requirements and damage on the substrate.

Herein, this review focuses on the nanostructures and nanomaterials using laser as synthesis and microfabrication technique, which are applied in energy conversion and storage. As well known, the absorption of laser by the precursor materials and then resulting in various effects, such as melting, plasma formation and vaporization, are the basis of laser processing of materials. As the consequence, the characteristics of the laser (laser intensity, wavelength and pulse width) and the photo-thermophysical properties of the precursors determine the extent of these effects. In this review, we initially discuss laser processing as the synthetic technique for nanomaterial synthesis, including carbon nanomaterials and non-carbon nanomaterials. Subsequently, we provide a comprehensive overview on the laser as a microfabrication technique applied in light-thermal conversion, batteries and supercapacitors, sensors, or actuators and electrocatalytic electrodes (Scheme 1). Finally, recent progress and advances in laser synthesis and microfabrication processing of nanomaterials for applications in various devices are discussed.

\section{Laser as the Synthetic Technique}

Recent technological advances in the development of diverse lasers have opened new avenues in material synthesis, no matter in solid form or in solution environment. The laser technique has long been utilized for material synthesis, which is realized by the photothermal reaction, photochemical reaction or photo-thermal-chemical reaction derived 


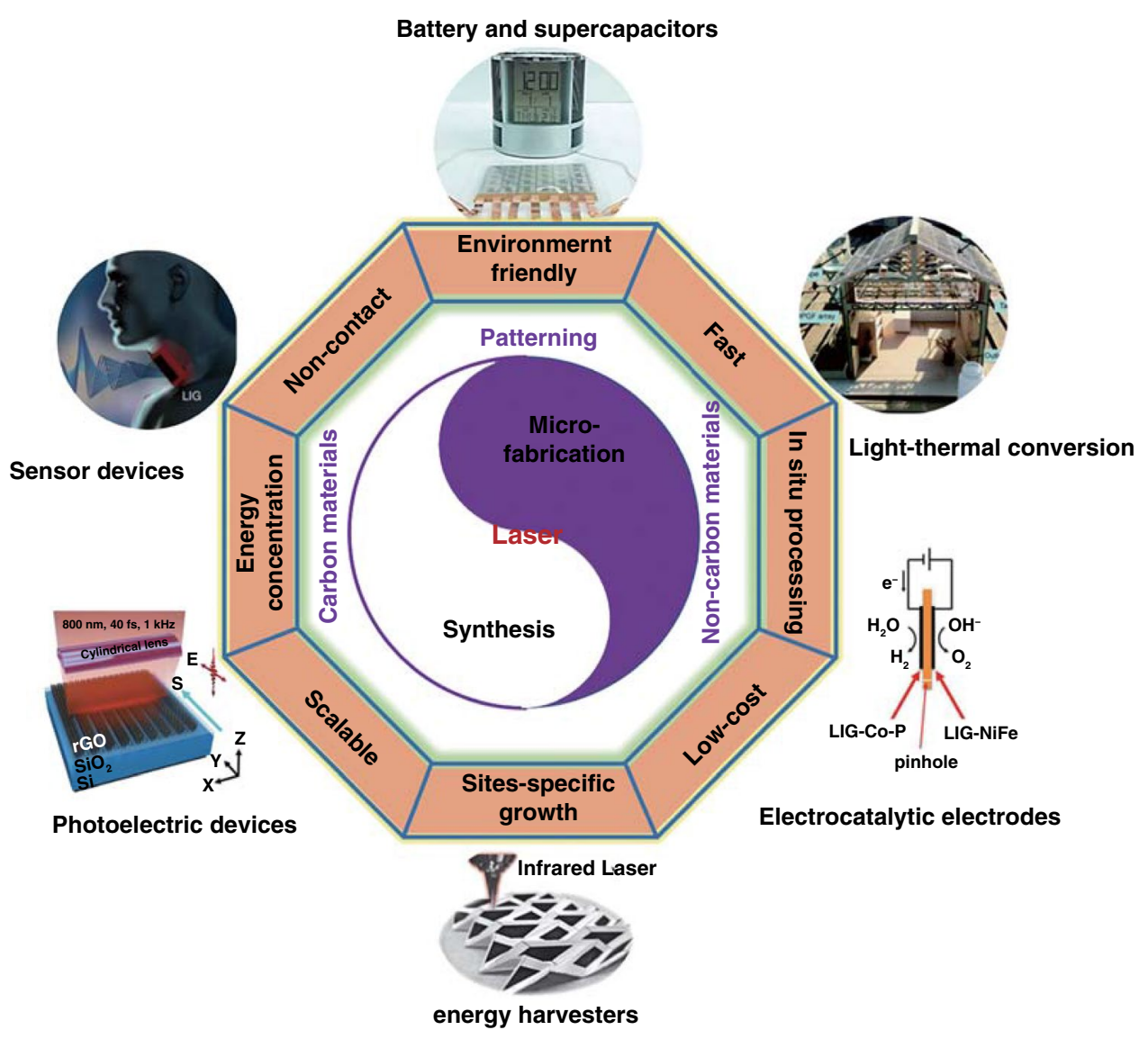

Scheme 1 Laser as a synthetic technique and a microfabrication technique and their applications in various functional devices

from an irradiated laser by generating confined electromagnetic field at a desired position with high controllability.

\subsection{Carbon Nanomaterials}

Among all of the synthesis methods, annealing or thermal treatment of the precursors is usually necessary to obtain the carbon nanomaterials $[12,13]$. Conventionally, the thermal treatment of polymer precursors is conducted in a furnace or an oven at a high temperature, which suffer from a quite slow cooling rate and high energy loss due to the smaller sample dimensions than the heated volume. In addition, the morphology and structure of the precursors were difficult to inherit or create new nanostructures. As an alternative to the conventional annealing, laser processing offers a potential solution to the above issues and enables construction of different nanostructures from the precursors to carbon materials, on account of the localized thermal effect without any interference with the surrounding materials during laser processing [14].

Various kinds of carbon nanomaterials can be derived through laser processing technologies, including graphenerelated material, diamond-like carbon, glassy carbon, and heteroatom-doped carbon. Specially, graphene-based structures have become a rising star owing to its unique physical and chemical properties [15, 16], which can be obtained from different precursors by laser processing, such as graphene oxide, polymers, $\mathrm{CH}_{4}, \mathrm{SiC}$ and so on. In this section, the recent progress in the laser processing of different carbon materials from various precursors is reviewed.

\subsubsection{Laser Synthesis of Graphene}

2.1.1.1 Laser Synthesis of Graphene from Graphene Oxide Graphene oxide (GO) has been widely utilized as the precursors for synthesizing the reduced graphene oxide (rGO) to remove the oxygen-containing groups by thermal 
reduction at a high temperature [17], chemical reduction by means of reductants [18], and photoreduction with light irradiation [19]. Among these, the laser synthesis of rGO has been demonstrated to be an efficient and facile approach for reduction of graphene oxide into graphene and provides an opportunity for localized reduction and controllable patterning [20]. Yannopoulos et al. compared the thermal reduction, chemical reduction, and laser-assisted reduction approaches of GO to rGO. It turned out that high-quality graphene-like structures with efficient defect healing and ultralow sheet resistance were produced by the laser-induced reduction of GO (Fig. 1a) [21], while the thermal reduction and chemical reduction methods cannot provide a high conductivity for the as-prepared rGO. This was because that the high temperature induced by laser $\left(>2500^{\circ} \mathrm{C}\right)$ was able not only to remove oxygen-containing species but also in favor of eliminating the structural defects in the formed rGO, which would result in a high conductivity for the rGO by laser-assisted reduction method. Wong et al. [22] reduced the electro-sprayed GO thin film into rGO and ablated the unwanted areas by using a $355 \mathrm{~nm}$ nanosecond laser. After tuning the output laser power, the patterned electrode arrays were completed. (Fig. 1b). In addition, Qu et al. fabricated an asymmetric Graphene/Graphene oxide fiber through the laser-assisted partial reduction of GO fibers with graphene in the scanned region and $\mathrm{GO}$ in the unexposed region (Fig. 1c). The obtained asymmetric G/GO fiber was an ideal material as a moisture-sensitive fiber actuator [23]. Thus, the laser synthesis of rGO possessed the advantage of controllable reduction of partial GO to rGO. This group further reported a spontaneous reduction of GO aerogel strategy by laser triggering (Fig. 1d). Pure graphene, doped graphene, and multifunctional graphene composited metals or metal oxides with macroscopic bulk structure have been prepared by this fast solvent- and reagent-free preparation method [24]. Only within $37.5 \mathrm{~ms}$, a $5 \mathrm{~cm}^{3} \mathrm{GO}$ aerogel was completely reduced to graphene bulk. Unlike the dense structure of GO fiber in Ref. [23] or dense GO film in Ref. [22], where only the exposed region of GO was reduced to the $\mathrm{rGO}$, the fewer stacked graphene sheets within the pore-rich structure of GO aerogel and the available air stored in the pores played the crucial roles for the sustainable reduction of GO.

As for the solid GO film typically suffers from the restacking as a result of the strong van der Waals interactions, which caused a low specific capacitance. The LightScribe laser of DVDs can simultaneously cause reduction and exfoliation of GO and then produce an open network of laser-scribed graphene (LSG). For instance, Kaner [25] used a Light Scribe DVD optical drive to perform on graphite oxide films, the graphene sheets were achieved and restacking was avoided. It was realized by a drop-cast GO thin film on a flexible substrate and then irradiating with an infrared laser inside a Light Scribe DVD optical drive. During the laser LightScribe process, the GO was reduced into the well-exfoliated LSG sheets, which can be indicated by the change in film color and the SEM images. Kaner et al. [26] also used a LightScribe DVD burner to fabricate graphene micro-supercapacitors over large areas by direct laser writing on graphite oxide films. Thanks to the precision of a laser, the desired graphene circuits were produced under the driving of the computer-designed pattern onto the GO film. Large scale and patterning were realized within a short time. Luo et al. [27] also used the scribing process for the reduction and patterning of graphene oxide film to realize the LSG sensors fabrication. This will be discussed in detail in Sects. 3.2 and 3.3.

As well known, laser reduction of GO conforms to the mechanisms of photochemical reduction under a short-wavelength laser (e.g., UV laser) and photothermal reduction under a relative long-wavelength laser (e.g., Vis and NIR laser). Recently, Guo et al. [28] proposed that by utilizing the transverse electric (TE) surface plasmons triggered by the gradient reduction of the GO film from its surface to the interior, a diverse laser-rGO interaction occurred through producing an inhomogeneous slab with the maximum dielectric permittivity (DP) at the surface and a smaller DP at deeper thicknesses that allows excitation of transverse electric (TE) mode surface plasmons (TE-SPs). This TESPs eventually resulted in interference intensity fringes and spatially periodic interactions (Fig. 1e). It was noted that the laser-processed grating structure strictly parallel to the TE polarization state of the incident light. This implies that complex topography preparation is feasible by changing only the polarization (Fig. 1f).

\subsubsection{Laser Synthesis of Graphene from Polymer} Besides the GO, polymers were another frequently used carbon source for laser synthesis of graphene, especially for the polyimide (PI). Different from the 2D sheet-like graphene derived from GO by laser, porous graphene with a larger specific surface area can be obtained by laser scribing of polymers. During the conversion process from polymers, the $s p^{3}$-carbon atom arrangement of polymers converted to $s p^{2}$-carbon atom arrangement under the photothermal effect induced by pulsed laser irradiation. Professor Tour's group devoted a considerable amount of effort 
(a)

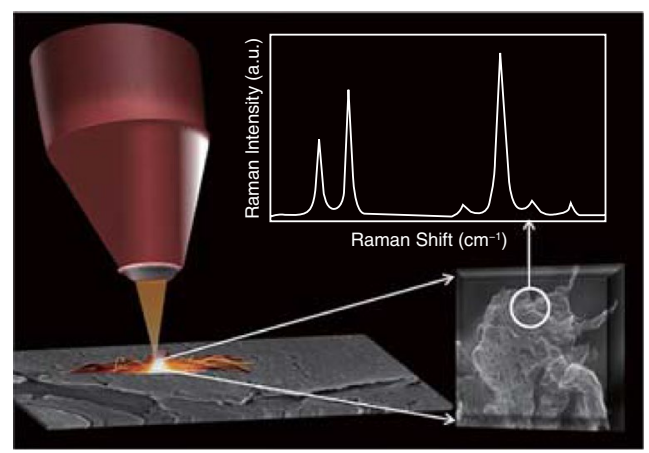

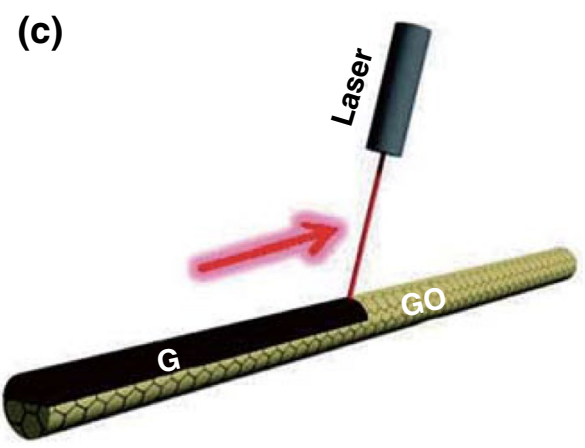

(b)

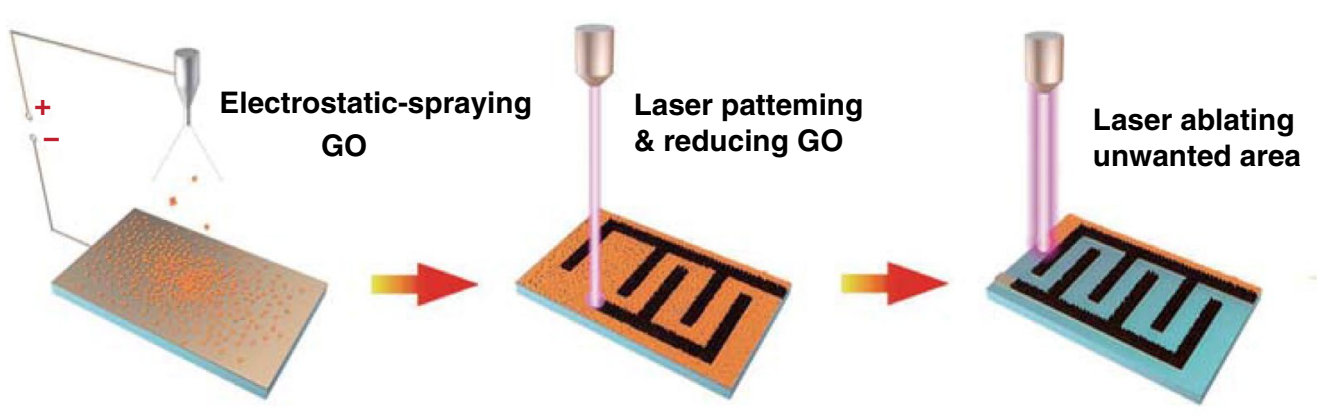

(d)

(d)

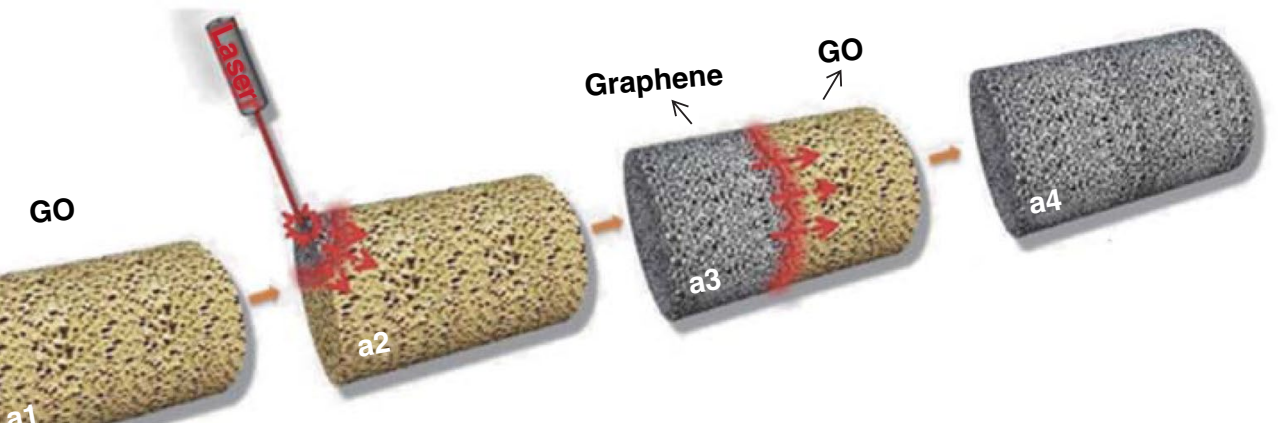

(e)

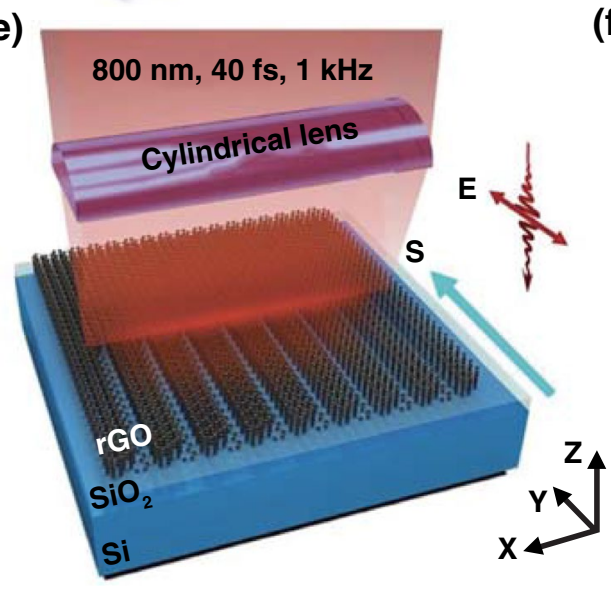

(f)
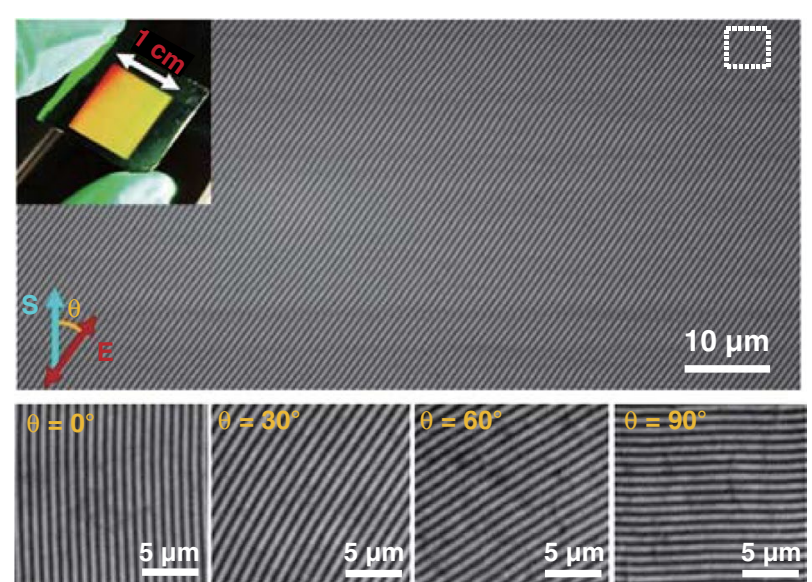

Fig. 1 a Reduction of GO by laser irradiation utilized a Nd-YAG laser (pulse width in the range of ms) with an excitation wavelength of 1064 nm [21]. b Schematic illustration of ultrathin laser-processed graphene-based micro-planar supercapacitors. After the different powers of laser treatment, the reduction and ablation of GO film were completed [22]. c Representation of positioned laser reduction on one side of a GO fiber. The black region corresponds to the laser-induced G region along the brown GO fiber [23]. d Schematic illustration of the preparation process of graphene bulks and functional counterparts induced by a laser shot within milliseconds [24]. e Schematic of grating processing of a GO film using cylindrical focusing of femtosecond laser pulses. f Photograph (insert) and SEM image of the large-area $\left(10 \times 12 \mathrm{~mm}^{2}\right)$ rGO. $\theta$ represents the angle between $\mathrm{S}$ and $\mathrm{E}$ [28] 
to laser-induced graphene (LIG) conversion from polyimide or the other polymers [29-31]. In 2014 [32], they reported a one-step laser scribing on commercial PI in air to form 3D-graphene layers $\left(\mathrm{CO}_{2}\right.$ laser with a laser power of $3.6 \mathrm{~W}$ ). The effect of laser power on the formation of LIG was investigated to obtain that the conversion from PI to LIG occurred at the threshold power of $2.4 \mathrm{~W}$. The thermal power dominated the quality of films when the laser power was $<4.2 \mathrm{~W}$, and a higher degree of graphitization occurred with the increase of laser power. When the laser power increased to above $4.2 \mathrm{~W}$, oxidation started to play an increasingly deleterious role in the film quality. In addition, the mechanism for laser scribing of polymers was also thoroughly investigated in this article. It was speculated that photothermal effects owing to the long wavelength $(\sim 10.6 \mu \mathrm{m})$ and relatively long pulse width $(\sim 14 \mu \mathrm{s})$ of the $\mathrm{CO}_{2}$ laser caused lattice vibrations, which led to extremely high localized temperatures $\left(2500{ }^{\circ} \mathrm{C}\right) . \mathrm{C}-\mathrm{O}, \mathrm{C}=\mathrm{O}$ and $\mathrm{N}-\mathrm{C}$ bonds were broken under such high temperatures and atoms recombination occurred to release the corresponding gases, which could be confirmed by the dramatically decreased oxygen and nitrogen contents in the polymer. The author also found out that the mechanism of laser graphitization in polymers was strongly correlated to the structural features of the repeat units, such as aromatic and imide repeat units. Through testing 15 different polymers by laser-induced graphitization process, it demonstrated that only two polymers, PI and poly(etherimide), both of which contain aromatic and imide repeat units, can form LIG, while the other step-growth polymers and the chaingrowth polymers cannot afford LIG. However, in 2018 [33], Their further research reported that multiple lasing method allows that any material that can be converted into amorphous carbon can be further treated by a $\mathrm{CO}_{2}$ laser beam to obtain graphene, such as Kapton, Kevlar, polysulfones, poly(etherimide), polyphenylene sulfide, phenolic resin, and cross-linked polystyrene. Finally, it can be concluded that the wavelength of the laser irradiation as well as the number of exposures are important to the formation of LIG. Then by means of this laser graphitization from PI technique, Professor Tour's group successively employed the laser-induced graphene for flexible and embeddable gas sensors [34], and preparing porous B-doped graphene with promising electrochemical performance by introducing $\mathrm{H}_{3} \mathrm{BO}_{3}$ into PI [35]. Recently, Zhang et al. [36] used the laser writing of Kevlar textile in air to prepare a Janus graphene/Kevlar textile. With the motorized and computercontrolled laser writing, LIG could be simply and rapidly written into various geometries from Kevlar textile. Similar to the conversion of PI, the $\mathrm{C}=\mathrm{O}$ and $\mathrm{N}-\mathrm{C}$ bonds in Kevlar being broken and the reorganization of remaining carbon atoms into graphene can be ascribed to photothermal effect induced by the laser irradiation.

Tour's group [37] also developed a 3D LIG foam by combining the printing process on basis of laminated object manufacturing and the laser treatment process, which break through the limitation of only $2 \mathrm{D}$ products on the PI substrate being able to be synthesized by traditional laserinduced graphene. They denoted this process as modified, automated 3D-printing process based on laminated object manufacturing (LOM). During the preparation process, ethylene glycol served as an adhesive through capillary forces between the layers, and stacked PI on top of one another was irradiated by a fiber laser, as shown in Fig. 2a. Except for laser-induced graphene from PI, Professor Tour's group also demonstrated a three-dimensional (3D) printing graphene foam (GF) by using a mixture of $\mathrm{Ni}$ and sucrose as precursor [38], which was also realized by in situ manually adding multiple layers of a mixture of $\mathrm{Ni}$ and sucrose to overcome the limitation of microsized scales due to the precursors contained in inkjet-printable or UV-curable inks for the traditional 3D printing technique. Graphene was formed under the template and catalyst effects of $\mathrm{Ni}$ and sucrose as carbon source. Besides, various naturally occurring substrates (Fig. 2b) such as paper, cloth, coconut shells, potato skins, cork [33] and polytetrafluoroethylene (Teflon, or PTFE) [39] have been tried to prepare LIG by this group. Some other groups also have done further researches on LIG based on the work of Tour's group [40]. Luo et al. [41] prepared laser-induced graphene paper (LIGP) with different shapes and structures. Similarly, they confirmed that the polymer precursor with considerable spaces was beneficial to a deep absorption of thermal energy resulted from laser and thus was conducive to the formation of LIGP. Alshareef et al. [42] used glucose-derived amorphous carbon nanospheres (CNS) as carbon source, and a highly turbostratic graphitic carbon electrode was fabricated by laser scribing, which was composed of a 3D framework structure dominated by mesoand macro-pores (Fig. 2c).

In conclusion, the polymer precursor for laser processing is a more appropriate approach to prepare porous and $3 \mathrm{D}$ graphene, which is realized by photothermal effects induced by laser. Thus, the $\mathrm{CO}_{2}$ laser with a long wavelength $(\sim 10.6 \mu \mathrm{m})$ is preferable choice when using polymers as precursors. $\mathrm{CO}_{2}$ lasers are unique compared to ordinary industrial lasers in that they usually have a wavelength of $\sim 10.6 \mu \mathrm{m}$ when output in the form of long-wave infrared. 
(a)

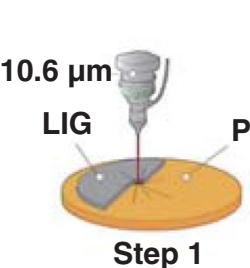

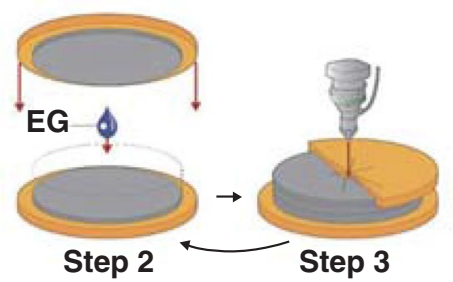
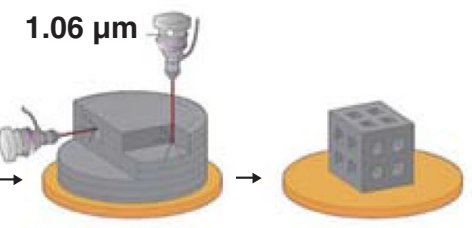

(c)
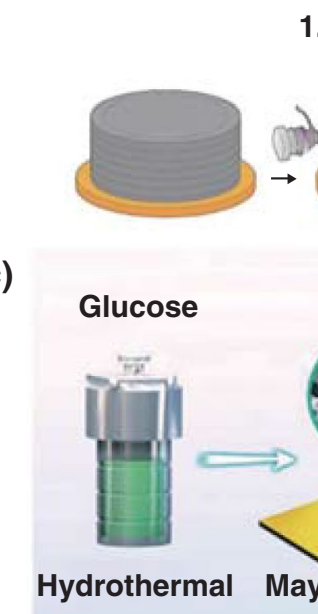

Glucose
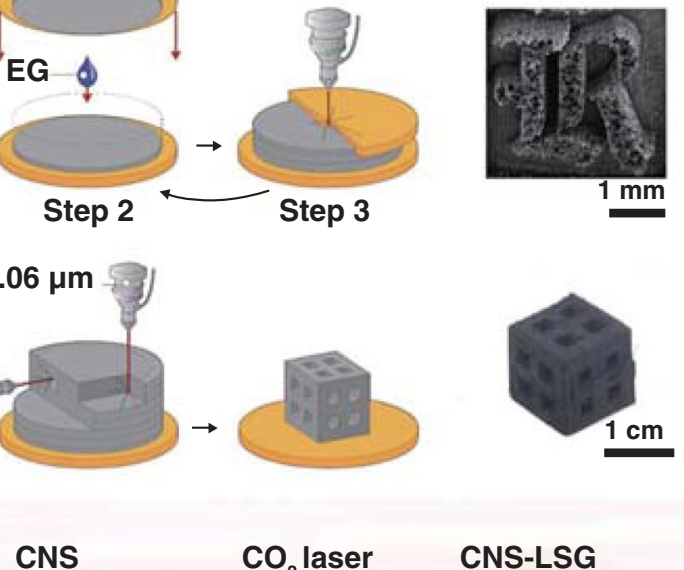

(b)
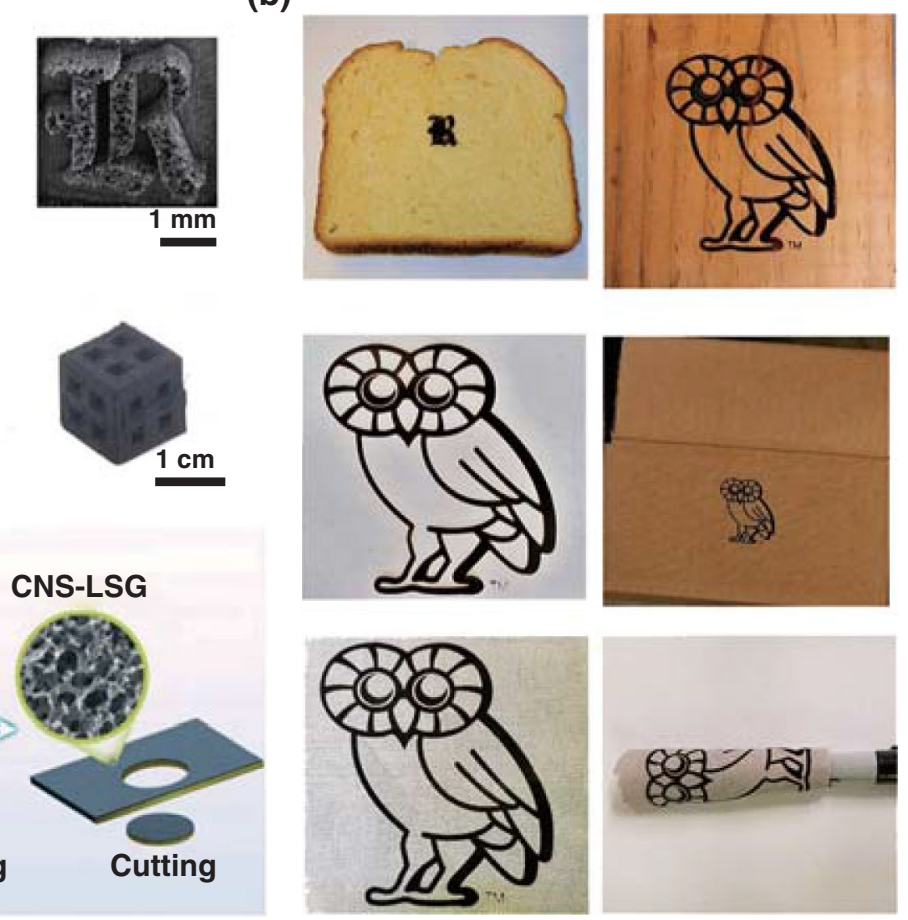

Fig. 2 a Manufacturing and processing of laser-induced 3D GFs [37]. b LIG induced from bread, fire-retardant treated pine wood, cotton paper, cardboard box, gray muslin cloth and muslin cloth wrapped around a marker [33]. c Schematic diagram of the laser scribing fabrication of CNSLSG electrode [42]

Many organic materials, including paper, wood, plastics, rubber, textiles, and leather, are highly absorbent for such long wavelengths. The mechanism for laser scribing of polymers was speculated that photothermal effects owing to the long wavelength of the $\mathrm{CO}_{2}$ laser caused lattice vibrations, which led to the breaking of $\mathrm{C}-\mathrm{O}, \mathrm{C}=\mathrm{O}$, and $\mathrm{N}-\mathrm{C}$ bonds and atoms recombination to form LIG. As reported [43], polyimide was ablated with a $308 \mathrm{~nm} \mathrm{XeCl}$ excimer laser, and the carbon material was characterized after $200-800$ pulses, but no graphene-based 2D Raman peaks were detected. By contrast, $\mathrm{a} \mathrm{CO}_{2}$ laser could yield LIG from a wide variety of substrates for only $3-5$ passes processing. Hence, the wavelength of the laser irradiation is important to the formation of LIG. Furthermore, laser-induced graphene from polymer precursors presents a novel strategy for simultaneous graphene formation and patterning.

As mentioned above, the localized high temperature induced by $\mathrm{CO}_{2}$ laser can be used to selectively convert some carbon precursors into graphene materials. In fact, the laser-induced graphitization comprises various photothermal reactions, photochemical reactions, or thermal accumulation effect from high repetition rate laser. In terms of thermal accumulation effect, because the time interval between sequential laser pulses is significantly shorter than the time required for heat to diffuse out of the focal volume, hence the energy from successive laser pulses accumulates in and around the focal volume over time. Wang et al. [44] utilized the high-repetition picosecond laser to processing the bakelite plate, which provides great potential to stimulate both research and industrial interest in the development of bakelite-derived carbon materials. It demonstrated that the heat accumulation effect was critical for laser-induced transient heating of bakelite materials, and the subsequent instantaneous high temperature field localized in the microscale domain to generate the hierarchically macropores and mesopores. Young-Jin Kim et al. [45] reported the direct laser writing of graphene oxide patterns using femtosecond laser pulses with different repetition rates. The results showed that the thermal accumulation effects dominantly affected the reduction degree and the linewidth of treated GO. Consequently, it can be concluded that, photochemical reduction under a short-wavelength laser and photothermal reduction under a relative long-wavelength laser are commonly used for laser-induced graphene. But the graphene produced by 
these two mechanisms is generally treated with nanosecond lasers, compared with ultra-short ps and fs lasers, nanosecond laser caused the low level of achievable precision for patterns. Fortunately, thanks to the recent development of fs and ps laser sources operating at high repetition rates of hundreds $\mathrm{kHz}$ up to a few $\mathrm{MHz}$, the development of thermal accumulation effects is expected to be an alternative in LIG, which can achieve the high-conductivity graphene under the premise of ensuring the precision of patterns.

\subsubsection{Laser Synthesis of Graphene from $\mathrm{CH}_{4}$ and $\mathrm{SiC}$} As mentioned above, although the laser-processed rGO had good electrical conductivity, abundant defects remain existed in the $s p^{2}$ carbon network. As a practical method, the chemical vapor deposition (CVD) and epitaxial growth (EG) of graphene were feasible methods to produce largescale graphene with high quality, while the fabrication of graphene patterns through CVD or EG was commonly time consuming and costly. Thus, developing a rapid approach for fabrication of graphene is essential. Lu et al. [46, 47] developed a fast growth method of graphene by laser direct writing (a focused continuous-wave laser beam with $\lambda=532 \mathrm{~nm}$, laser power $=5 \mathrm{~W}$ ) on a thin $\mathrm{Ni}$ foil in $\mathrm{a} \mathrm{CH}_{4}$ and $\mathrm{H}_{2}$ atmosphere, which can precisely control the position of graphene pattern and realize the improvement of growth rate than that of general CVD method. For instance, a graphene pattern with an area of $10 \times 10 \mu \mathrm{m}^{2}$ can be rapidly grown in $0.2 \mathrm{~s}$. A similar strategy was also reported by Zhong et al. [48]. Besides the CVD method, epitaxial growth of graphene was another choice. In order to solve the problem of high growth temperature for EG method, Salleo et al. [49] demonstrated a scalable epitaxial graphene synthesis technique based on laser-induced surface decomposition of the Si-rich face on silicon carbide ( $\mathrm{SiC}$ ) single-crystal (pulsed $\mathrm{KrF}$ laser with $248 \mathrm{~nm}$ and $25 \mathrm{~ns}$ ) (Fig. 3a). Furthermore, Choi and Lee et al. [50] reported epitaxial growth of solid-phase N-doped graphene on the doped silicon carbide ( $\mathrm{SiC}$ ) substrate driven by pulsed $\mathrm{XeCl}$ excimer laser $(\lambda=308 \mathrm{~nm}$, pulse duration $\sim 30 \mathrm{~ns}$ ). Compared with the gas-phase doped graphene method, this strategy can precisely control the doping concentration of graphene by tuning the dopant concentration of SiC substrate (Fig. 3b). The above reported laser epitaxial growth of graphene was all performed in a high-vacuum condition. Yannopoulos and Siokou et al. reported that epitaxial growth of large-area graphene on the surface of $\mathrm{SiC}(0001)$ using a continuous-wave infrared $\mathrm{CO}_{2}$ laser was realized (Fig. 3c) [51], which does not require high-vacuum or strict sample-chamber conditions. In addition, another advantage for the $\mathrm{CO}_{2}$ laser was manifested that the very high heating rate derived from $\mathrm{CO}_{2}$ laser efficiently avoided the different $\mathrm{Si}$ desorption rates from adjacent $\mathrm{SiC}$ steps to form homogeneous graphene. In conclusion, the laser synthesis technique by means of EG presented many advantages. Firstly, large-scale production, time and cost saving as well as patterning without nanolithography were still exhibited in laser processing. Secondly, this method operates at low temperatures on account of the laser-induced local high temperature, which does not necessitate high vacuum and/ or SiC pre-treatment. Lastly, controllable doping concentra-
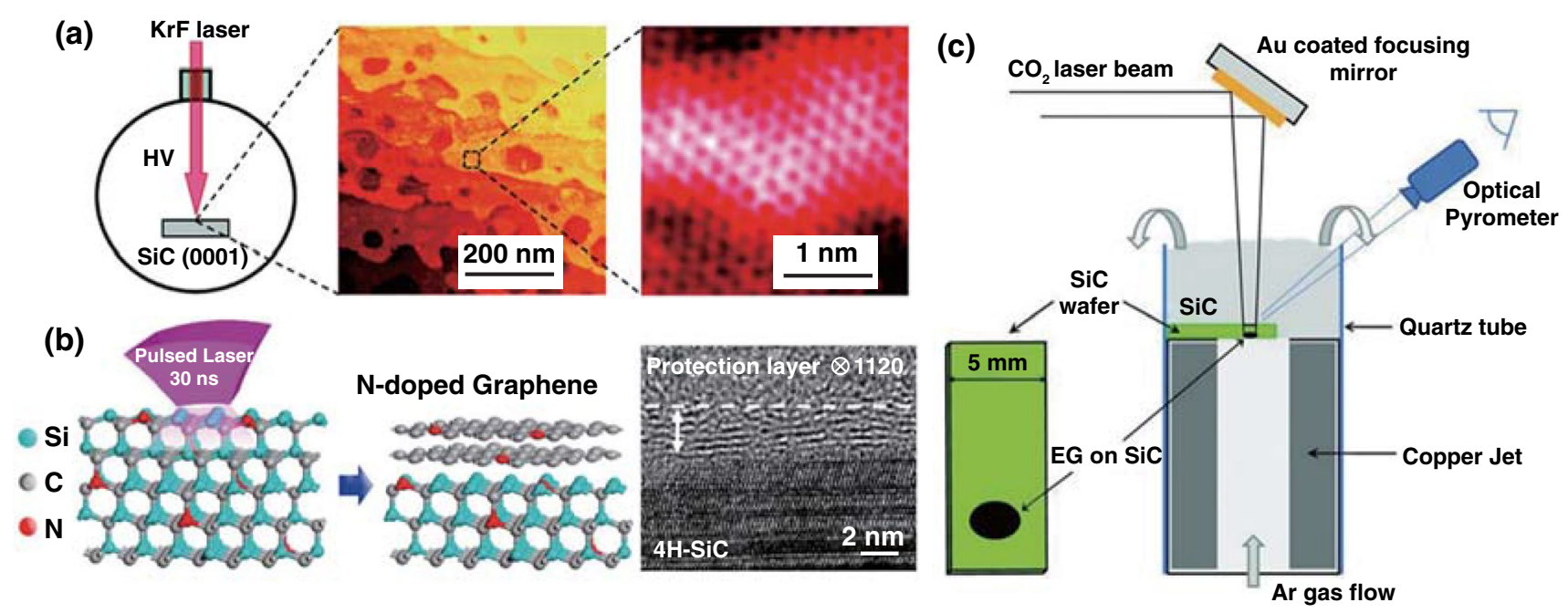

Fig. 3 a Illustration of laser-induced epitaxial graphene synthesis [49]. b Schematic illustration of the synthesis method for laser-induced $\mathrm{N}$-doped graphene on $\mathrm{N}$-doped $\mathrm{SiC}$ substrate and cross-sectional HRTEM image of multilayer N-doped graphene on 4H-SiC (0001) [50]. c Schematic diagram of the $\mathrm{CO}_{2}$-laser-induced epitaxial growth of graphene on $\mathrm{SiC}$ wafers [51] 
tion of graphene can be easily realized by tuning the dopant concentration of the $\mathrm{SiC}$ substrate.

\subsubsection{Laser Synthesis of Diamond-like Carbon}

Graphene has good electrical conductivity and transparency to some extent. Diamond-like carbon (DLC) as another amorphous form of carbon exhibited the electrical insulator property due to kinship with diamond and visible and infrared range transparency. Therefore, combining the properties of DLC and graphene could innovatively obtain a transparent conductive material coating on an insulated transparent substrate. Laser synthesis of diamond-like carbon and graphene provided an accurate, convenient, clipping method to realize this innovative solution. Stock et al. [52] explored the preparation of DLC thin films from a high-purity graphite target by pulsed laser deposition (PLD). It is worth noting that the high-vacuum condition with residual pressure less than $10^{-8}$ mbar was essential. Then by using the obtained DLC as substrate, UV laser surface annealing was performed to modify the first atomic layers of DLC thin-film structure by graphene-like layers with high conductivity. It demonstrated that the obtained graphene layer on DLC had comparable conductivity and transparency performances to those of ITO. In addition, Fan et al. [53] used hydrocarbon species including a mixture of acetylene $\left(\mathrm{C}_{2} \mathrm{H}_{2}\right)$, ethylene $\left(\mathrm{C}_{2} \mathrm{H}_{4}\right)$ and oxygen $\left(\mathrm{O}_{2}\right)$ as the precursor, a combustion torch was used to produce the flames and an ultraviolet (UV) laser was used to excite the combustion species in the direction of perpendicular to the combustion flames and parallel to the substrate (Fig. 4a, b). By analyzing the nucleation process of diamond growth, they proposed the two critical surface reactions during diamond growth: (1) addition of reactive hydrocarbon radicals to the active surface sites and (2) H-abstraction from hydrocarbon radicals to create more reactive sites to accept hydrocarbons and stable $s p^{3}$ hybridized carbon bonds. Therefore, the $\mathrm{H}$-abstraction from hydrocarbons by UV laser-induced photolysis to produce abundant reactive species play a dominant role in promoting diamond growth, which can shorten the diamond nucleation time and suppressed the nondiamond carbon accumulation.

\subsubsection{Laser Synthesis of Heteroatom-Doped Carbon}

During the laser processing, the high localized temperature caused by the photothermal effects of laser played a key role in material preparation, meaning that laser was used as a heat source. So ordinary materials prepared by heating synthesis can be similarly achieved by laser. Therefore, heteroatom-doped carbon can also be rapidly synthesized by laser and realize patterning in a large scale. In terms of laserinduced-doped graphene, Professor Tour's group prepared porous B-doped graphene with promising electrochemical performance by introducing $\mathrm{H}_{3} \mathrm{BO}_{3}$ into $\mathrm{PI}$, as mentioned in Sect. 2.1.1.2 [35]. Alshareef et al. [54] prepared nitrogen-atom-doped graphene using urea-containing polyimide as the precursor on $\mathrm{Cu}$ foil. The binder-free, additive-free, and conductive anodes for Na-ion battery was fabricated by single-step laser-based transformation. Li et al. [55] prepared the $\mathrm{S}$ - and $\mathrm{N}$-doped graphene patterns on glass and polyethylene terephthalate (PET) substrates by using organic polybenzimidazole (PBI) ink as the precursor. During the fabrication process, a UV laser beam with $355 \mathrm{~nm}$ wavelength was used to break the $\mathrm{C}-\mathrm{S}$ bond $(2.8 \mathrm{eV})$ from (a)

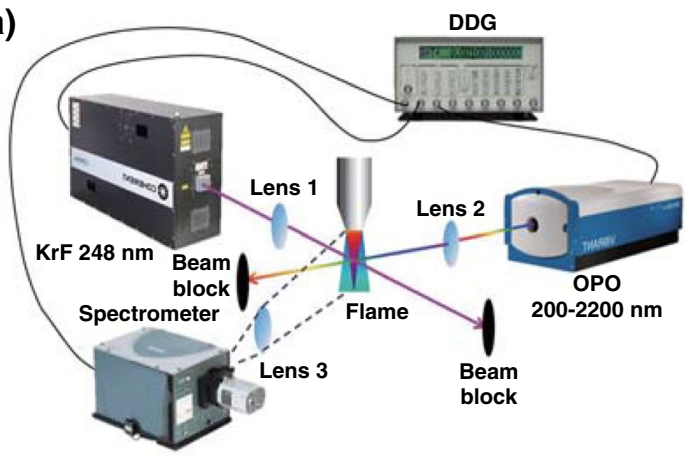

(b)

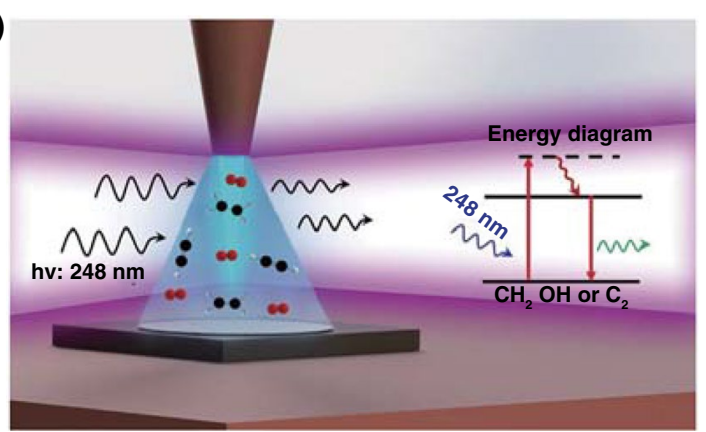

Fig. 4 a Schematic diagram of the optical emission spectroscopy (OES) and laser-induced fluorescence (LIF) setup to characterize the species in the combustion flame with UV laser irradiation. b Schematic illustration of the UV-laser-assisted diamond combustion CVD setup [53] 
dimethyl sulfoxide (DMSO) and the $\mathrm{C}-\mathrm{N}$ bond (3.14 eV) from polybenzimidazole. In addition, Professor Yuge prepared $\mathrm{B}$ - and $\mathrm{N}$-codoped single-walled carbon nanohorns by $\mathrm{CO}_{2}$ laser processing of a boron-containing carbon target under nitrogen atmosphere [56]. Besides of nitrogen, other heteroatom-doped graphene was also synthesized by laser processing. Ruoff et al. [57] reported a Raman laser $\left(\lambda_{\text {laser }}=488 \mathrm{~nm}\right)$ irradiation to prepare the F-doped graphene with fluoropolymer-covered graphene as the precursors. The laser-induced decomposition of the fluoropolymer produced active fluorine radicals and then reacts with the $s p^{2}$-hybrized graphene to form C-F bonds. Therefore, similar to laser synthesis of graphene and other carbon materials, introduction of heteroatom precursors into the raw materials was essential for laser synthesis of heteroatom-doped carbon. By considering the light-absorption characteristics of the carbonization precursor and the precision of the laser, the appropriate type of laser can be selected, and then, heteroatom-doped carbon materials were prepared through regulating parameters such as laser power, frequency, and pulse width of laser.

As mentioned above, laser synthesis of carbon materials from polymers is mainly based on the absorption of laser by the precursor, which results in the heating effects. As the consequence, the $\mathrm{CO}_{2}$ laser is the preferable choice because that the infrared laser with a long wavelength is conducive to the photothermal reaction to carbonization. For the laser-induced rGO from graphene oxides, although the photothermal effect and photochemical effect simultaneously happened, photochemical effect through rebinding of atoms within GO induced by laser was dominated. Thus, laser wavelength covering UV, Vis and NIR wavelength range is all adaptable. The effects of parameters of laser on the composition nature of obtained carbon materials are summarized in Table 1.

\subsection{Non-carbon Nanomaterials}

\subsubsection{Laser Synthesis of Non-carbon Nanomaterials in Non-aqueous Environment}

Except for the synthesis of different carbon nanomaterials, laser processing was also commonly developed to fabricate some other non-carbon nanomaterials, such as metal oxides, metal carbides and metal disulfides, especially as a large-scale and fast fabrication method. Laser synthesis of non-carbon nanomaterials is primarily based on the photothermal effects and/or the photochemical effects induced by the irradiated laser, where the absorption of laser by the precursors results in some specific effects. Specially, ablation or heating dominate the nanomaterials formation during the laser synthesis of non-carbon nanomaterials in non-aqueous environment.

2.2.1.1 Metal and Metal Oxides Metal nanomaterials and metal oxide nanomaterials have been widely used in various applications in energy storage [58], energy conversion [59] and environmental treatment [60]. In recent years, many synthetic methods, including chemical vapor deposition (CVD) [61], liquid chemical method [62-65], hydrothermal method [66] and electrochemical method [67], have been developed. However, large-scale manufacturing of these nanocrystals with high performance remained very difficult. Therefore, the laser synthesis method attracted increasing attention for its fast, facile and large-scale fabrication process, as well as operation at low temperatures [68].

As mentioned above, ablation or heating dominated the nanomaterials formation during the laser synthesis of noncarbon nanomaterials in non-aqueous environment. With regards to the laser ablation synthesis of nanomaterials, a target surface was irradiated by a beam of high-energy pulsed laser. The reflection and absorption simultaneously occurred, and once the absorbed laser energy exceeded the evaporation temperature of the target, the target would melt and evaporate a large number of atoms, electrons and ions, thus forming a plasma on the surface of the target. After shifting the pulsed laser, the plasma expanded and then cooled and crystallized to prepare nanomaterials. For instance, $\mathrm{Li}$ et al. [69] reported a general strategy to manufacture a series of metal oxides $\left(\mathrm{MO}_{x}, \mathrm{M}=\mathrm{Ti}, \mathrm{Mn}, \mathrm{Fe}, \mathrm{Co}\right.$, $\mathrm{Ni}, \mathrm{Cu}, \mathrm{Mo}, \mathrm{Ag}, \mathrm{Sn}, \mathrm{W}$, and $\mathrm{NiFe}$ ) with hierarchical nanostructure on corresponding metal substrates by laser ablation. When using as the electrocatalysts, additional binders were avoided to assist the adhesion of electrocatalyst nanoparticles on substrates. The universality for various metal oxides synthesis, large-scale manufacturing and fast synthesis process demonstrated the advantages of laser ablation synthesis (Fig. 5a, b). Zheng et al. [70] grew preferentially [001]-oriented $\mathrm{BiVO}_{4}$ on FTO substrates through the laser ablation of the $\mathrm{BiVO}_{4}$ target. Compared with the $\mathrm{BiVO}_{4}$ with randomly oriented grains produced by sol-gel drop-casting method, the laser ablation method has a lot of advantages in sample preparation. This system is capable of controlling 
Table 1 Effects of parameters of laser on the composition nature of obtained carbon nanomaterials

\begin{tabular}{|c|c|c|c|c|c|}
\hline Precursor & Laser source & Parameters & Properties of carbon & Applications & References \\
\hline GO & Nd-YAG laser & $1064 \mathrm{~nm}, \mathrm{~ms}$ & rGO with low resistance & & {$[21]$} \\
\hline GO & & $355 \mathrm{~nm}, \mathrm{~nm}$ & $\begin{array}{l}\text { rGO with expanded } \\
\text { structure }\end{array}$ & Micro-supercapacitors & {$[22]$} \\
\hline GO fibers & Argon-ion laser & $458 \mathrm{~nm}$ & $\begin{array}{l}\text { rGO with high conduc- } \\
\text { tivity }\end{array}$ & $\begin{array}{l}\text { Moisture-sensitive fiber } \\
\text { actuator }\end{array}$ & {$[23]$} \\
\hline GO aerogel & & $1 \mathrm{~W}, \mathrm{~ms}$ & $\begin{array}{l}\text { Heteroatom-doped rGO } \\
\text { bulk }\end{array}$ & $\begin{array}{l}\text { Eletrocatalysis, Li-ion } \\
\text { batteries, supercapaci- } \\
\text { tor, methanol oxidation }\end{array}$ & {$[24]$} \\
\hline GO & $\begin{array}{l}\text { LightScribe DVD opti- } \\
\text { cal drive }\end{array}$ & Infrared laser & rGO sheets & $\begin{array}{l}\text { Electrochemical capaci- } \\
\text { tors electrode }\end{array}$ & {$[25]$} \\
\hline GO & LightScribe DVD burner & Infrared laser & rGO sheets & Micro-supercapacitors & [26] \\
\hline $\begin{array}{l}\text { Commercial polymer } \\
\text { films }\end{array}$ & $\mathrm{CO}_{2}$ laser & $\begin{array}{l}10.6 \mu \mathrm{m}, 14 \mu \mathrm{s}, \\
2.4-5.4 \mathrm{~W}\end{array}$ & $\begin{array}{l}\text { Porous graphene } \\
\text { films (only PI and } \\
\text { poly(etherimide) can } \\
\text { form) }\end{array}$ & Micro-supercapacitors & {$[32]$} \\
\hline Polyimide (PI) & $\mathrm{CO}_{2}$ laser $(75 \mathrm{~W})$ & $10.6 \mu \mathrm{m}$ & Porous graphene & Gas sensors & [34] \\
\hline Boric acid containing PI & $\mathrm{CO}_{2}$ laser & $10.6 \mu \mathrm{m}, 14 \mu \mathrm{s}, 4.8 \mathrm{~W}$ & Porous graphene & Micro-supercapacitors & {$[35]$} \\
\hline $\begin{array}{l}\text { PI, laminated object } \\
\text { manufacturing }\end{array}$ & $\mathrm{CO}_{2} \operatorname{laser}(75 \mathrm{~W})$ & $10.6 \mu \mathrm{m}$ & Graphene foams & $\begin{array}{l}\text { Energy storage and } \\
\text { stress sensor device }\end{array}$ & {$[37]$} \\
\hline $\mathrm{Ni} /$ sucrose layers & $\mathrm{CO}_{2}$ laser $(75 \mathrm{~W})$ & $10.6 \mu \mathrm{m}$ & Graphene foams & Damping materials & {$[38]$} \\
\hline Cloth, paper or food & $\begin{array}{l}\mathrm{CO}_{2} \text { laser }(75 \mathrm{~W}) \mathrm{CO}_{2} \\
\text { laser }(50 \mathrm{~W})\end{array}$ & $10.6 \mu \mathrm{m} 9.3 \mu \mathrm{m}$ & Porous graphene & Micro-supercapacitors & {$[33]$} \\
\hline Teflon & $\mathrm{CO}_{2}$ laser $(50 \mathrm{~W})$ & $9.3 \mu \mathrm{m}, 5.0 \mathrm{~W}$ & $\begin{array}{l}\text { Fluorinated carbon } \\
\text { materials }\end{array}$ & $\begin{array}{l}\text { Tuning the band gap } \\
\text { of FG }\end{array}$ & [39] \\
\hline PI paper & $\mathrm{CO}_{2}$ laser & $10.6 \mu \mathrm{m}, 0.75-2.0 \mathrm{~W}$ & Graphene paper & $\begin{array}{l}\text { Strain sensors, micro- } \\
\text { supercapacitors, } \\
\text { superhydrophobic } \\
\text { membrane, acetone } \\
\text { sensor, antibacterium } \\
\text { device }\end{array}$ & [41] \\
\hline $\mathrm{CH}_{4}$ and $\mathrm{H}_{2}$ & Solid state laser & $\begin{array}{l}532 \mathrm{~nm} \text {, continuous } \\
\text { wave, } 5 \mathrm{~W}\end{array}$ & Graphene patterns & & [46-48] \\
\hline $\mathrm{SiC}$ single crystal & KrF laser & $\begin{array}{l}248 \mathrm{~nm}, 25 \mathrm{~ns}, \\
1.2 \mathrm{~J} \mathrm{~cm}^{-2}\end{array}$ & $\begin{array}{l}\text { Epitaxial graphene on } \\
\mathrm{SiC}\end{array}$ & & [49] \\
\hline $\begin{array}{l}\text { High doped } 4 \mathrm{H}-\mathrm{SiC} \\
\text { wafers }\end{array}$ & $\mathrm{XeCl}$ laser & $308 \mathrm{~nm}, 30 \mathrm{~ns}$ & $\begin{array}{l}\text { N-doped epitaxial } \\
\text { graphene }\end{array}$ & & {$[50]$} \\
\hline $6 \mathrm{H}-\mathrm{SiC}$ & $\mathrm{CO}_{2}$ laser & $\begin{array}{l}10.6 \mu \mathrm{m} \text {, continuous } \\
\text { wave }\end{array}$ & $\begin{array}{l}\text { Epitaxial graphene on } \\
\mathrm{SiC}\end{array}$ & & {$[51]$} \\
\hline Graphite target & KrF laser & $248 \mathrm{~nm}, 25 \mathrm{~ns}, 600 \mathrm{~mJ}$ & Diamond-like carbon & $\begin{array}{l}\text { Optical and photovoltaic } \\
\text { applications }\end{array}$ & {$[52]$} \\
\hline Urea-doped PI film & $\mathrm{CO}_{2} \operatorname{laser}(75 \mathrm{~W})$ & $\begin{array}{l}10.6 \mu \mathrm{m}, 14 \mu \mathrm{s}, \\
2.4-5.4 \mathrm{~W}\end{array}$ & $\mathrm{~N}$-doped graphene & Na-ion batteries & {$[54]$} \\
\hline $\begin{array}{l}\text { Polybenzimidazole } \\
\text { (PBI) in DMSO }\end{array}$ & UV laser & $355 \mathrm{~nm}$, ps & $\mathrm{N}, \mathrm{S}$-doped graphene & $\begin{array}{l}\text { Flexible electronics, } \\
\text { imbedded sensors, } \\
\text { smart wearables, and } \\
\text { lithium-ion batteries }\end{array}$ & {$[55]$} \\
\hline $\begin{array}{l}\text { Boron-containing carbon } \\
\text { target }\end{array}$ & $\mathrm{CO}_{2}$ laser & $\begin{array}{l}\text { Continuous wave, } \\
3.5 \mathrm{~kW}\end{array}$ & $\begin{array}{l}\mathrm{B}, \mathrm{N} \text {-doped single- } \\
\text { walled carbon nano- } \\
\text { horns }\end{array}$ & & {$[56]$} \\
\hline $\begin{array}{l}\text { Fluoropolymer-covered } \\
\text { graphene }\end{array}$ & Raman laser & $488 \mathrm{~nm}$ & F-doped graphene & & {$[57]$} \\
\hline
\end{tabular}


the variables during the synthesis such as temperature, type of reactive gas and the pressure; thus, epitaxial films as well as various morphologies, compositions and phases of products can be fabricated. As demonstrated, this preferentially [001]-oriented $\mathrm{BiVO}_{4}$ exhibited higher performance as the photoanode materials for photoelectrochemical water splitting. Most of the laser ablation synthesis strategies of metal and metal oxides were utilized in the liquid environment, which was discussed in Sect. 2.2.2.

With regards to the laser heating synthesis of nanomaterials, the significantly localized and rapid photothermal effect induced by a focused laser was employed to replace the conventional thermal treatment for the nucleation and growth of nanomaterials. For instance, the laser-assisted pyrolysis method was a traditional synthesis strategy for metal oxide nanomaterials [71-73]. Xu et al. [74] fabricated N-doped $\mathrm{SnO}_{2}$ nanoparticles through this laser-assisted pyrolysis process, which using $\mathrm{Sn}(\mathrm{OH})_{4}$ suspension as the precursor with $\mathrm{NH}_{3}$ for doping and a gaseous sensitizer $\left(\mathrm{C}_{2} \mathrm{H}_{4}\right)$ for absorbing laser photons (Fig. 5i). The as-synthesized $\mathrm{N}$-doped $\mathrm{SnO}_{2}$ nanoparticles exhibit excellent cycling stability and rate capability as anode materials in lithium-ion batteries (LIBs), which was attributed to the formed unreactive $\mathrm{Sn}-\mathrm{N}$ bonding in the structure during charge/discharge and the small particle sizes as a result of laser pyrolysis. However, the heat transfer of the laser-assisted pyrolysis process was usually limited by the gaseous precursor and generally obtained the product with poor phase purity. Metal-organic frameworks (MOFs) provided ideal contact between carbonaceous and metallic precursors on an atomic scale and preserved efficient photothermal conversion under laser irradiation [75]. Ogale et al. [76] selected MOFs of zeolitic imidazolate frameworks (ZIF-67) as precursors to achieve the metal and heteroatom-doped, porous graphene hybrid electrodes by laser direct writing, which set a precedent for laser carbonization of MOF under ambient for micro-supercapacitor application. Deng et al. [77] selected different porous MOFs to be processed by pulsed laser, a series of metal nanoparticles including $\mathrm{Fe}, \mathrm{Ni}, \mathrm{Co}, \mathrm{Cu}, \mathrm{Cd}$, $\mathrm{Zn}$, In, $\mathrm{Pb}$, and $\mathrm{Bi}$ with uniform sizes and gaps were produced (Fig. 5c). The self-reduction process of metal ions atomically dispersed in MOFs and then assembled across the pores under laser irradiation, which contributed to the formation of metal nanoparticles (MNPs). In addition, the formed thin layers of graphene on the surface can efficiently protect metal nanoparticles from oxidation and aggregation.
By controlling the processing position of laser, the conversion sites from MOFs to MNPs were controlled and the desirable patterns were finally generated (Fig. 5d-h). Thus, this method can be called nanoscale laser metallurgy and patterning (nano-LaMP). The mechanism of the MNPs production through laser irradiation on MOFs was proposed and then confirmed in this article (Fig. 5f). Firstly, the coordination between metal ions and organic ligands in MOFs leads to high light absorptivity. Secondly, the high photothermal conversion efficiency leads to the rapidly increased temperature of the MOFs, and the increased temperature was high enough to decompose the organic ligands in the MOF. Then, a local reductive atmosphere composed of $\mathrm{H}_{2}, \mathrm{CH}_{4}, \mathrm{CO}$, and $\mathrm{C}_{2} \mathrm{H}_{2}$ was created to reduce the metal cations in MOF and subsequently assembled to form MNPs with protective graphene layers under the synergy effect of the reductive atmosphere and extremely high temperature at the local position resulted from laser movement. This work provided a new perspective for laser synthesis of nanopowders free of prefabrication of films. By using the same nano-LaMP method, Deng et al. [78] recently found out that metal species in the MOF resulted in different final products after nano-LaMP. For instance, the metal featuring with unsaturated d orbitals $\left[\mathrm{Hf}\left(5 \mathrm{~d}^{2}\right), \mathrm{Zr}\left(4 \mathrm{~d}^{2}\right), \operatorname{Ti}\left(3 \mathrm{~d}^{2}\right), \mathrm{Cr}\left(3 \mathrm{~d}^{5}\right), \mathrm{V}\left(3 \mathrm{~d}^{3}\right), \operatorname{Fe}\left(3 \mathrm{~d}^{6}\right)\right.$ and $\operatorname{Mo}\left(4 d^{5}\right)$ ] (Fig. 5j) in MOF was inclined to convert to transition metal carbide nanoparticles (TMCs), because that these metals could form hybrid orbitals with carbon to form metal carbides rather than metal nanoparticles. In addition, these TMCs needed an extremely high temperature to form stable metal carbides compared with the formation of metals (Fig. 5j); therefore, the extremely high temperature resulted from pulsed laser made it possible for the reduction of metal ions to TMCs. In conclusion, the characteristic of metal species in MOFs as well as the laser synthesis method along with high temperature, reductive atmosphere $\left(\mathrm{CO}\right.$ and $\left.\mathrm{H}_{2}\right)$ and instant heating and cooling facilitated the formation of a large variety of TMCs (Fig. 5k).

Hybrid materials composed of graphene and metal oxides were also developed to be fabricated by laser processing, as laser-induced graphene from polymers has been widely studied and significant advances have been made. Tour et al. [79] scribed a metal-complex containing polyimide film by the $\mathrm{CO}_{2}$ laser, different metal oxide nanoparticles including $\mathrm{Co}_{3} \mathrm{O}_{4}, \mathrm{MoO}_{2}$, and $\mathrm{Fe}_{3} \mathrm{O}_{4}$ embedded in porous graphene were formed. This work provided an advanced method for synthesis of metal oxide nanoparticles/graphene hybrid 


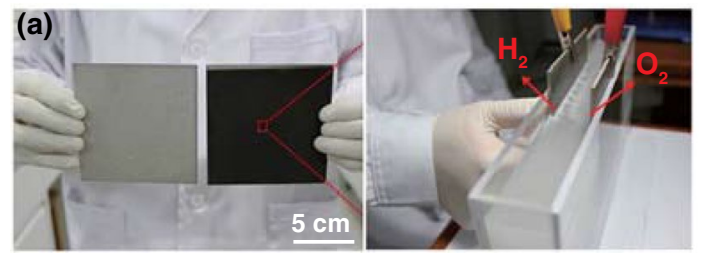

\begin{tabular}{|c|c|c|c|c|c|c|c|c|c|c|c|c|c|c|c|c|c|}
\hline \multicolumn{17}{|c|}{ (b) } & \multirow{2}{*}{\begin{tabular}{|l|}
$\mathrm{He}$ \\
$\mathrm{Ne}$ \\
\end{tabular}} \\
\hline L & $\mathrm{Be}$ & & & & & & & & & & & B & C & $\mathbf{N}$ & 0 & $F$ & \\
\hline $\mathrm{Na}$ & $\mathrm{Mg}$ & & & & & & & & & & & Al & $\mathrm{Si}$ & $\mathbf{P}$ & $\mathrm{s}$ & $\mathrm{Cl}$ & $\mathrm{Ar}$ \\
\hline$K$ & $\mathrm{Ca}$ & Sc & $\mathrm{Ti}$ & $\mathbf{v}$ & $\mathrm{Cr}$ & $\mathrm{Mn}$ & $\mathrm{Fe}$ & Co & $\mathrm{Ni}$ & $\mathrm{Cu}$ & $\mathrm{Zn}$ & $\mathrm{Ga}$ & Ge & As & $\mathrm{Se}$ & $\mathrm{Br}$ & $\mathrm{Kr}$ \\
\hline $\mathrm{Rb}$ & $\mathrm{Sr}$ & $Y$ & $\mathrm{zr}$ & $\mathrm{Nb}$ & Mo & Tc & Ru & Rh & $\mathrm{Pd}$ & $\mathrm{Ag}$ & $\mathrm{Cd}$ & In & Sn & Sb & \begin{tabular}{|l|} 
\\
\end{tabular} & 1 & $\mathrm{Xe}$ \\
\hline Cs & $\mathrm{Ba}$ & La & $\mathrm{Hf}$ & $\mathrm{Ta}$ & w & $\mathrm{Re}$ & Os & Ir & $\mathrm{Pt}$ & $\mathrm{Au}$ & $\mathrm{Hg}$ & $\mathrm{Ti}$ & $\mathrm{Pb}$ & $\mathrm{Bi}$ & Po & At & $\mathrm{Rn}$ \\
\hline $\mathrm{Fr}$ & $\mathrm{Ra}$ & $\mathrm{Ac}$ & $\mathrm{Rf}$ & D & $\mathrm{sg}$ & Bh & Hs & Mt & Ds & $\mathrm{Rg}$ & & & & & & & \\
\hline
\end{tabular}

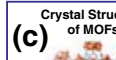

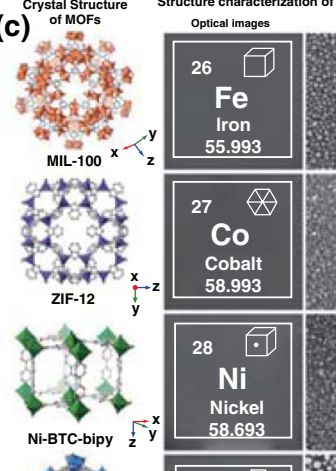

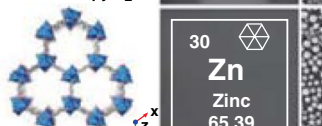

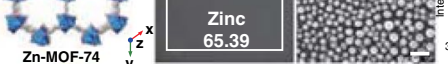

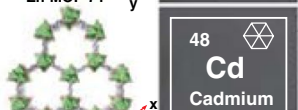

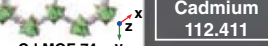

Fet ${ }_{\text {In }}^{490}$

CPM-5 $\left.^{2} z+\right\}^{x} \begin{array}{r}\text { Indium } \\ 114.818 \\ \hline\end{array}$

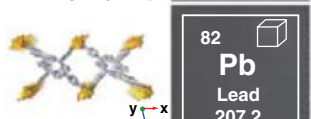

Pb-TCPP ${ }^{\mathrm{y}_{F}} \mathrm{x} \begin{array}{r}\text { Lead } \\ 207.2\end{array}$

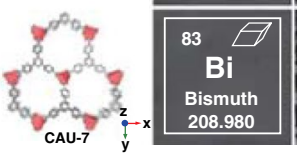

(i)

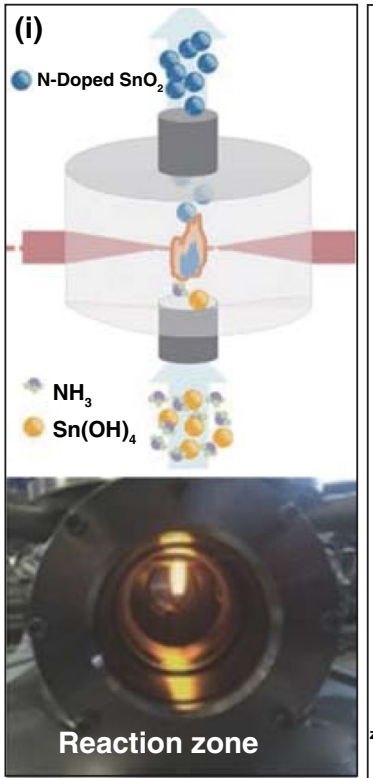

sent ingases

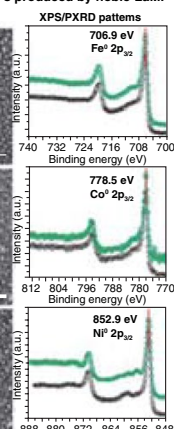

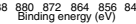

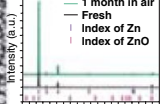

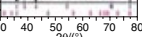
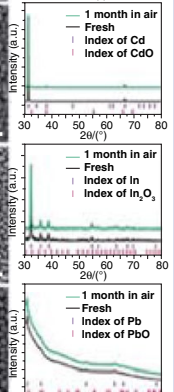
$30+40+50 \div 60$

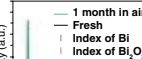

(d)

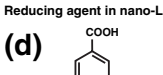

Reductant in nano-Lamp

Nanoscale Laser Metallurgy and Patterning

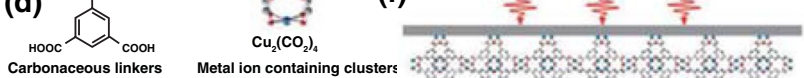
-

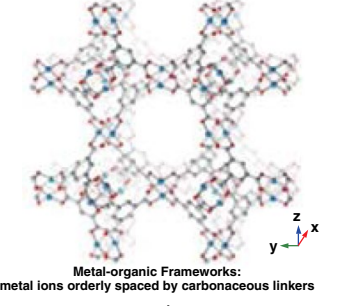

(e)

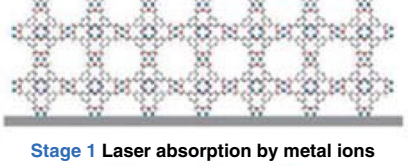
$\div \frac{1}{7}$
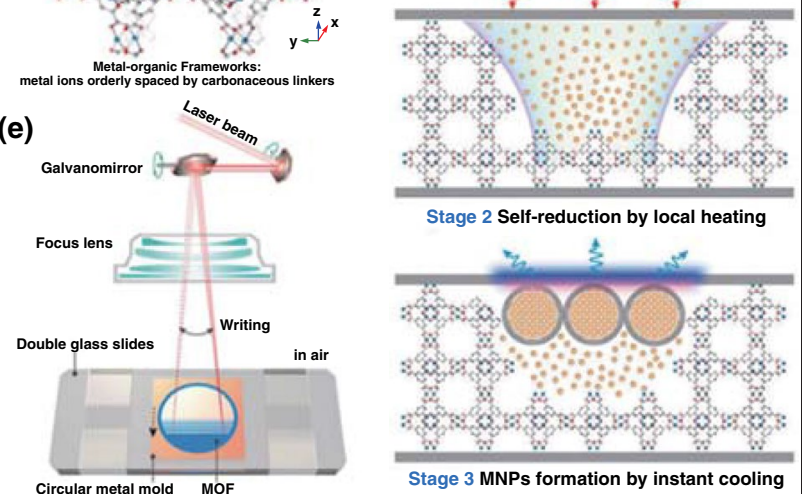

Stage 2 Self-reduction by local heating

(g)

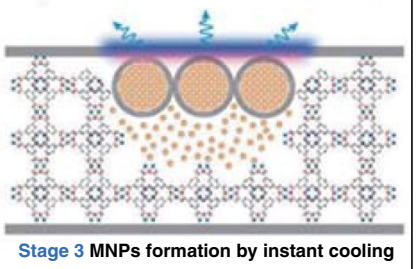

(h)

$\lim _{20} \lim _{40} 40607080$

${ }^{1}$ H (j)

${ }^{3}$ Li ${ }^{4} \mathrm{Be}$

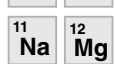

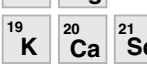

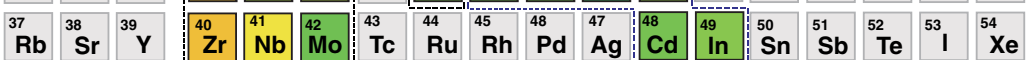
\begin{tabular}{|l|l|l|l|l|l|l|l|l|l|l|l|l|l|l|l|l|l|}
\hline 55 & 56 & 57 & 72 & 73 & 74 & 75 & 76 & 77 & 78 & 79 & 80 & 81 & 82 & 83 & 84 & 85 & 86 \\
\hline
\end{tabular} Cs Ba La

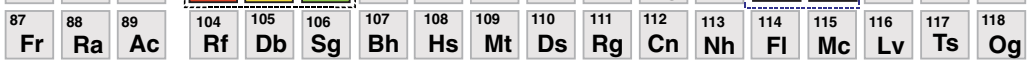
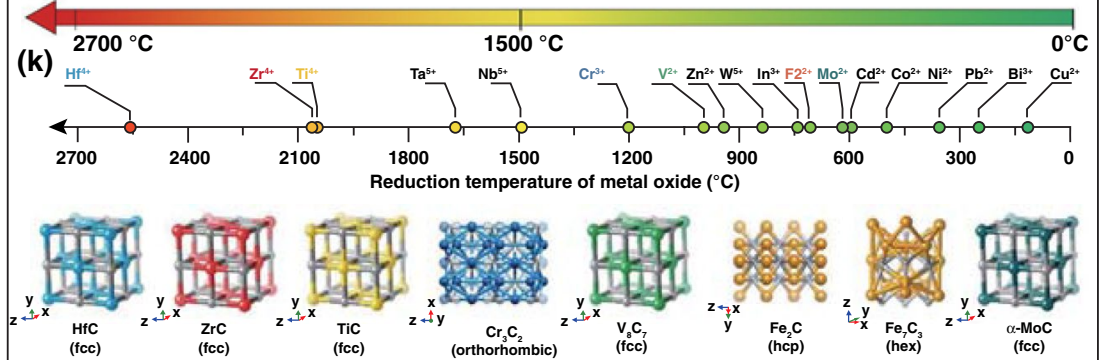
\Fig. 5 a Digital photograph of Ni plates $\left(10 \times 10 \mathrm{~cm}^{2}\right)$ before (left) and after (right) laser ablation and the overall water splitting device by Ni plate. $\mathbf{b}$ The applied metals and alloys highlighted within a periodic table [69]. c Various non-noble MNPs produced by the nano-LaMP method in air displayed along with their corresponding MOF crystals. From left to right, the crystal structure of MOFs, optical images, SEM images, PXRD patterns, and XPS patterns of MNPs. HKSUT-1 precursor $\mathbf{d}$ and illustrations of the experimental setup e for the nano-LaMP method. $\mathbf{f}$ Mechanism for the production of MNPs by laser irradiation on MOFs in air. $\mathbf{g}$ Optical image of the MOF crystals prepared for nano-LaMP. The scale bars are inset in $\mathbf{g}$ $20 \mu \mathrm{m}$ and $\mathbf{h} 200 \mu \mathrm{m}$ [77]. i Illustration of the laser pyrolysis process of $\mathrm{N}$-doped $\mathrm{SnO}_{2}$ [74]. j Periodic table shows the reduction temperatures of various metallic elements according to Ellingham diagram. $\mathbf{k}$ TMCs synthesized in this study using MOF as precursor and laser as energy source [78]

materials by laser processing. Meanwhile, through two-step laser scribing, $\mathrm{Co}_{3} \mathrm{O}_{4} / \mathrm{LIG}, \mathrm{MnO}_{x} / \mathrm{LIG}$ and $\mathrm{NiFeO}_{x} / \mathrm{LIG}$ were also prepared by this group [80], where the first laserinduced graphene and then soaking the LIG by metal ions solution for second-time laser processing were contained. In addition, they verified that the nanoparticles could convert from metal oxides to metal dichalcogenides, but the lateral sulfating treatment was essential.

2.2.1.2 Metal Carbides As laser scribing is a relatively common method for synthesis of carbon materials, the metal carbide-graphene composites synthesized by laser were also developed. Lin et al. [81] developed a laser directwrite patterning process to fabricate molybdenum carbidegraphene (MCG) conductive composites directly on paper substrates, which was realized by soaking the fibrous paper in the Mo-gelatin ink and then direct laser conversion of MCG by a $\mathrm{CO}_{2}$ laser with wavelength of $10.6 \mu \mathrm{m}$ (Fig. 6a, $\mathrm{b}, \mathrm{e})$. After the conversion, the coexistence of graphene and $\mathrm{Mo}_{3} \mathrm{C}_{2}$ was verified by Raman and XRD results (Fig. 6c, d). It was demonstrated that gelatin-based ink could produce higher conductivity than other hydrogel polymers, which was attributed to the formation of lamellar morphology in layer-by-layer form and the absorption enhancement of $\mathrm{CO}_{2}$ laser by strongly binding with $\mathrm{Mo}^{5+}$ ions under the effect of porcine skin peptides with rich amino acid functional groups. This work potentially promoted laser synthesis of metal carbide-graphene composites for practical applications in recyclable and disposable paper-based electronics. Based on this work, this group further proposed the ultrathin carbides on versatile substrates through $\mathrm{CO}_{2}$ laser processing of a lamellar hydrogel/metal-ion matrix [82]. Different metal ions were investigated, and it can be observed that $\mathrm{Co}^{2+}$ and $\mathrm{W}^{6+}$ gelatin produced the composites of carbides and metal hybrid phases. The $\mathrm{Ti}^{4+}$ and $\mathrm{Zr}^{4+}$ gelatin hydro- gels were converted to carbide and oxide composites, while $\mathrm{Fe}^{3+}$ and $\mathrm{Ni}^{2+}$ gelatin dominantly produced metal oxides with small portions of carbides. No crystalline phase was produced by $\mathrm{Zn}^{2+}$ gelatin (Table in Fig. 6f). Therefore, the finally formed products are determined by two critical factors, including the efficiency of laser absorption by the metal-gelatin and the activation energy of carbonization, which determine whether the carbides can be formed.

2.2.1.3 Metal Disulfides In the past decades, numerous attempts to fabricate the transition metal dichalcogenides (TMDs) with monolayer by the chemical vapor deposition (CVD) process had been performed [83]. However, on account of being time-consuming, low thermal efficiency and required transfer of the CVD process, developing alternative synthesis methods were required. Laser synthesis of the transfer-free TMDs provided a promising strategy. In terms of laser synthesis of TMDs nanomaterials, laser thinning and laser annealing were two commonly used strategies. The laser thinning method relies on the sublimation of the outermost layer and heat is introduced by the absorption of laser. Because that the van der Waals force between TMDs layers is very weak, the produced heat is difficult to transfer through the substrate; thus, the sublimation of the outermost layer occurs with the bottom layer of TMDs which remain tightly attaching on the substrate. For example, Steele et al. [84] employed a focused laser beam to fabricate monolayer $\mathrm{MoS}_{2}$ from multilayered $\mathrm{MoS}_{2}$ flakes by the laser-thinning method (Fig. 7a). A MoS 2 monolayer domain surrounded by multilayer film through the growth of $\mathrm{MoS}_{2}$ films and subsequent laser thinning process was also produced by Sow et al. [85]. With this approach, functional junctions with different band gaps were readily fabricated by laser thinning $\mathrm{MoS}_{2}$ domains with different thicknesses, which exhibited superior photoresponse characteristics (Fig. 7b). In addition, laser ablation-induced defects on TMDs also depends on the sublimation of part of the TMDs through the photothermal effects by laser. In this case, a series of van der Waals heterostructure arrays, including $\mathrm{VSe}_{2} / \mathrm{WSe}_{2}, \mathrm{NiTe}_{2} /$ $\mathrm{WSe}_{2}, \mathrm{CoTe}_{2} / \mathrm{WSe}_{2}, \mathrm{NbTe}_{2} / \mathrm{WSe}_{2}, \mathrm{VS}_{2} / \mathrm{WSe}_{2}, \mathrm{VSe}_{2} / \mathrm{MoS}_{2}$, and $\mathrm{VSe}_{2} / \mathrm{WS}_{2}$, were prepared by laser-patterning periodic arrays of nucleation sites on monolayer or bilayer semiconducting TMDs to selectively grow metallic TMDs. The laser ablation for patterning played an important role in providing nucleation sites for growth of TMDs [86].

The laser annealing method is using laser as a heating source to promote the synthesis reaction between different precursor species. For instance, Tenne et al. [87] creatively used ultrashort-pulse laser to process a mixture of bulk transition-metal dichalcogenides and $\mathrm{Pb} / \mathrm{PbO}$ to fabricate 


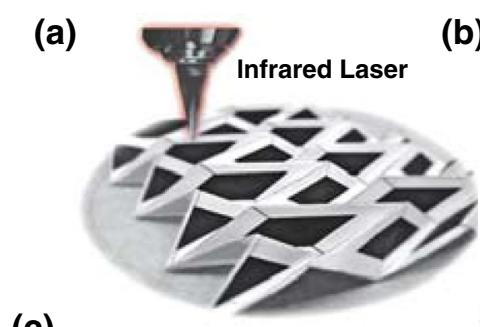

(c)

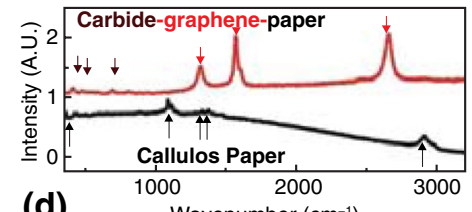

(d)

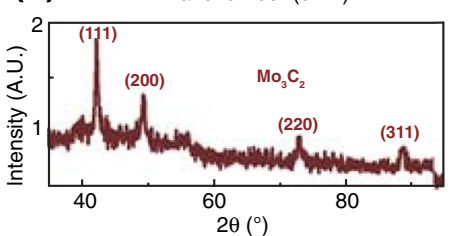

(b)

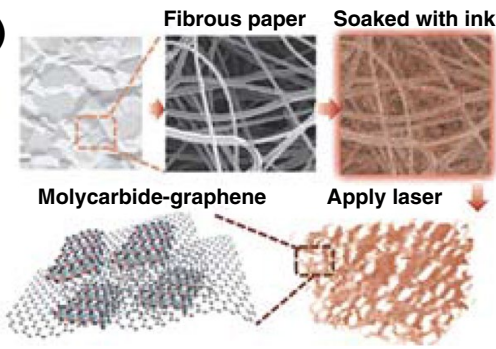

(e)

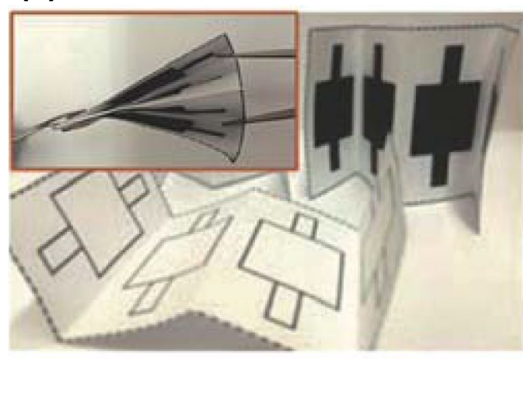

(f)

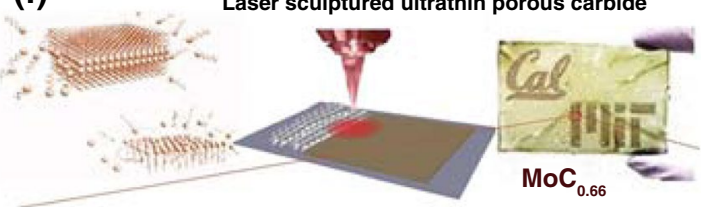

Table 1 Summary of the composition of various hydrogels and their obtained products with laser ablation Salt Precursor Solvent Polymer media Product $\mathrm{MoCl}_{5}(2 \mathrm{~m}) \quad$ Dl water Gelatin (>30 wt\%) MoC $\mathrm{MoCl}_{5}(2 \mathrm{~m}) \quad$ Dl water Gelatin (1 wt\%) $\quad \mathrm{MoO}_{2}$ $\mathrm{MoCl}_{5}(2 \mathrm{~m}) \quad$ DI water Gelatin (5-10 wt\%) $\mathrm{MoO}_{2}+\mathrm{Mo}_{2} \mathrm{C}$ $\mathrm{MoCl}_{5}(2 \mathrm{~m}) \quad$ DI water PVP $\mathrm{MoCl}_{5}(2 \mathrm{~m})$ $\mathrm{WCl}_{6}(1 \mathrm{~m})$ $\mathrm{CoSO}_{4}(2 \mathrm{~m})$ $\mathrm{NiSO}_{4}(2 \mathrm{~m})$ $\mathrm{FeCl}_{3}(2 \mathrm{~m})$ DI water PEO NMP Gelatin DI water Gelatin

DI water Gelatin

DI water Gelatin

$\mathrm{Zr}\left(\mathrm{NO}_{3}\right)_{4}(2 \mathrm{~m}) \quad$ DI water Gelatin $\begin{array}{llll}\mathrm{Zr}\left(\mathrm{NO}_{3}\right)_{4}(2 \mathrm{~m}) & \text { DI water } & \text { Gelatin } & \mathrm{ZrC}+\mathrm{ZrO} \\ \mathrm{Zn}\left(\mathrm{NO}_{3}\right)_{2}(2 \mathrm{~m}) & \text { DI water } & \text { Gelatin } & \mathrm{NA} \\ \text { Tetrabutyl Titanate } & \text { NMP } & \text { Gelatin }(<5 \mathrm{wt} \%) & \mathrm{TiC}+\mathrm{TiO}_{2}\end{array}$

Fig. 6 a An optical photograph of a fabricated origami structure after the direct laser-write MCG patterning process (black color areas) on a paper substrate (white color areas). b Schematic illustration of the simplified MCG process from fibrous paper, soaked with the gelatin-mediated ink containing $\mathrm{Mo}^{5+}$ ions, laser conversion process, to the resulting MCG composites. $\mathbf{c}$ Raman spectroscopy and $\mathbf{d}$ XRD patterns of the MCG sample. e Two partially folded, four $2 \times 2 \mathrm{~cm}^{2}$ electrodes on a paper substrate: (top) after the laser conversion process and (bottom) before the conversion process. (inset) A fully folded device with two electrodes on top and two electrodes at the bottom for a two-capacitor in sandwich structure to be connected in series or parallel as supercapacitors [81]. f IR laser ablation generates highly porous structures and the summary of the composition of various hydrogels and their obtained products with laser ablation [82]

inorganic fullerene-like and nanotube-like TMDs nanostructures, the catalytic effects of metal assisted with the ultrafast laser-induced thermal annealing contributed to the formation of different TMDs nanostructures. Lamberti et al. [88] reported rapid one-pot synthesis of $\mathrm{MoS}_{2}$-decorated laserinduced graphene $\left(\mathrm{MoS}_{2}\right.$-LIG) by direct writing of polyimide foils coating with a layer of $\mathrm{MoS}_{2}$ dispersion. After laser writing, the $\mathrm{MoS}_{2}$ can be in situ decorated into the surface of 3D arrangement of agglomerated and wrinkled graphene flakes. The metal sulfide (CdS or PdS) decorated graphene composites by laser-induced synchronous carbonization and sulfidation of a metal-complex-containing polyethersulfone layer were also reported [89]. The prepared LI-CdS/PdS-G@ ITO afforded both the porous structure and uniform distribution of metal sulfides, which presented an efficient photoanode for photoelectrochemical detection of $\mathrm{Cu}^{2+}$ with significant selectivity and sensitivity. $\mathrm{WO}_{3}$ and Se powders can also be used as the reaction precursors, Chueh et al. [90] utilized laser annealing as a heating source to synthesize few-layer $\mathrm{WSe}_{2}$ by the reaction between $\mathrm{WO}_{3}$ and $\mathrm{Se}$ gas (Fig. 7c). The phase transformation from $\mathrm{WO}_{3}$ to $\mathrm{WSe}_{2}$ was confirmed by Raman spectrum, and the distinct interface between $\mathrm{WO}_{3} / \mathrm{WSe}_{2}$ and $\mathrm{SiO}_{2}$ can be clearly observed in the optical images of the deposited film before and after laser annealing. This laser irradiation-assisted selenization (LIAS) process not only had the advantages of being ultrafast ( $<20 \mathrm{~min}$ ), low-cost and low synthesis temperature, but also exempted from the additional transfer process of TMDs. Furthermore, the laser irradiation-assisted synthesis process can also be adapted to the other TMDs such as $\mathrm{MoSe}_{2}$, which demonstrated wide applicability. It is noted that most of the fabrication process of transition metal dichalcogenides by laser is based on two-step treatment, including the first growth of TMDs film and then laser treatment; the LIAS method provides a new strategy to synthesize TMDs by the gas-solid reaction utilizing laser as heating source.

\subsubsection{Heteroatom-Doped Transition Metal Com-} pounds Except for the laser synthesis of heteroatom-doped carbon, the laser processing technique was also utilized for incorporation of heteroatoms into the transition metal compounds. For instance, the laser-induced chemical modification of suspended TMD monolayer films via local exchange of the chalcogen atoms has been reported [83]. With the 

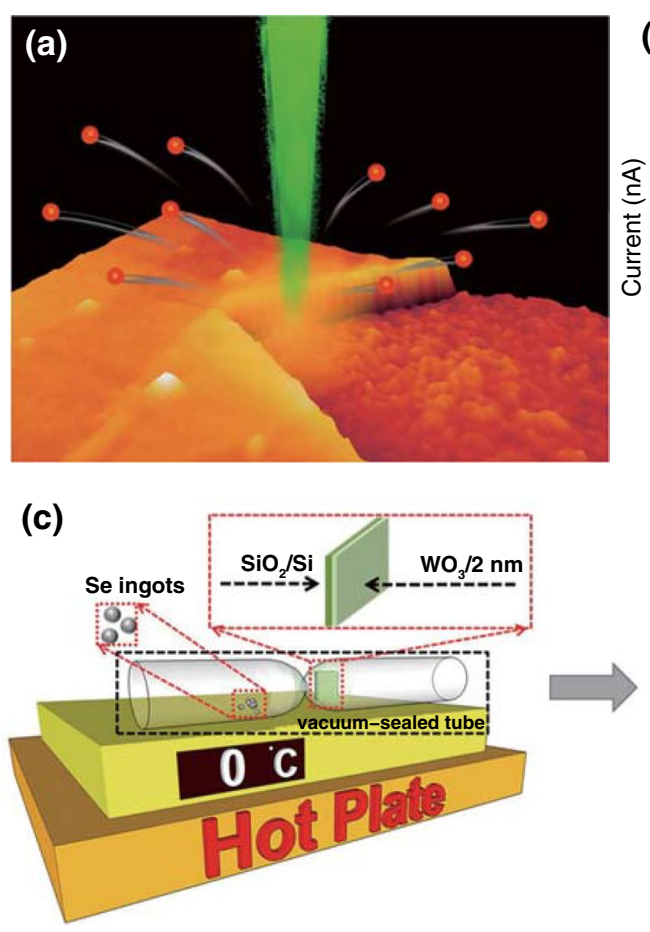
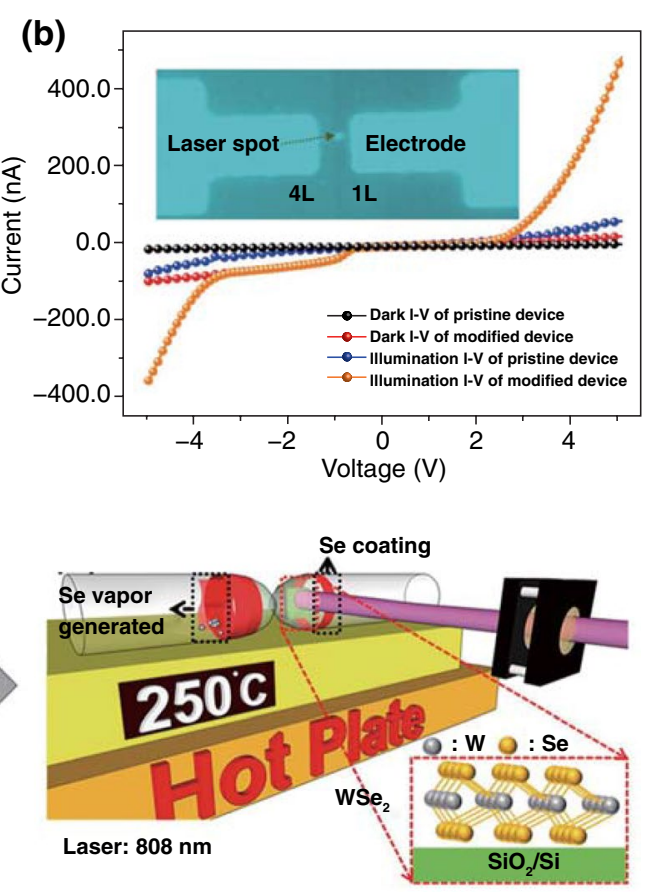

Fig. 7 a Schematic of controllably thinning multilayered $\mathrm{MoS}_{2}$ down to single layer by laser [84]. b Typical I-V characteristics of pristine and modified photodetection devices at dark and laser illumination condition [85]. c Schematic illustration of the rapid synthesis of the WSe ${ }_{2}$ by the LIAS process [90]

proposed method, total or partial locally replacing selenium by sulfur atoms was achieved, which exhibited an excellent performance in nanodevices composed of heterogeneous 2D materials. In addition, the synthesis of oxide thermoelectric material of $\mathrm{Bi}_{2} \mathrm{Sr}_{2} \mathrm{Co}_{1.8} \mathrm{O}_{x}$ via laser floating zone [91] and the synthesis of rare-earth-doped $\mathrm{SrTiO}_{3}(\mathrm{Y}, \mathrm{Dy}, \mathrm{Sm}$, $\mathrm{Pr}$, La-doped $\mathrm{SiTiO}_{3}$ ) via laser melting [92] also have been reported, demonstrating the potential advantage of laser synthesis of heteroatom-doped transition metal compounds. Liu et al. [93] used the laser-drilled micropores strategy to prepare the hybrid electrocatalyst of Fe-doped $\mathrm{NiS}_{2} / \mathrm{MoS}_{2}$ on a CNT film with periodic micropores, the hybrid electrocatalyst provided strengthened interfacial interactions and abundant active sites, improving both thermodynamic catalytic activity and active site density. Therefore, different laser synthesis strategies can be utilized for incorporation of heteroatoms into transition metal compounds, the optimization of laser power, exposure time, and reactive atmosphere is crucial to control the heteroatoms dopant on the transition metal compounds.

2.2.1.5 Other Non-carbon Nanomaterials Organic-inorganic halide perovskites have emerged as promising materials for optoelectronics, especially photovoltaics [94, 95].
As well known, the optimum annealing crystallization temperature for $\mathrm{MAPbI}_{3}$ perovskite film was $100{ }^{\circ} \mathrm{C}$. However, it is limited by the energy and time consuming, and incompatibility with low temperature fabrication requirement of flexible polymers or plastic substrates for the traditional thermal-annealing process, laser annealing-induced crystallization process provided a novel annealing approach for precisely controlling the crystallization position and achieving larger grains with lower density of trap states and higher carrier mobility, especially for reducing carrier recombination and enhancing photovoltaic performance of perovskite solar cells (PSCs). Yu et al. [96] introduced a continuouswave laser $(\lambda=450 \mathrm{~nm})$ irradiation to rapidly crystallize and prepare $\mathrm{CH}_{3} \mathrm{NH}_{3} \mathrm{PbI}_{3}$ films with dense and homogeneous grains. The obtained planar-heterojunction solar cells showed the optimal efficiency of $17.8 \%$ with a remarkably high open-circuit voltage of $1.146 \mathrm{~V}$. In addition, Kim et al. [97] used the near-infrared (NIR) laser $(\lambda=1064 \mathrm{~nm})$ to introduce controllable crystallization of $\mathrm{MAPbI}_{3}$ perovskite solar cells, the inverted-type perovskite solar cells with efficiency of 11.3 and $8.0 \%$ on typical glass and flexible polymer substrates, respectively, were demonstrated. Recently, Yan et al. [98] also used the fast laser annealing to induce a higher temperature and selectively grew large perovskite 
grains. By tuning the laser processing parameters, including the scanning speed, laser wavelength and output power, the optimum perovskite films with high crystallinity and perovskite solar cells with high energy conversion efficiency and durability were successfully fabricated. Besides the crystallization of perovskite films for PSCs, the fs laser processing $\mathrm{Bi}_{2} \mathrm{WO}_{6}$ with a strong enhancement of the structural organization and crystallinity were also reported [99].

Different lasers commonly induced different temperatures due to a different absorption capability of the precursor, thus produced different types of non-carbon materials. In conclusion, the characteristics of precursor species and the laser radiation (laser intensity, wavelength, and interaction time, etc.) are of vital importance. The effects of precursors and parameters of laser on the composition nature of the obtained non-carbon materials are summarized in Table 2.

As mentioned above, laser as a synthetic technique can construct various nanostructure during the laser processing. However, more nanostructure styles have not been realized compared with those constructed by wet chemical methods. Therefore, in situ transformation from the preconstructed

Table 2 Effects of precursors and parameters of laser on the composition nature of the obtained non-carbon nanomaterials

\begin{tabular}{|c|c|c|c|c|c|}
\hline Precursor & Laser source & Parameters & Products & Applications & Refs \\
\hline $\begin{array}{l}\text { Metal substrates (Ti, Mn, } \\
\text { Fe, } \mathrm{Co}, \mathrm{Ni}, \mathrm{Cu}, \mathrm{Mo} \\
\mathrm{Ag}, \mathrm{Sn}, \mathrm{W}, \text { and } \mathrm{NiFe})\end{array}$ & $\begin{array}{l}\text { Nanosecond (ns) pulsed } \\
\text { laser }\end{array}$ & $532 \mathrm{~nm}, 12 \mathrm{~ns}, 0.4 \mathrm{~mJ}$ & $\begin{array}{l}\text { Hierarchical nanostruc- } \\
\text { tured metal oxides }\end{array}$ & $\begin{array}{l}\text { Electrocatalytic water } \\
\text { splitting }\end{array}$ & [69] \\
\hline $\mathrm{SiH}_{4}, \mathrm{C}_{2} \mathrm{H}_{4}$ & $\mathrm{CO}_{2}$ laser & $10.6 \mu \mathrm{m}, 18 \mathrm{kHz}$ & $\mathrm{Si} @ \mathrm{C}$ & $\begin{array}{l}\text { Anode material for } \\
\text { lithium-ion batteries }\end{array}$ & [71] \\
\hline Toluene or pyridine, $\mathrm{SF}_{6}$ & $\mathrm{CO}_{2}$ laser & $10.6 \mu \mathrm{m}$ & $\begin{array}{l}\text { Undoped or N-doped } \\
\text { carbon nanodots }\end{array}$ & $\begin{array}{l}\text { Visible-light photoca- } \\
\text { talysis }\end{array}$ & [72] \\
\hline $\mathrm{Sn}(\mathrm{oh})_{4}, \mathrm{NH}_{3}, \mathrm{C}_{2} \mathrm{H}_{4}$ & $\mathrm{CO}_{2}$ laser & $10.6 \mu \mathrm{m}$ & $\mathrm{N}$-doped $\mathrm{SnO}_{2}$ & $\begin{array}{l}\text { Anode material for } \\
\text { lithium-ion batteries }\end{array}$ & [74] \\
\hline MOFs & Nanosecond pulsed laser & $1.5 \mathrm{~W}$ & $\begin{array}{l}\text { Non-noble metal nano- } \\
\text { particles }\end{array}$ & SERS devices & [77] \\
\hline MOFs & $\begin{array}{l}\text { Nanosecond pulsed fiber } \\
\text { laser }\end{array}$ & $\begin{array}{l}1064 \mathrm{~nm}, 80 \mathrm{~ns}, 20 \mathrm{kHz} \text {, } \\
6 \mathrm{~W}\end{array}$ & Transition metal carbides & Catalytic CO conversion & [78] \\
\hline $\begin{array}{l}\text { Metal-complex contain- } \\
\text { ing polyimide (MC-PI) } \\
\text { film }\end{array}$ & $\mathrm{CO}_{2}$ laser & $10.6 \mu \mathrm{m}, 14 \mu \mathrm{s}, 4.8 \mathrm{~W}$ & $\begin{array}{l}\text { Porous graphene with } \\
\text { embedded metal oxide } \\
\text { nanocrystals }\end{array}$ & ORR & [79] \\
\hline $\mathrm{PI}, \mathrm{Co}\left(\mathrm{NO}_{3}\right)_{2}$ & $\mathrm{CO}_{2}$ laser & $\begin{array}{l}10.6 \mu \mathrm{m} \text {, two-step laser } \\
\text { processing }\end{array}$ & $\mathrm{Co}_{3} \mathrm{O}_{4} / \mathrm{LIG}$ & $\begin{array}{l}\mathrm{Zn} \text {-air and } \mathrm{Li}-\mathrm{O}_{2} \text { bat- } \\
\text { teries }\end{array}$ & {$[80]$} \\
\hline $\mathrm{PI}, \mathrm{MoS}_{2}$ dispersion & $\mathrm{CO}_{2}$ laser & $10.6 \mu \mathrm{m}$ & $\mathrm{MoS}_{2}$-decorated LIG & Flexible supercapacitor & [88] \\
\hline PI, ZIF-67 & $\mathrm{CO}_{2}$ laser & $10.6 \mu \mathrm{m}, 9-10 \mathrm{~W}$ & $\begin{array}{l}\text { Metal-decorated and } \\
\text { heteroatom-doped } \\
\text { porous graphene }\end{array}$ & Micro-supercapacitors & [76] \\
\hline Multilayered $\mathrm{MoS}_{2}$ film & & $532 \mathrm{~nm}, 100 \mathrm{~mW} \mathrm{~cm}{ }^{-2}$ & $\mathrm{MoS}_{2}$ single layer & Photodetector device & {$[84,85]$} \\
\hline $\begin{array}{l}\text { Mixture of } \mathrm{MoS}_{2} \text { (or } \\
\mathrm{WS}_{2} \text { ) and } \mathrm{Pd}\end{array}$ & Nd:KGW laser & $513 \mathrm{~nm}, 170 \mathrm{fs}$, & $\begin{array}{l}\mathrm{WS}_{2} \text { or } \mathrm{MoS}_{2} \text { nanostruc- } \\
\text { tures }\end{array}$ & & [87] \\
\hline $\mathrm{WO}_{3}$ film, Se ingots & & $808 \mathrm{~nm}$, continuous wave & Few-layer $\mathrm{WSe}_{2}$ & $\begin{array}{l}\text { Field effect transistor } \\
\text { (FET) devices }\end{array}$ & [90] \\
\hline $\mathrm{WSe}_{2}, \mathrm{H}_{2} \mathrm{~S}$ & Diode laser & $532 \mathrm{~nm}, 0.3 \mathrm{~mW}$ & S-doped $\mathrm{WSe}_{2}$ & & [83] \\
\hline $\begin{array}{l}\text { Fibrous paper, gelatin } \\
\text { inks containing } \mathrm{Mo}^{5+}\end{array}$ & $\mathrm{CO}_{2}$ laser & $10.6 \mu \mathrm{m}, 0.5-4.0 \mathrm{~W}$ & $\begin{array}{l}\mathrm{Mo}_{3} \mathrm{C}_{2} \text {-graphene com- } \\
\text { posites }\end{array}$ & $\begin{array}{l}\text { Electrochemical sensors, } \\
\text { piezoelectret generator, } \\
\text { supercapacitors }\end{array}$ & [81] \\
\hline $\begin{array}{l}\text { Gelatin containing } \mathrm{Mo}^{5+} \\
\mathrm{W}^{6+}, \mathrm{Co}^{2+}\end{array}$ & $\mathrm{CO}_{2}$ laser & $10.6 \mu \mathrm{m}, 2 \mathrm{~W}$ & $\begin{array}{c}\mathrm{MoC}_{\mathrm{x}}, \mathrm{WC}_{\mathrm{x}}, \mathrm{CoC}_{\mathrm{x}} \text { on } \\
\text { versatile substrate }\end{array}$ & $\begin{array}{l}\text { Flexible supercapacitor, } \\
\text { solar-energy harvesting } \\
\text { membrane }\end{array}$ & [82] \\
\hline $\mathrm{MAPbI}_{3}$ perovskite film & Continuous-wave laser & $\begin{array}{l}1064 \text { or } 450 \text { or } 405 \text { or } \\
660 \mathrm{~nm}\end{array}$ & $\begin{array}{l}\text { Crystallization of } \\
\mathrm{MAPbI}_{3} \text { perovskite } \\
\text { film }\end{array}$ & Perovskite solar cells & [96-98] \\
\hline $\mathrm{Bi}_{2} \mathrm{WO}_{6}$ & Ti:sapphire laser & $800 \mathrm{~nm}, 30 \mathrm{fs}, 200 \mathrm{~mW}$ & $\begin{array}{l}\text { Crystallization of } \\
\mathrm{Bi}_{2} \mathrm{WO}_{6}\end{array}$ & & [99] \\
\hline
\end{tabular}


nanostructures through the thermal effect of the unfocused laser is also a potential proposal for expanding the application of laser synthesis process. Furthermore, laser as a synthetic technique is not limited to the aforementioned applications. Laser synthesis have great potential for many other development directions. For instance, more compound species can be controllably synthesized by laser ablation under different atmospheres instead of only air or Ar atmosphere, such as the synthesis of nitrides under the $\mathrm{N}_{2}$ or $\mathrm{NH}_{3}$ atmosphere, synthesis of sulfides under the $\mathrm{H}_{2} \mathrm{~S}$ atmosphere, synthesis of carbides under the $\mathrm{CH}_{4}$ atmosphere and even synthesis under the $\mathrm{CO}_{2}$ atmosphere for oxides or carbides with unique properties.

\subsubsection{Laser Synthesis of Nanomaterials in Liquid}

The laser synthesis of nanomaterials can be performed in two distinct conditions, including the non-aqueous environment and the liquid environment. Therein, laser synthesis of nanomaterials in liquid environment has been widely applied as a versatile technique to construct various colloidal nanostructures. According to the processing mode and the formation mechanism of nanoparticles, laser synthesis can be classified into three methodologies: laser ablation in liquids (LAL), laser fragmentation in liquids (LFL), and laser melting in liquids (LML) [100]. As a synthesis technique of nanomaterials, LAL and LFL were the most commonly utilized methods to prepare nanomaterials. Then in this section, we reviewed on the recently researched nanomaterials with innovative phases through LAL and LFL in liquid.

\subsubsection{Laser Synthesis of Nanomaterials by Laser Abla-} tion in Liquid The LAL technique has inspired extensive researches on nanomaterial synthesis and modification in liquid as well as the properties and applications of the LAL-induced nanomaterials. Two LAL techniques, including the "top-down" synthesis of pulsed laser ablation of a solid target in liquids (PLAL) and the "bottom-up" method of pulsed laser irradiation of colloidal nanoparticles in liquids (PLICN) were promising liquid-based laser protocols for complex nanomaterials. Most PLAL synthesis processes were realized by laser heating the solid target, and then, the initial products including plasma, vapor, and droplets with micro-nanosizes could be produced, which further reacted with the liquid solvent to form the final colloidal nanoparticles [101]. The PLICN technique was that pulsed laser irradiation of a precursor solution, where nucleation and growth of nanomaterials occurred as a result of the laser-induced chemical reactions [102].

As mentioned above, the PLAL process went through the plasma and the gasification stage, and the subsequent substance diffusion and interaction with liquid solvents after bubble collapse. In general, lasers with a short pulse-width and high-energy density were beneficial to the generation of plasma and vapor products, while nanodroplet products were usually caused by lasers with low-power density. The formation of nanostructures was attributed to their interaction with the surrounding liquid solvents and the ultrafast quenching of laser. Owing to the variety of solid targets and liquid solvents, nanomaterials including alloys, metals, oxides, hydroxides, nitrides, carbides, sulfides and composites were achievable by PLAL [103].

In terms of the synthesis of metals and alloys by PLAL, the "bare" unprotected Au nanoparticles were frequently prepared by laser ablation of Au target or Au particles in solution [104-106], which were applied for the catalytic applications. In order to enhance the catalytic activity of individual gold nanoparticles (AuNPs), using AuFe alloys plate [107] or Pt-Au powder-mixture compression [108] as the target for PLAL synthesis method, a homogeneous Au-Fe nanoalloy with a Fe content up to 11 at\% for OER and PtAu alloys for the 4-NP reduction were achieved. Replacing the deionized water by some metal ions solution, the PLAL technique can also be utilized to synthesize alloys. Mukherjee et al. [109] proposed a laser ablation of $\mathrm{Co}$ target in $\mathrm{K}_{2} \mathrm{PtCl}_{4}$ solution, the PtCo nanoalloy embedded in $\mathrm{CoO}_{x}$ matrices was synthesized. Liang et al. [110] prepared Au-ZnO nanospheres with $\mathrm{Au}$ NPs in different particle size encapsulated in $\mathrm{ZnO}$ nanospheres through laser irradiation of the Au target and $\mathrm{Zn}$ target in liquid, respectively. Otherwise, Liu and Du et al. reported the synthesis of RuAu single-atom alloys (SAAs) [111] and $\mathrm{RhO}_{2}$ clusters embedded in the surface of $\mathrm{Rh}$ nanoparticles [112] by PLAL technique, the strong quenching effect played an important role in fabricating metastable nanostructures with novel properties (Fig. 8a). The ternary metal alloy AuAgPt was developed by laser-irradiation of chemically synthesized Au@AgPt yolk-shell nanocubes in liquid to induce alloying (Fig. 8b) [113]. In addition, laser driven the plasma resonance absorption performance for noble metal nanoparticles was applied to realize some plasmon-driven chemical process. For instance, Pan et al. [114] reported that through two steps of the first synthesis of $\mathrm{Au}$ nanoparticles by PLAL of Au plate and then photochemical 


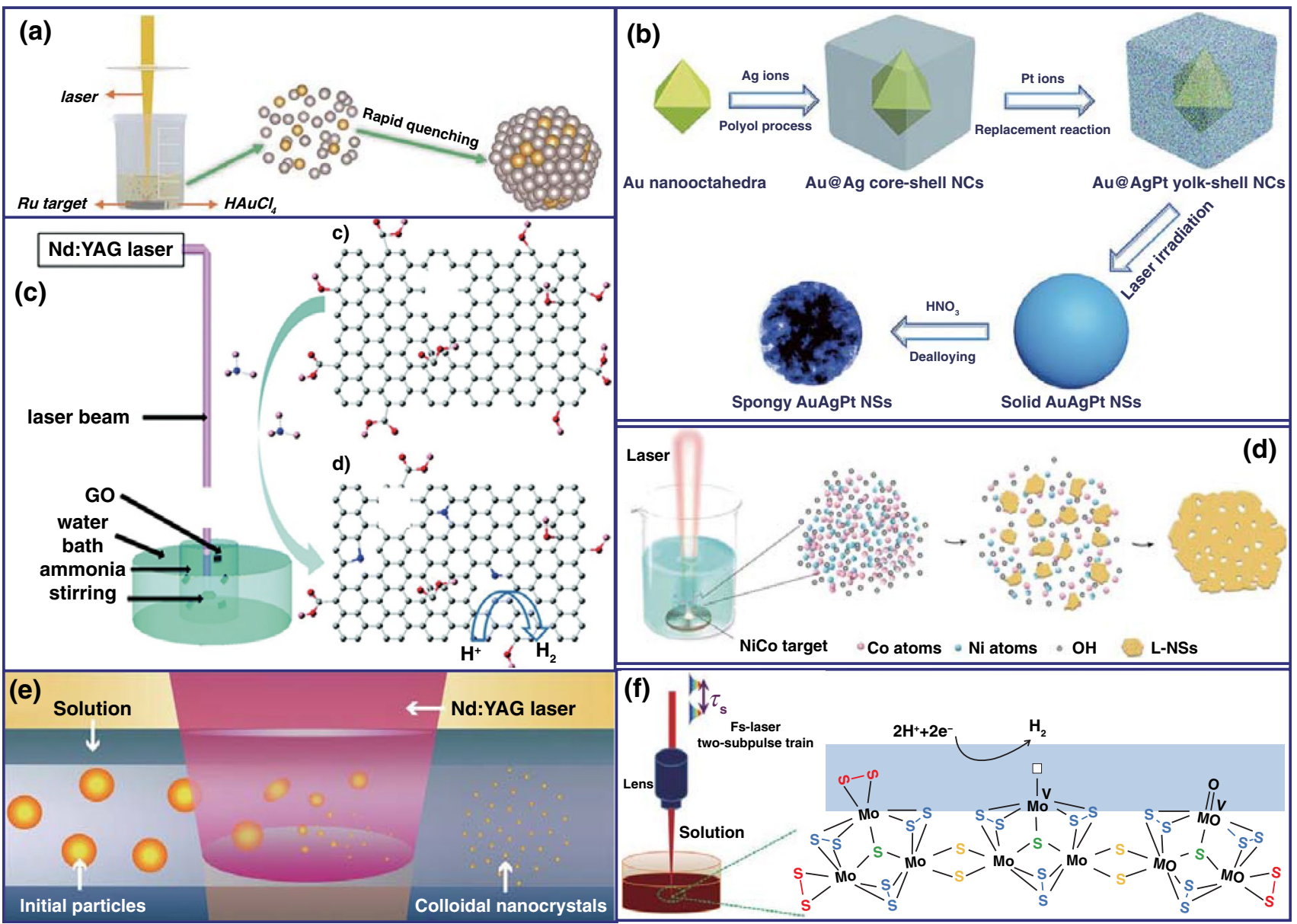

Fig. 8 a Schematic setup of PLAL and the formation process of RuAu SAA nanoparticles [111]. b Schematic diagram for the formation process of spongy AuAgPt [113]. c Illustration of the preparation of nitrogen-doped graphene oxide by laser irradiating a solution containing graphene oxide and ammonia [115]. d Laser ablation of CoNi alloy target in $1 \mathrm{M} \mathrm{KOH}$ solution [119]. e Schematic illustration of the fabrication processes of laser synthesis and processing of colloids [127]. $\mathbf{f}$ Controllable synthesis of nanosized amorphous $\mathrm{MoS}_{\mathrm{x}}$ by fs laser [132]

reaction between $\mathrm{Au}$ nanoparticles and $\mathrm{CuCl}_{2}$ under $532 \mathrm{~nm}$ pulsed laser, the $\mathrm{Cu}$ nanoclusters were achieved due to the reduction of $\mathrm{Cu}^{2+}$ ions by plasmon-generated "hot electrons" from $\mathrm{Au}$.

In terms of the synthesis of metals oxides and hydroxides by PLAL, Du et al. synthesized an N-doped graphene oxide by PLAL of a solution composed of ammonia and graphene oxide, which achieved a high pyridinic $\mathrm{N}$ dopant (51\%) (Fig. 8c). The PLAL process provided a simple and fast approach to prepare $\mathrm{N}$-doped graphene oxide compared with the conventional method, and the obtained $\mathrm{N}$-doped GO exhibited an improved electrochemical HER performance [115]. Bao et al. [116] ablated CoO micropowders by femtosecond (fs) laser pulses in pure water, and the generated $\mathrm{CoO}$ nanoparticles suspended in water were collected directly for solar water-splitting. Müller et al. [118] reported the crystalline $\mathrm{Co}_{3} \mathrm{O}_{4}$ nanoparticles $(<5-\mathrm{nm})$ [117] and $[\mathrm{Ni}-\mathrm{Fe}]$-layered double hydroxides (LDHs) as highly active catalysts for oxygen evolution. $\mathrm{Co}_{0.75} \mathrm{Ni}_{0.25}(\mathrm{OH})_{2}$ nanosheets with high-density pores via PLAL process were similarly realized (Fig. 8d) [119]. Kim et al. [120] reported thin NiFe LDH nanostructures on 1D-CdS nanorods synthesized by using PLAL. The efficient carrier transport attributed to heterostructures greatly inhibits the recombination of carriers.

Ternary oxide nanocrystals (TONs) have received increasing attention for their inherent optoelectronic properties, 
such as good electrical conductivity and multiple active sites; thus, they have been well exploited for energy and catalytic applications [121, 122]. However, adoption of surfactants or growth-guiding agents for traditional synthetic methods will decrease the charge transport in products and hence degrade the device performance. Therefore, PLAL provides an attractive, imperative, and green approach to synthesize TONs. Zeng et al. reported a universal PLAL and subsequent hydrothermal growth for various TONs synthesis. A series of TONs, including $\mathrm{Zn}_{2} \mathrm{SnO}_{4}, \mathrm{NiCo}_{2} \mathrm{O}_{4}$, $\mathrm{Zn}_{2} \mathrm{GeO}_{4}, \mathrm{ZnFe}_{2} \mathrm{O}_{4}, \mathrm{Fe}_{2} \mathrm{GeO}_{4}$, and $\mathrm{ZnMnO}_{3}$ were synthesized, which confirmed the universality of this method. During the synthesis process, the PLAL-generated highly reactive species, such as metal ions, clusters, $\mathrm{H}^{+}$and $\mathrm{OH}^{-}$will facilitate the formation of various TONs in the subsequent hydrothermal process [123]. Based on this work, Zeng et al. prepared $\mathrm{Zn}_{2} \mathrm{SnO}_{4}$ nanocrystals with an average size of $140 \mathrm{~nm}$ by PLAL and subsequent hydrothermal synthesis to construct high-performance nanoscale photodetectors [124]. Yang et al. [125] reported a defective $\alpha-\mathrm{Ag}_{2} \mathrm{WO}_{4}$ nanorods prepared by PLAL. The thermodynamic disequilibrium created by laser ablation combined with the weak bond energy of $\mathrm{Ag}_{2} \mathrm{WO}_{4}$ induced abundant $\left[\mathrm{WO}_{6}\right]$ cluster distortions into the crystal lattice. Similarly, the hydrogen-interstitial $\mathrm{CuWO}_{4}$ nanomesh was prepared by PLAL for the application of single-component full spectrum-active photocatalysts for hydrogen evolution [126]. Wang et al. [127] reported the laser synthesis of ligand-free $\mathrm{La}: \mathrm{BaSnO}_{3}$ nanocrystals by PLAL, and by embedding this laser generated nanocrystals in $\mathrm{BiVO}_{4}$ photoanode matrix, an enhanced charge transport for photoelectrode was achieved (Fig. 8e).

In terms of the synthesis of molybdenum sulfide by PLAL, spherical $\mathrm{MoS}_{2}$ nanoparticles with onion-like structure and internal shrinkage cavities can be prepared through laser ablation of $\mathrm{MoS}_{2}$ target in deionized water [128]. Lee et al. [129] prepared a high concentration of few-layer $\mathrm{MoS}_{2}$ via laser exfoliation of bulk $\mathrm{MoS}_{2}$ in liquid, the $\mathrm{S}$ vacancy and crystal phase transformation were controlled and a dramatically improved electrocatalytic activity toward HER was obtained. Furthermore, the author demonstrated that the presence of protons from solvents with low $p K_{\mathrm{a}}$ values was conducive to creating $S$ vacancies by extracting $S$ atoms to form $\mathrm{H}_{2} \mathrm{~S}$, and simultaneously facilitated the $2 \mathrm{H}$-to- $1 \mathrm{~T}$ phase transition of $\mathrm{MoS}_{2}$ by sliding $\mathrm{S}$ atoms. Amorphous molybdenum sulfide $\left(\mathrm{a}-\mathrm{MoS}_{x}\right.$ ) with abundant defect-rich active sites was synthesized by the femtosecond laser ablation of ammonium tetrathiomolybdate aqueous solution with PLICN (Fig. 8f) [130], which was reviewed in the following as the "bottom-up" method. Besides of $\mathrm{MoS}_{2}$, very recently, $\mathrm{Du}$ et al. [131] used C and O co-doped BN nanospheres as the precursor for PLAL treatment, it demonstrated that the laser-modified boron nitride exhibits unique electrical conductivity and high corrosion resistance under oxidizing conditions, which attributed to the interlayer B-B dipolar interaction.

In contrast to the "top-down" synthesis of PLAL on bulk targets, the "bottom-up" method of PLICN is also a promising liquid-based laser strategy for nanomaterial design [133]. Liang et al. utilized the photo-excited electrons generated by laser processing $\mathrm{SnO}_{\mathrm{x}}$ in a $\mathrm{PtCl}_{6}{ }^{2+}$ solution, and hybrid catalysts composed of Pt clusters anchored on the surface of $\mathrm{SnO}_{2}$ were obtained, which presented high activity and long-term durability for methanol oxidation [134]. Zheng et al. [102] proposed two distinct reaction pathways of a $\mathrm{Co}^{2+}, \mathrm{Ni}^{2+}$, and $\mathrm{Mn}^{2+}$ ion-containing aqueous solution irradiated by lasers with different wavelengths ( 532 or $1064 \mathrm{~nm}$ ). The different laser wavelengths resulted in different product formation mechanisms. As demonstrated, the ionization of water molecules to produce reducing species such as solvated electrons $\left(\mathrm{e}_{\mathrm{aq}}{ }^{-}\right)$and hydrogen radicals $\left(\mathrm{H}^{\cdot}\right)$ in the solution dominantly occurred when the $532 \mathrm{~nm}$ laser was utilized, and hollow $\left(\mathrm{Ni}_{0.18} \mathrm{Mn}_{0.45} \mathrm{Co}_{0.37} \mathrm{O}_{x}\right)$ metal oxide nanoparticles as the final product were formed after the reduction of metal ions by these reducing species and further laser heating. While the $1064 \mathrm{~nm}$ laser mainly induced vibration of water molecules, then the stretched $\mathrm{OH}$ groups of water molecules facilitated the hydrolysis reaction of metal ions and led to the formation of $\left(\left[\mathrm{Ni}_{0.15} \mathrm{Mn}_{0.15} \mathrm{Co}_{0.7}(\mathrm{OH})_{2}\right]\right.$ $\left.\left(\mathrm{NO}_{3}\right)_{0.2} \cdot \mathrm{H}_{2} \mathrm{O}\right)$ hydroxide nanostructures. Recently, Liu et al. [135] reported a laser-assisted, continuous, solution route for the simultaneous reduction and modification of graphene oxide with Pt, PtPd alloys, $\mathrm{RuO}_{2}$ and $\mathrm{MnO}_{\mathrm{x}}$ nanoparticles, which demonstrated the versatility of PLICN in synthesizing functional nanoparticle-modified graphene materials.

Laser-based photohydrothermal synthesis of metal oxides was another kind of PLICN technique. Digital $\mathrm{ZnO}$ nanowires arrays were achieved by this rapid and one-step selective digital direct growth method, which was realized by localized temperature increase after the thin metal layer absorbed the focused laser, and then induced rapid photohydrothermal 
reaction of $\mathrm{Zn}\left(\mathrm{NO}_{3}\right)_{2}$ solutions near the focal spot region $[136,137]$. However, the spatial size was generally limited by the thermal diffusion and the size of the focused laser spot. Ko et al. grew $\mathrm{ZnO}$ or $\mathrm{TiO}_{2}$ nanowires on a selected area that was even smaller than the laser focus size by laser-based photohydrothermal synthesis. The size of laserinduced temperature field can be effectively reduced through reducing the physical dimension or decreasing thermal conductivity of the laser absorption layer substrate. A smaller nanowire array on PI substrate instead of metal absorption layer can also be successfully synthesized, due to the visiblelight absorption capacity and low thermal conductivity of PI [138].

Besides the metal oxides and metal hydroxides, the PLICN technique was also used for other components. For example, Wang et al. [139] prepared Cl-functionalized carbon dots (Cl-CDs) in chlorobenzene via simple laser treatment, which were embedded in perovskite films to regulate both the films morphology and the electronic structures. An improved performance for perovskite solar cells was achieved. Du et al. [122] firstly prepared c-BN NPs with an average size of $3.5 \mathrm{~nm}$ at ambient temperature and pressure by exploiting a laser-induced photochemical effect on a dioxane solution of ammonia borane. Beyond that, Irannejad et al. [140] used a focused femtosecond laser to process the air/graphene oxide solution interface to produce rGO gels without any reductive additives, the reduction of the GO and gel formation occurred simultaneously by removing the hydroxyl, carboxyl functional groups and water in the same time. However, when the laser beam was focused inside the graphene oxide solution, only the reduction of GO solution occurred, no gel formed.

\subsubsection{Laser Synthesis of Nanomaterials by Laser Frag-} mentation in Liquid Laser synthesis of nanomaterials by LFL is induced by the absorption of laser energy with microparticle powder suspensions or nanoparticle colloids. Photothermal vaporization and coulomb explosion are the mechanisms for LFL (Fig. 9a) [141]. To trigger an LFL process in the liquid, commercial solid-state lasers are often combined. Lasers with the pulse width of nanosecond level
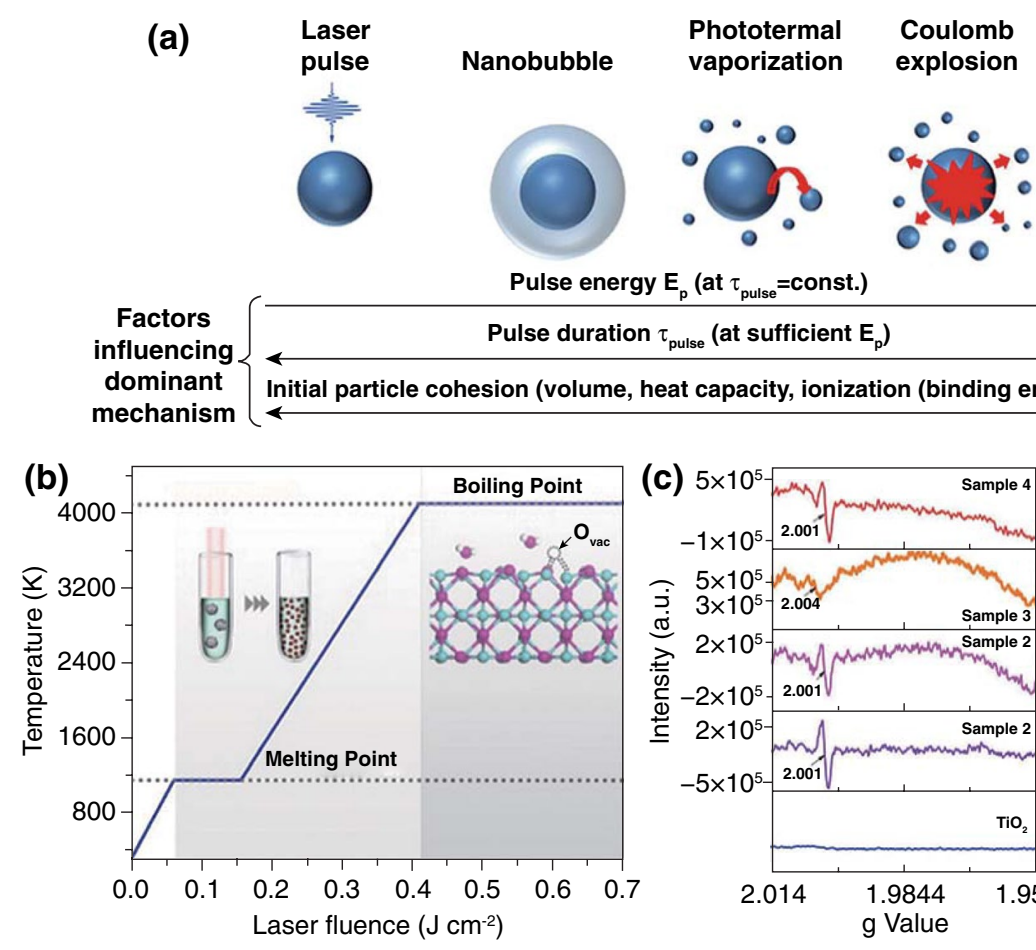

$E_{p}\left(\right.$ at $\tau_{\text {pulse }}=$ const.) 
frequently trigger the photothermal vaporization, while coulomb explosion is triggered by the ultrashort lasers with ps or fs level and is caused by charge repulsion of ionized NPs. LFL can combine both the advantages of size reduction and defect introduction into products, which regulate the electronic structure and lead to a significant improvement of the catalytic activities. Zhou et al. reported that $\mathrm{Co}_{3} \mathrm{O}_{4}$ nanoparticles with a high activity were prepared via the LFL process (Fig. 9b). Ultrafine nanoparticles with abundant oxygen vacancies induced by laser irradiation can significantly improve both electrical conductivity and energy adsorption [142]. Defect-induced electronic reconstruction has also been realized by LFL of photocatalysts and electrocatalysts. G. Yang et al. performed LFL to obtain $\mathrm{TiO}_{2-x}$-graphene oxide mixtures (Fig. 9c-e). After LFL, the conduction band (CB) moved below $0 \mathrm{eV}$ in the range of -0.01 to $-0.55 \mathrm{eV}$, which resulted in a $0.87 \mathrm{eV}$ decrease of the band gap for the visible-light absorption [143]. Zhao et al. employed LFL to liberate the $\mathrm{N}$-doped carbon nanotubes (N-CNTs) confined Co single-atom sites as an efficient selective-hydrogenation material for quinoline. Furthermore, the catalytic conversion of quinoline derivatives with methyl, hydroxyl, and halogen groups into corresponding 1,2,3,4-tetrahydroquinolines was also realized by this liberated catalyst [130]. Musselman et al. [144] utilized the nonresonant intense pulsed laser to fragment and then direct the 2D materials from bulk flakes to assembled nanorod structures. The obtained graphene nanorods, $\mathrm{MoS}_{2}$ nanorods, $\mathrm{WS}_{2}$ nanorods and $\mathrm{BN}$ nanorods suggested the potential in transparent conducting applications.

LAL is summarized to be a "top-down" or "bottom-up" physiochemical method, which usually uses the bulk solid targets (PLAL) or a precursor solution and additional metal absorption layer (PLICN) in liquid condition as the precursors. Therefore, the laser parameters required for LAL are in a wide range, which covering the laser wavelengths from ultraviolet (UV), visible (Vis) to near-infrared (NIR), and the pulse widths from femtosecond, picosecond, nanosecond, microsecond, millisecond, and even extending to the continuous-wave $(\mathrm{CW})$ range. In general, the visible laser with $532 \mathrm{~nm}$ wavelength was frequently utilized to process powder precursors in liquid, while the near-infrared laser with $1064 \mathrm{~nm}$ wavelength was utilized for target precursor. Ultrafast lasers such as fs or ps laser were usually used for synthesis of nanomaterials through laser fragmentation in liquid, which induced the coulomb explosion process. The effects of the precursors and parameters of laser on the composition nature of obtained nanomaterials in liquid are summarized in Table 3.

\section{Laser as Microfabrication Technique for Application}

Laser as a microfabrication technique means that the laser is used as an energy source to precisely focus on desirable positions and create patterns locally without affecting the adjacent area [146]. From the major terms, laser synthesis is involved in the laser microfabrication process. Namely, laser as a microfabrication technique is composed of the simultaneous laser synthesis and patterning during the laser processing. Laser microfabrication technique has the advantages of high production efficiency, low cost, stable and reliable processing quality; therefore, it has the good economic and social benefits. In particular, ultrashort pulse femtosecond laser can produce ultrahigh light intensity, it possesses the preponderances of precision and low damage threshold, ultrasmall heating affected area, and can almost precisely process various kinds of materials. In this section, the as-patterned materials after microfabrication through the laser are reviewed, which present high performance in energy storage and conversion devices such as batteries, supercapacitors, sensors and electrocatalytic materials [147].

\subsection{Light-Thermal Conversion Devices Fabricated by Laser Technology}

Solar-driven water evaporation, wastewater purification and energy conversion are potential green and sustainable technologies; thus, the efficient solar energy harvesting and photothermal conversion play the important role in these applications [148]. In addition, the efficient light-toheat conversion instead of other forms of energy and heat transferring to the applied process also should be satisfied [149]. It is noteworthy that the light-to-heat conversion efficiency depends greatly on the absorbing material. Therefore, light-thermal conversion materials with high conversion efficiency and broad solar absorption range have attracted widespread interests, such as carbon-based materials, semiconductors, metals and polymers [149-151].

For the light-thermal conversion materials, not only excellent optical and thermal properties are essential, economic practicality and manufacturing simplicity on a large scale should also be taken into account. The laser processing technique provides a reliable and cost-effective strategy for fabricating nanomaterials with broad-spectrum 


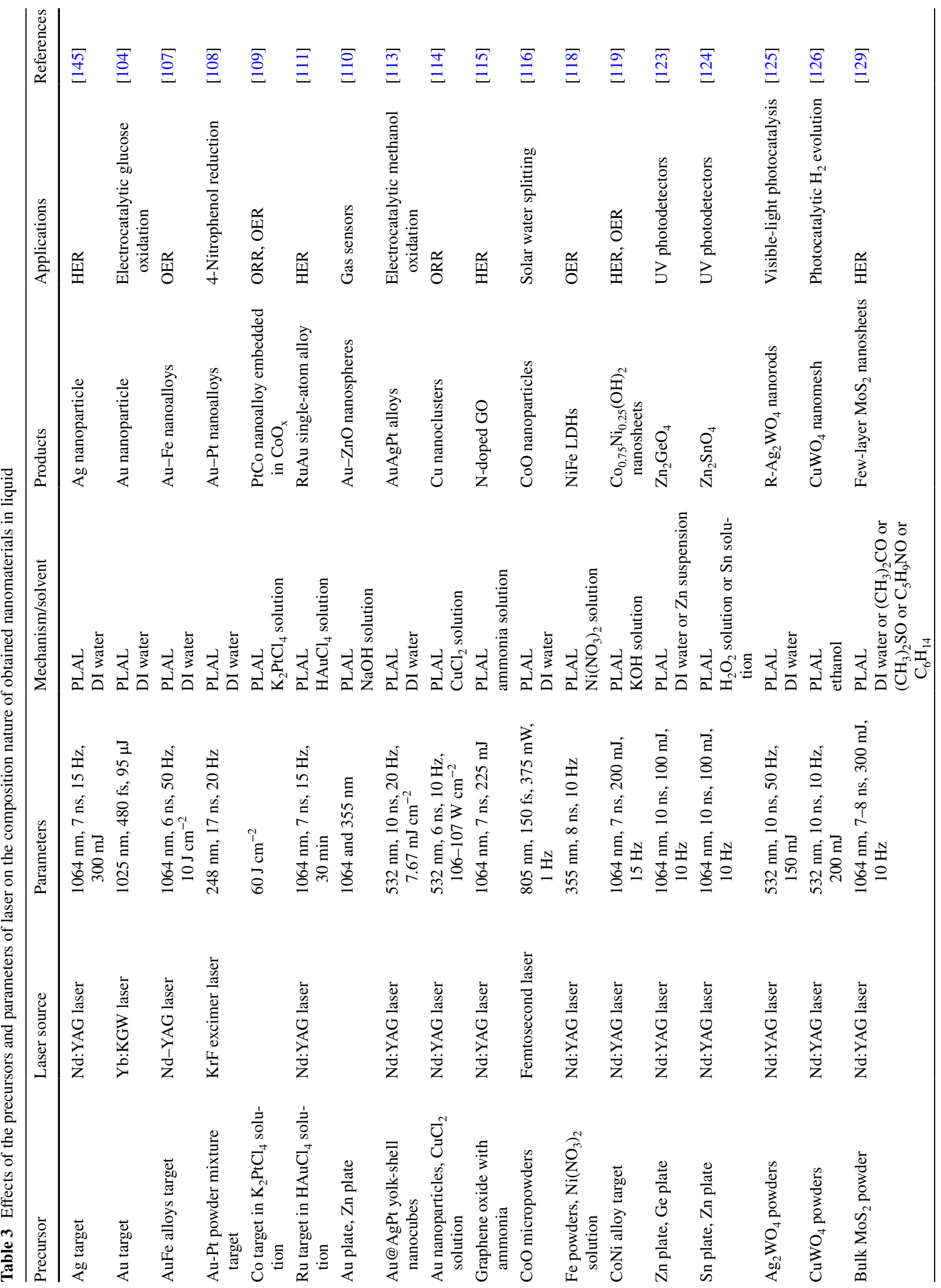




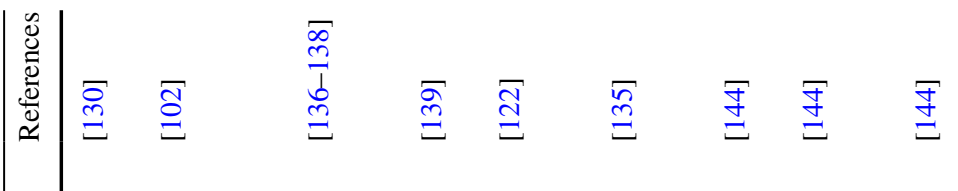

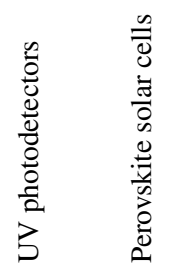

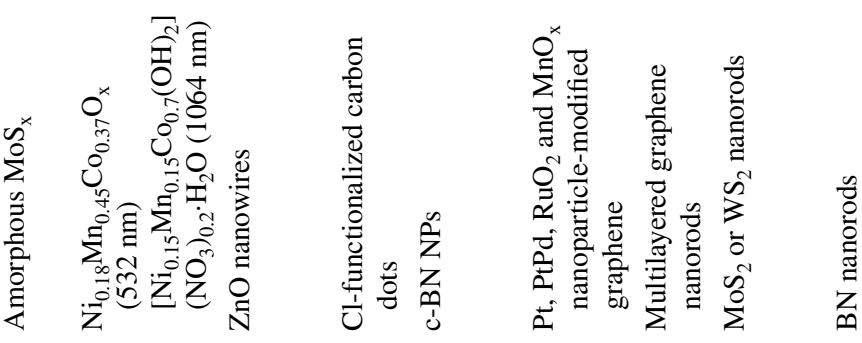

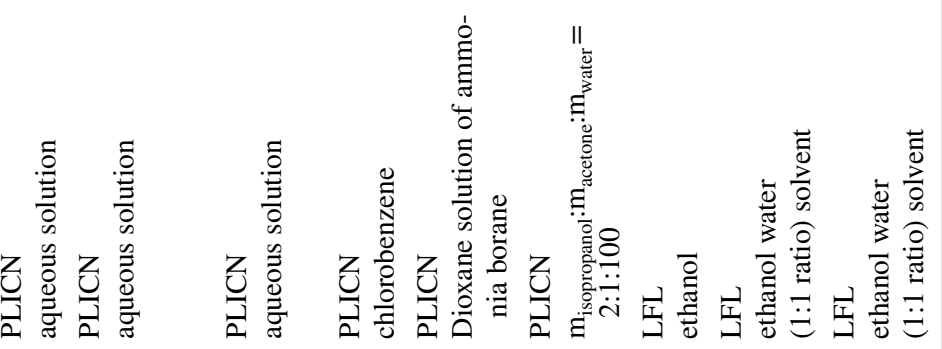

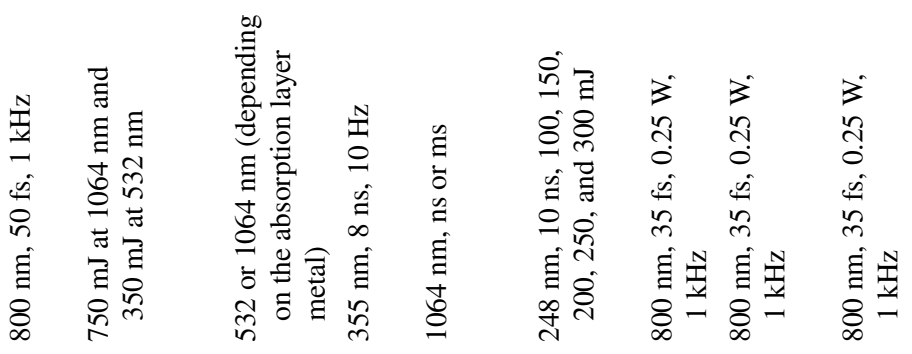

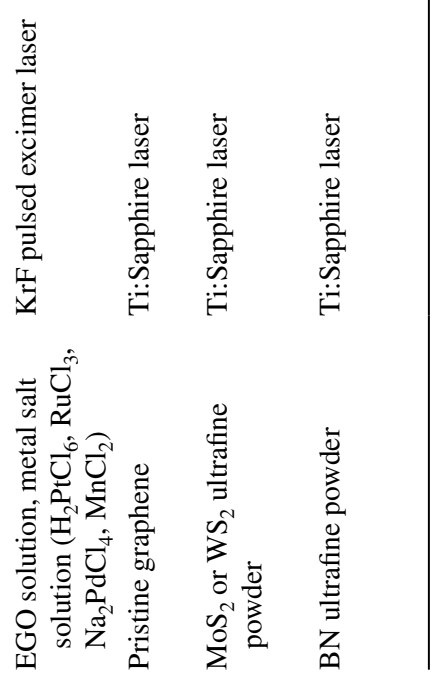


solar energy absorption on a large scale. In particular, these laser-microfabricated materials are widely applied to various photothermal conversion, anti-reflection and light harvesting applications [152, 153]. By successively constructing microstructures and nanostructures via ultrafast laser patterning and subsequent thermal oxidation, an infrared antireflection nanowire array was obtained on a $\mathrm{Cu}$ surface [154]. Attributed to the light trapping by the microstructures, as well as the enhanced photophonon dissipation by the nanowire structure, the ultralow reflectance of $0.6 \%$ was achieved for the infrared light with a $17 \mu \mathrm{m}$ wavelength. Furthermore, Fan et al. also fabricated the cauliflower-shaped copper nanostructures by laser direct writing, which exhibited extremely high broadband omnidirectional absorption of sunlight with high water evaporation efficiency [155]. And then, a universal strategy for fabricating micro/nanohybrid antireflection structures on different metal surfaces by laser direct-writing method was proposed by this group (Fig. 10a, b), the minimum reflectance on $\mathrm{W}, \mathrm{Cu}$, and Ti substrates at ultraviolet to near-infrared spectrum reached $2.5 \%, 1.4 \%$, and $0.29 \%$, respectively [156].

Carbon-based photothermal materials, including graphene, carbon nanotubes, carbon black and graphite, have been used for highly efficient full-spectrum solar absorption materials. Creating a nanostructure with a 3D framework of pores and arrays can reduce light reflection and minimize angular dependence of the incident light. Qu et al. prepared an efficient three-dimensional solar steam generation (SSG) material platform through laser 3D printing technology (Fig. 10c). The as-fabricated graphene framework with a
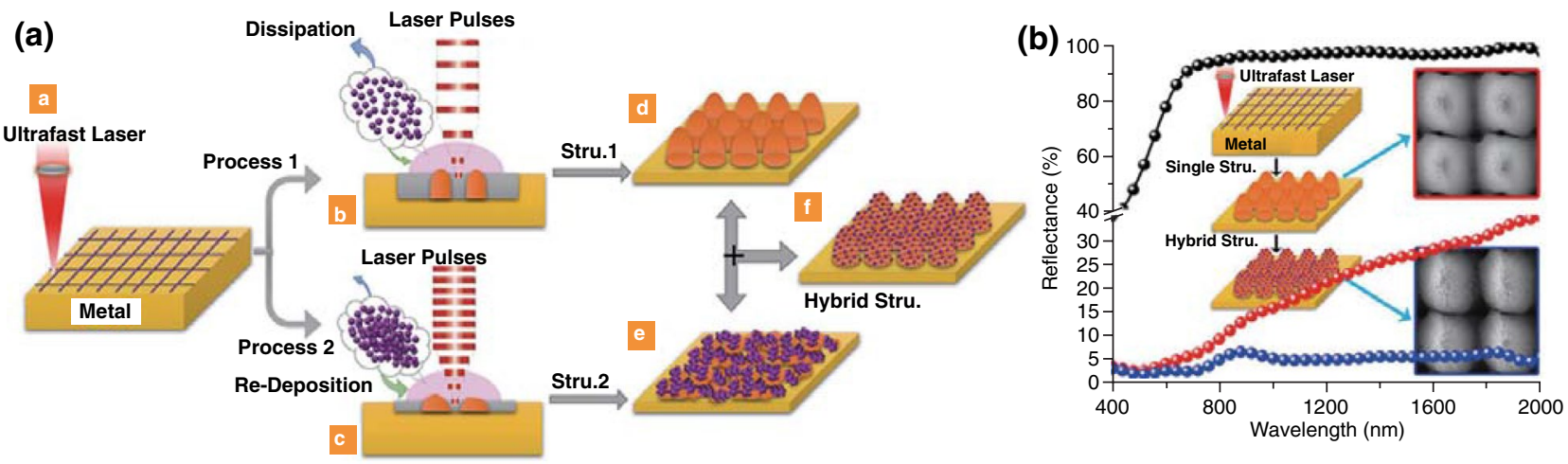

(c)

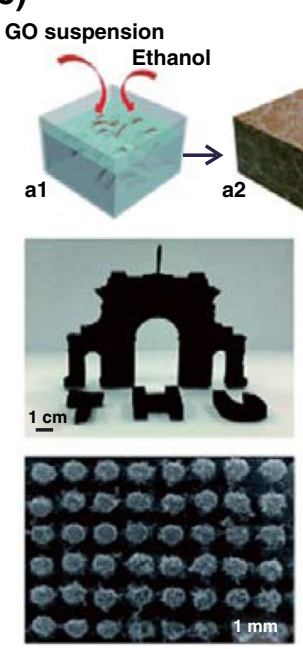

High precision laser
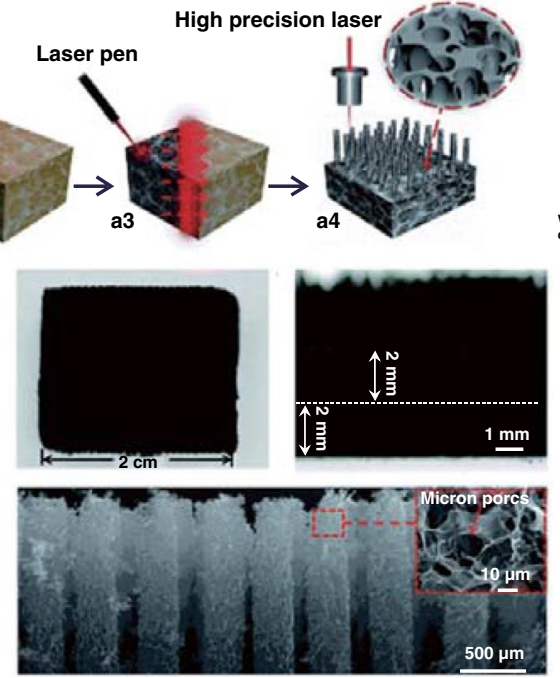

(d)

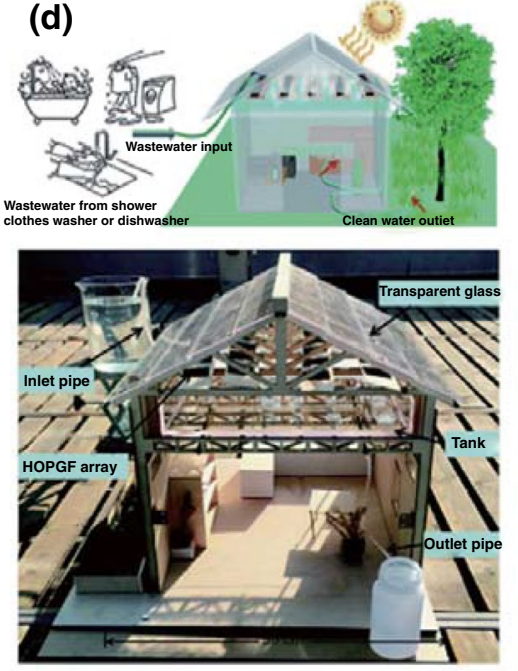

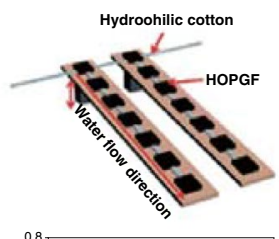
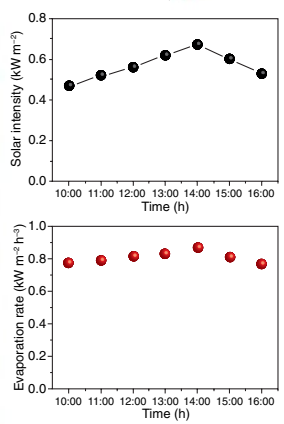

Fig. 10 a Schematic illustrations of the pulse injection controlled ultrafast laser direct-writing strategy. b Hemispherical reflectance of different structures in the UV-Vis-NIR region [156]. c Schematic illustration of the preparation of highly vertically ordered pillar array of graphene framework (HOPGF) and the cross-sectional scanning electron microscopy (SEM) images of HOPGF. d Schematic illustration of a house supplying clean water based on SSG and the photograph of a laboratory-made house model under the sunlight at Beijing [157] 
highly vertically ordered pillar array enlarged both the available evaporation area and free space within the graphene framework (Fig. 10c), which resulted in an extremely high evaporation rate of $2.10 \mathrm{~kg} \mathrm{~m}^{-2} \mathrm{~h}^{-1}$ under 1 sun irradiation (Fig. 10d) [157].

By utilizing the photothermal effects, Zheng et al. [158] proposed an optothermally gated photon nudging (OPN) technique under laser processing. By virtue of an optothermal surfactant thin layer to regulate the interaction between particles and the substrate, the manipulation of colloidal particles into any desired pattern positions with optical scattering force was achieved. However, the orientational control of anisotropic nanoparticles and sub-20 nm position accuracy remained challenging due to the optical diffraction limit.

\subsection{Battery and Supercapacitors Fabricated by Laser Technology}

Two kinds of typical electrochemical energy storage (EES) device, including batteries and supercapacitors, have been increasingly developed by researchers. However, the application of EES devices has often been limited by poor mechanical performance, low power density, high cost, and short cycle life of devices [159]. The laser microfabrication technologies provide efficient direct-writing processed and novel, low-cost, reliable, environment-friendly and templatefree patterning methods to design and fabricate high-performance electrodes for high-quality energy storage devices.

\subsubsection{Supercapacitors}

Supercapacitors (SCs), also known as electrochemical capacitors, were considered as one of the most promising EES systems due to their fast charge-discharge capacity, long cycle life, high power density and safety [160-162]. In recent years, laser-based technologies have been used for $\mathrm{SCs}$ in laser-derived graphene microfabrication and preparation from graphene oxides [163, 164] or polymers [32, 165 , 166]. In 2012, using LightScribe DVD burner, Kaner et al. [25] directly laser-reduced the GO to laser-scribed graphene (LSG) in one step for scalable fabrication of SCs, which led to the microfabrication of many LSG electrodes and flexible SCs. For example, they also used a LightScribe DVD burner to interdigitate graphene electrodes on the disc, and more than 100 micro-supercapacitors can be produced on a single disc in $30 \mathrm{~min}$ or less [26]. Noteworthily, the produced devices are extremely thin and are completely flexible. Lamberti et al. [167] reported a type of porous laser-induced graphene with a large surface area and good electrical conductivity, which was fabricated by a $\mathrm{CO}_{2}$ laser direct-writing PI sheet. As illustrated in Fig. 11a, after transferring the obtained LIG onto PDMS as the stretchable and flexible electrodes to fabricate LIG/PDMS supercapacitors, stable mechanical and electrochemical properties under highly stretching conditions were achieved. Moreover, laser microfabrication technologies also have been utilized to fabricate micro-supercapacitors (MSCs) with outstanding capacitive performance, which allowed massive construction of microelectrode patterns on a flexible substrate [168, 169]. With this technique, the five parallel rows of six series-connected MSCs was simultaneously fabricated and displayed the high voltage output of $9.6 \mathrm{~V}$, successfully powering the electronic pen container with music alarm [169] (Fig. 11b, c). It also demonstrated that the compact hybrid 3D MSCs array integrated with solar cells contributed to efficient solar energy harvesting and storage. Besides, carbon-metal oxide nanocomposites, such as $\mathrm{MnO}_{2}$ /graphene [170], graphene/ $\mathrm{RuO}_{2}$ [171], $\mathrm{TiO}_{2} /$ graphene [172], LIG/NiO/Co $\mathrm{O}_{4}$ [173], and metal/oxide [170], have been prepared via laser or laser combining with other fabrication processes, which can efficiently improve power density and energy density of SCs. Li et al. [174] demonstrated that the laser microfabrication technique was also widely applied in pseudocapacitive materials. As shown in Fig. 11d, hybrid composites of pseudocapacitive materials, such as $\mathrm{MnO}_{2}, \mathrm{FeOOH}$ and polyaniline (PANI) integrated with LIG, were achieved by combining the laser microfabrication for patterns with the subsequent electrodeposition process. At the fixed current density of $0.25 \mathrm{~mA} \mathrm{~cm}^{-2}$, the volumetric and areal specific capacitance of the LIG-FeOOH//LIG- $\mathrm{MnO}_{2}$ asymmetric device was calculated to be $5.4 \mathrm{~F} \mathrm{~cm}^{-3}$ and $21.9 \mathrm{~m} \mathrm{~F} \mathrm{~cm}^{-2}$, respectively (Fig. 11e). Through comparison, the presence of pseudocapacitive materials in MSCs benefits for a greater electrochemical performance than some commercial SCs, and even comparable to Li thin-film batteries (Fig. 11f), which was ascribed to the high capacitance of metal oxides and the electrical conductivity of LIG. In resent report, Wu et al. firstly developed conductive MOF [175] grown on LSG selectively as electrodes for electrochemical micro-supercapacitors with greatly enhanced performance. Teng et al. [176] combined electrophoresis deposition with laser microfabrication to 
(a)

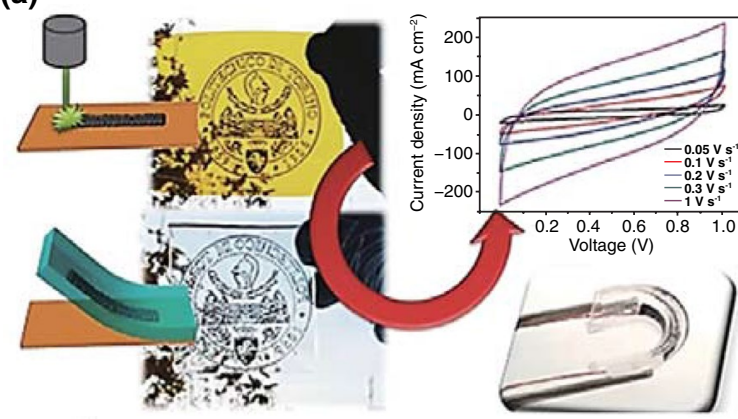

(d)
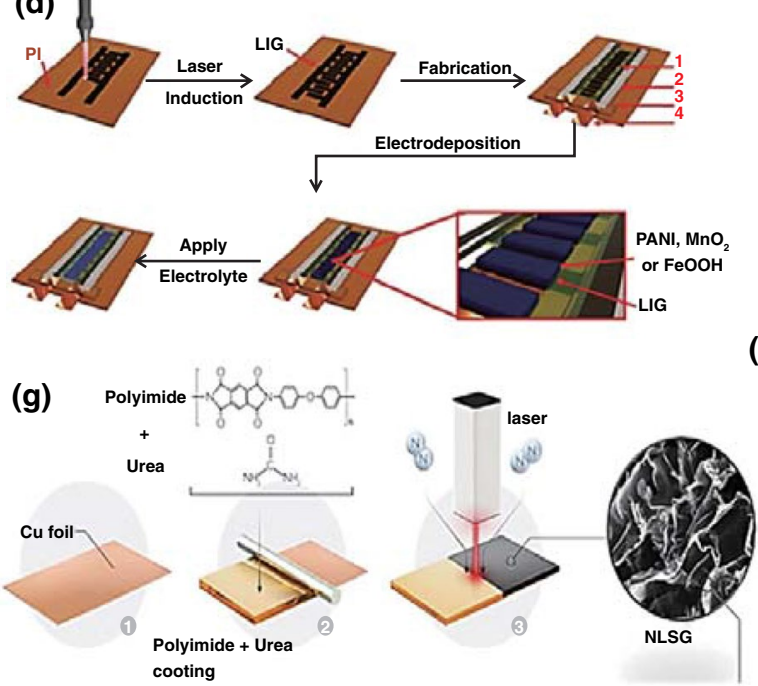

(b)

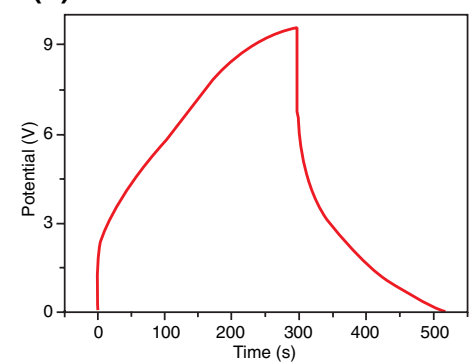

(e)

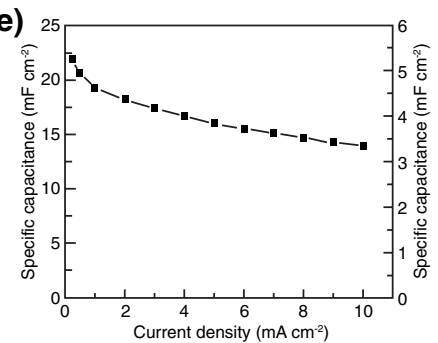

(h)

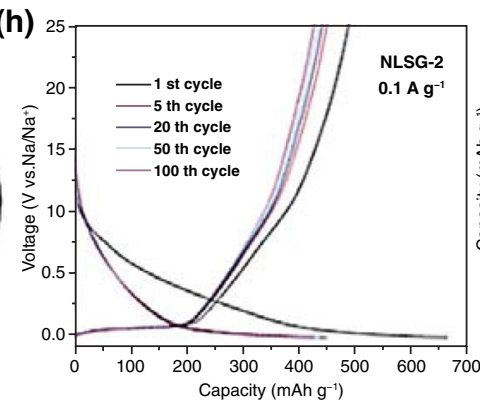

(c)
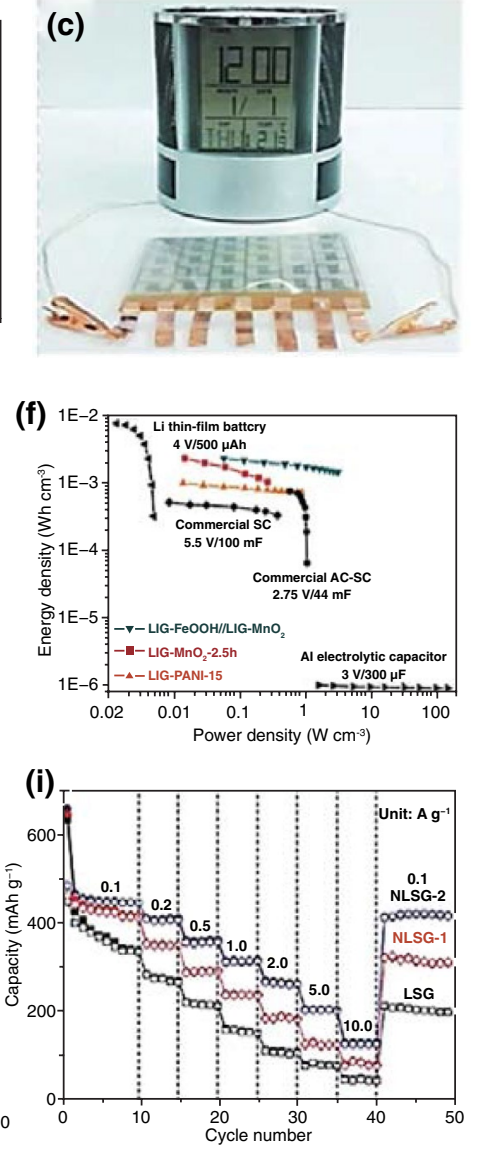

Fig. 11 a Manufacturing and processing of laser-induced graphene electrodes for highly stretchable supercapacitors [167]. b Galvanostatic charge/discharge curves of the MSC array at the current density of $0.5 \mathrm{~mA} \mathrm{~cm}{ }^{-2}$. $\mathbf{c}$ Electronic pen container with music alarm was powered by the $6 \mathrm{~S} \times 5 \mathrm{P}$ AMSC array [169]. d Scheme of the fabrication of MSCs with LIG-MnO 2 , LIG-FeOOH, or LIG-PANI. e Areal and volumetric specific capacitance of LIG-FeOOH//LIG- $\mathrm{MnO}_{2}$ over a current density range of $0.25-10 \mathrm{~m} \mathrm{~cm}^{-2}$. f Ragone plots of LIG-MnO ${ }_{2}^{-2.5} \mathrm{~h}, \mathrm{LIG}-$ PANI-15, and LIG-FeOOH//LIG- $\mathrm{MnO}_{2}$, compared with commercially available energy storage devices [174]. g Schematic to illustrate the process flow used to fabricate the nitrogen-doped 3D graphene directly onto $\mathrm{Cu}$ foil through laser scribing. $\mathbf{h}$ Galvanostatic charge/discharge profiles of NLSG-2 electrode at $0.1 \mathrm{~A} \mathrm{~g}^{-1}$. i Rate performance of LSG, NLSG-1, and NLSG-2 electrodes at different current densities [54]

pattern the activated mesophase pitch carbon integrated with a gel electrolyte on the substrate, which was utilized for the on-chip assembly of micro-supercapacitors. In addition, Wang and Fang et al. [177] fabricated a femtosecond laser-etched MXene MSCs with double-side configuration via arbitrary on- and through-substrate connections of MXene MSC units. The MXene double-side MSC fabricated by the series connection of 12 spiral pattern MXene MSC units with interdigital electrodes of $10 \mu \mathrm{m}$ width interspace can output a large working voltage of $7.2 \mathrm{~V}$. In contrast to the complexities of necessitating masks and the wet-etching process for photolithography, laser microfabrication process is low-cost, quick, and readily scalable.

\subsubsection{Battery}

As well known, batteries with fast surface redox reaction always have high energy density but low power density and poor cycling performance. Such limitations restrict their applications as independent energy storage devices. Recently, the laser microfabrication technology, which attracted special attention, has been deemed promising to minimize the fabrication costs, increase the operational lifetime and enhance the power density performance of batteries [178]. Laser-assisted chemical vapor pyrolysis (LaCVP) [179] was used to synthesize the active materials in batteries. For instance, Muna et al. [180] reported preparation of 
the Si-based nanostructured electrodes using LaCVP as an anode material in advanced lithium-ion batteries for potential practical usages, which achieved high performance, dramatic cyclability and fast scalable production in high purity. Zhang et al. [181] used the laser-induced $\mathrm{MnO} / \mathrm{Mn}_{3} \mathrm{O}_{4} / \mathrm{N}$ doped-graphene hybrid as binder-free anodes for lithiumion batteries, which performed a high reversible capacity of $992 \mathrm{mAh} \mathrm{g}^{-1}$ at $0.2 \mathrm{~A} \mathrm{~g}^{-1}$ and excellent rate capacity of $365 \mathrm{mAh} \mathrm{g}^{-1}$ at $2.0 \mathrm{~A} \mathrm{~g}^{-1}$, as well as a high cycling stability. Laser fabrication technologies have also been used for electrochemical storage of Na-ions batteries. Zhang et al. [182] demonstrated that $\mathrm{CO}_{2}$ laser irradiation was a fast and effective way to fabricate hard carbons for application in Na-ion batteries, where the structural organization degree was increased by laser microfabrication through producing locally ordered turbostratic carbon. Furthermore, Zhang et al. [54] fabricated N-doped 3D graphene directly bonded to the current collectors as anode for sodium-ion batteries, which was manufactured through a direct laser-scribing process under nitrogen gas atmosphere (Fig. 11g). Because of the high concentration of nitrogen doping and high electrochemical surface area of LSG, the laser-fabricated electrode exhibited excellent electrochemical performance with an initial discharge capacity of $659 \mathrm{mAh} \mathrm{g}^{-1}$ and a recovered charge capacity of $485 \mathrm{mAh} \mathrm{g}^{-1}$ (Fig. 11h). In addition, Na-ion capacities up to $425 \mathrm{mAh} \mathrm{g}^{-1}$ at $0.1 \mathrm{~A} \mathrm{~g}^{-1}$ and $148 \mathrm{mAh} \mathrm{g}^{-1}$ at $10 \mathrm{~A} \mathrm{~g}^{-1}$ were achieved with excellent rate capabilities and cycling durability (Fig. 11i). This work points out a promising route for fabrication of metal-ion capacitors directly on current collectors via optimized laser conditions. It was noteworthy that, only a few works on the application of laser processing in batteries were reported. Hence, laser processing in batteries, especially for the fabrication of active materials directly on current collectors via the optimized laser microfabrication technique should be extensively explored for electrochemical storage of different metal cations in the future.

\subsection{Sensor Devices Fabricated by Laser Technology}

Because of the instantaneous local high temperature and pressure environment occurred on the surface of materials when irradiation by laser technology, the surface structures of laser-treated materials are porous and fluffy, which have some unique advantage to be the sensitive layer of pressure or gas sensor. Furthermore, the pattern array device is easy to be obtained by laser microfabrication method. Therefore, most devices fabricated by laser technology are suitable to be used as sensor devices [183]. In this section, different sensor devices fabricated by laser technology were reviewed.

\subsubsection{Force Sensor}

Force sensors are widely used in various fields, such as smart textiles, wearable electronics, artificial intelligence robots and structural health monitoring [184]. As mentioned in Sect. 2.1, carbon materials were commonly fabricated by laser ablation. Generally, they were also nanomaterials for application in force sensors. Rahimi et al. reported a unidirectional strain sensor based on transfer and embedment of carbonized patterns fabricated by laser microfabrication of thermoset polymers (Fig. 12a), which obtained the stretchability of up to $100 \%$, and sensitivity of up to 20,000 . They used this technique for realizing measurement of finger motion in real time (Fig. 12b, c) [185]. Tao et al. fabricated an intelligent artificial throat using a similar method. The graphene foam fabricated through laser pyrolysis was the sensitive layer for AI throat, which could not only generate sound by thermal acoustic but also detect sound by piezoresistive effect (Fig. 12d, e) [186]. Laser-induced carbon materials with $3 \mathrm{D}$ pattern structures by two-step fabrication extended their applications in force sensors [187]. For example, Tour et al. utilized the 3D patterned graphene foams by laser laminated object manufacturing in strain sensors to monitor the pulse fluctuation frequency [37]. Araromi et al. patterned PDMS-carbon composite layers by laser ablation, the high-resolution and mechanically robust electrode was achieved for stretchable silicone elastomer actuators and sensors. They validated that the devices fabricated by laser microfabrication can realize the large area of up to A4-size and high sensitivity (Fig. 12f) [188]. Luo et al. [27] used the scribing process for the reduction and patterning of graphene oxide film to realize LSG sensor fabrication. The versatility of LSG sensors provided a promising strategy for monitoring and mapping large-scale deformation and strain distribution of polymeric composites. Nag et al. used the laser-patterned composite of multi-walled carbon nanotube (MWCNT) as conductive film and PDMS as substrate for the flexible and wearable sensor application, which realized monitoring of respiration and limb movements [189]. Besides of 
(a)
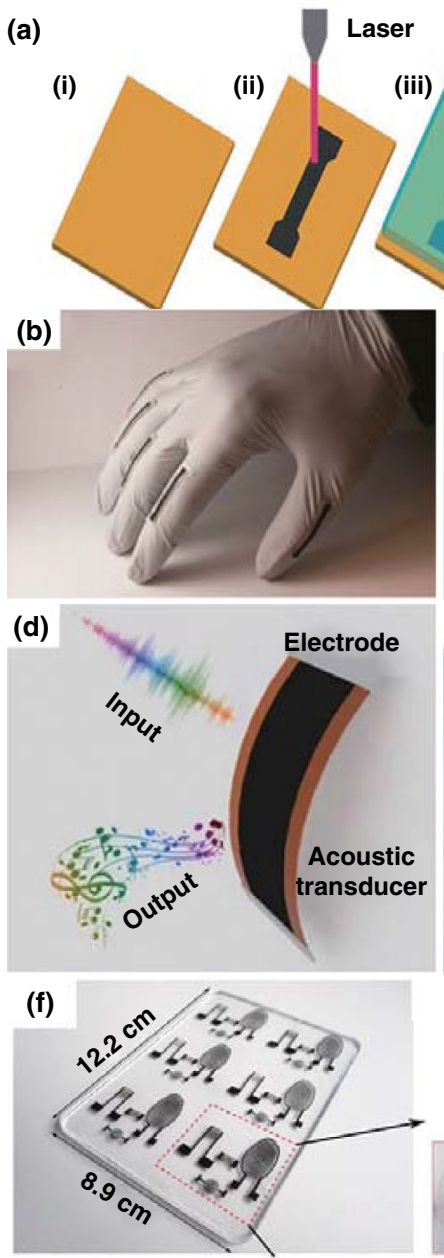

(iii) (iv)

(iv)

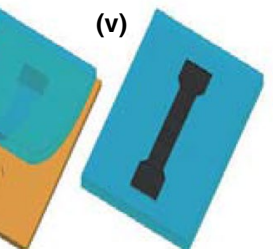

(c)
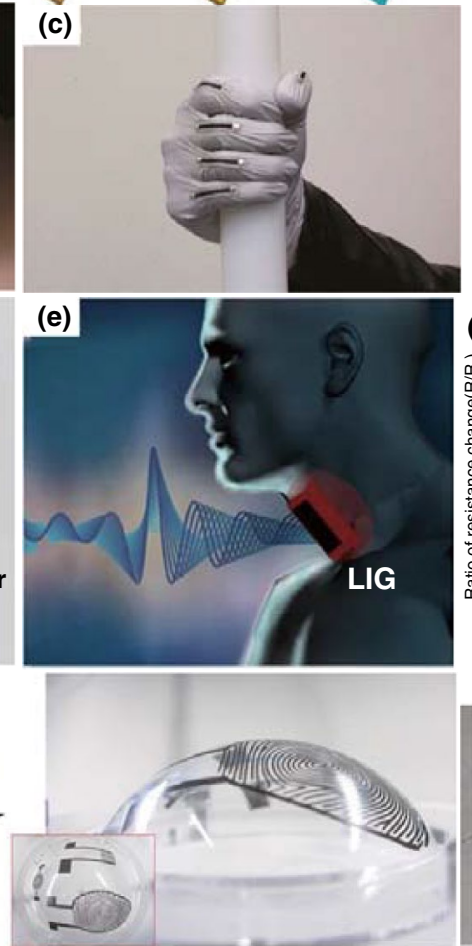

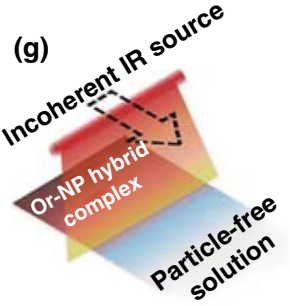

(i)

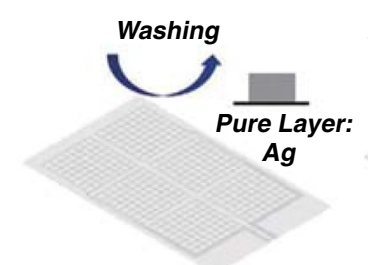

(iii)

(h)

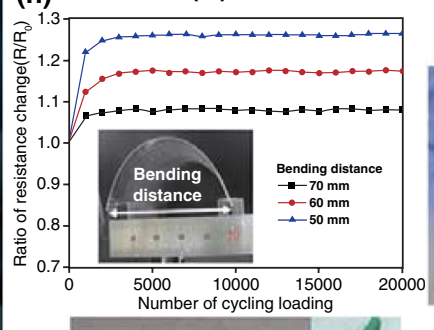

(j)

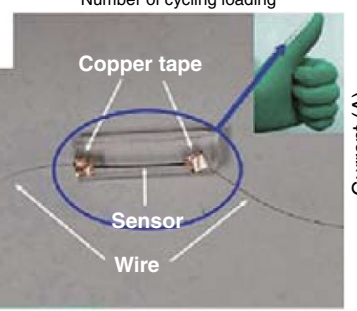

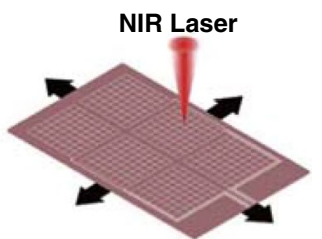

(ii)

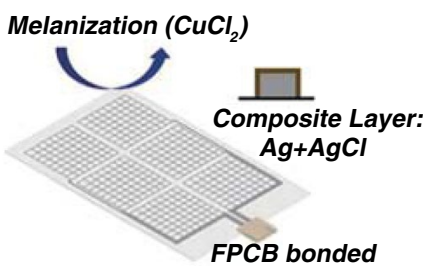

(iv)
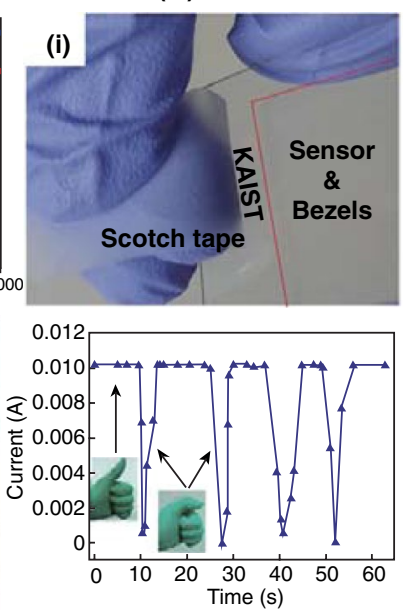

Fig. 12 a Schematic of the fabrication process for stretchable carbon nanocomposite using laser pyrolization of polyimide; b, c Human finger motion detection with stretchable carbon traces [185]. d LIG has the ability of emitting and detecting sound in one device; e Artificial throat can detect the movement of throat and generate controllable sound, respectively [186]. f Interdigitated transducer geometries produced by laser ablation of cast carbon-silicone bonded to an elastomer [188]. $\mathbf{g}$ Overall fabrication steps of the touch device using the laser process. $\mathbf{h}$ Cycling bending test for the laser-processed touch sensor, as a function of bending distance. The bending rate was $500 \mathrm{~mm}^{\mathrm{min}}{ }^{-1}$. The inset is a photograph of bending test setup. i Peeling test using a conventional scotch tape after 100 times [191]. j Photograph and human motion detection of finger with flexible sensor based on copper electrode [192]

the composite of MWCNT and PDMS, Nag et al. also tried to use Al film as the conductive layer on PI substrate. The laser microfabrication-induced aluminum interdigitated electrodes for tactile sensors were sensitive to finger pressure [190].

Except for the carbon materials, the patterned non-carbon electrodes by laser microfabrication also have excellent sensitivity for sensors. Son et al. performed organometallic metallization using laser thermochemical treatment (Fig. 12g). Attributed to the advantage of device patterning by laser, a high pressure resolution can be obtained by sensor arrays (Fig. 12h, i) and this laser patterning method was crucial for high-yield industrial production [191]. Bai et al. prepared the patterned devices based on copper electrode by laser microfabrication, high sensitivity and mechanical robustness were realized when it was applied as a touch switch (Fig. 12j) [192]. Arnaud Spangenberg et al. [193] used the near-infrared fs laser irradiation to prepare crystallized $\mathrm{TiO}_{2}$ and $\mathrm{TiO}_{2} / \mathrm{C}$ nanocomposite microstructures as microsized pressure sensors. When using the AFM tip to gradually approach the sensor, the pressure sensing exhibited the sensitivity at the microscale from a single line and a repeatable response. 


\subsubsection{Gas Sensor}

Gas sensors, such as CO detectors, humidity sensors or other harmful gas sensors, play an important role in health monitoring. Therefore, gas sensors are significant for our daily lives. Laser microfabrication technology also derived many excellent researches in this field [194].

As mentioned above, the laser-induced structure of carbon nanomaterials is porous and floppy, which means that the devices based on laser-induced carbon structure are also suitable for gas sensors [34]. For instance, Wu et al. fabricated a graphene-based $\mathrm{NH}_{3}$ sensor by one-step laser treatment of PI. The response/recovery time of this $\mathrm{NH}_{3}$ sensor were 214 and $222 \mathrm{~s}$ for detection of $75 \mathrm{ppm} \mathrm{NH}_{3}$, respectively. In addition, the sensitivity and cyclic stability were greatly improved under the heating temperature of $70{ }^{\circ} \mathrm{C}$ (Fig. 13a, b) [195]. The laser-fabricated molybdenum carbide/graphene composites mentioned above can not only apply for paper-based supercapacitors, but also for the gas sensors and electrochemical ion detectors applications [81].
Park et al. used the interdigitated rGO obtained by one-step laser treatment as a humidity sensor pasted on fingernail (Fig. 13c-f), where wearable monitoring was realized [196]. Drmosha et al. reported a Pt-loaded $\mathrm{rGO} / \mathrm{ZnO}$ gas sensor fabricated by laser, the significant selectivity and response of about $99 \%$ toward hydrogen with a low concentration of $400 \mathrm{ppm}$ was achieved, which was 5 and 10 times higher than those of the $\mathrm{rGO} / \mathrm{ZnO}$ composite and pure $\mathrm{ZnO}$, respectively [197]. In addition, Chang et al. precisely fabricated the spiral graphene pattern electrodes as the sensing test region by double scanning of the picosecond laser. The obtained gas sensor had high detection sensitivity to the $\mathrm{CO}, \mathrm{H}_{2} \mathrm{O}$, and air (Fig. 13g) [198].

\subsubsection{Other Devices Fabricated by Laser Technology}

One-step laser carbonization provided more possibilities for other flexible devices. For example, Yan et al. reported a kind of electrophysiological sensor composed of

(c)
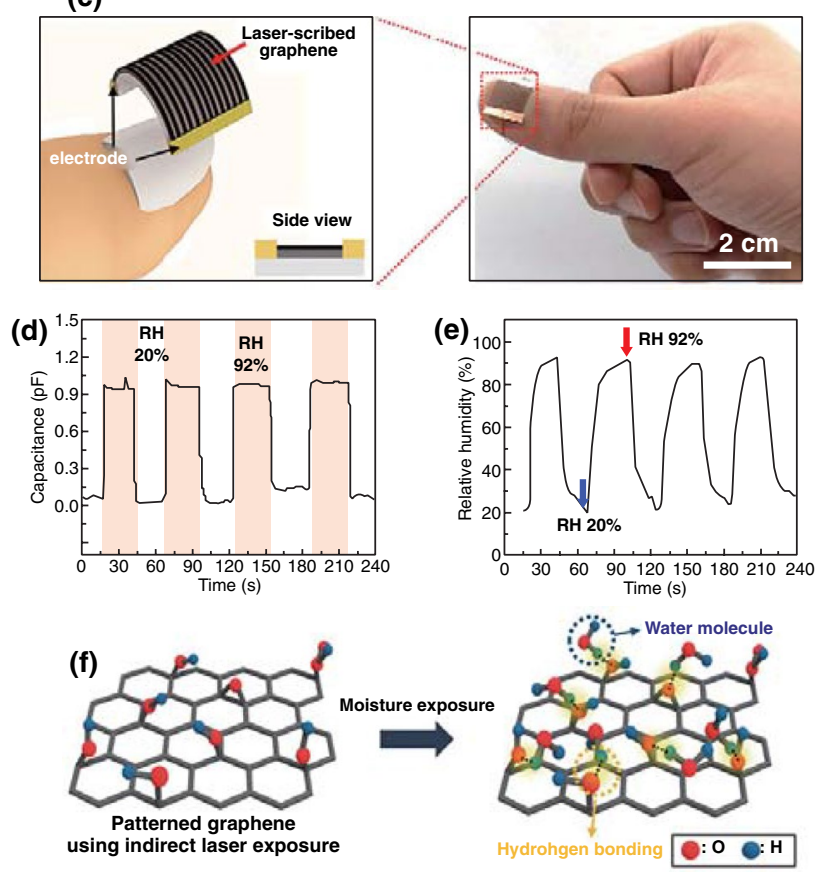

Fig. 13 a Normalized real-time resistance response/recovery behavior of the sensor to $235 \mathrm{ppm} \mathrm{NH}_{3}$ at various desorption temperature from 50 to $90{ }^{\circ} \mathrm{C}$. b Real-time cycling response of the sensor to $235 \mathrm{ppm} \mathrm{NH}_{3}$ gas at $70{ }^{\circ} \mathrm{C}$ [195]. $\mathbf{c}$ Schematic view and digital image of the laser-scribed rGO-based flexible humidity sensor attached on a nail. d Real-time signal responses as measured cyclic capacitance changes from the laser direct-writing (LDW) GO-based humidity sensor, exposed to RH in the range of 20-92\% at 30 s intervals. e Monitored relative humidity (RH) changes collected from the real-time data logger correspond to the graph in $\mathbf{d}$. f Schematic drawing of absorption process of water molecules by hydrogen bonding on the partially reduced GO surface after moisture exposure [196]. g Schematic of the gas detection setup [198] 
laser-patterned porous graphene as the sensing components and sugar-templated silicone elastomer sponges as the substrates (Fig. 14a). The sensors exhibited much higher water vapor permeability $\left(18 \mathrm{mg} \mathrm{cm}^{-2} \mathrm{~h}^{-1}\right)$ than those without pores, which solved the problem of limited gas permeability. More importantly, this strategy used simple and effective laser processing instead of thin-film deposition, photolithography, or other complex procedures [199]. Stanford et al. fabricated a high output power triboelectric nanogenerator (TENG) by $\mathrm{CO}_{2}$ laser treated polymers (Fig. 14b) [200]. High output power TENG through laser-treated surface of friction materials was also fabricated by Huang [201].

Most of the sensor devices transformed the strain/pressure or chemical energy to the electric energy [202]. However, the stretchable organic light-emitting device (OLED) was another sensor device that was mechanically insensitive to fatigue strain. OLED has become a promising alternative in electronic skin and deformable displays. Sun et al. developed a stretchable OLED with an ordered drape pattern through laser-programmable microfabrication, the stretch-release circulation can be controlled and the maximum efficiency of $72.5,68.5$, and $70 \mathrm{~cd} \mathrm{~A}^{-1}$ at mechanical strain of $0 \%, 40 \%$, and $70 \%$, respectively, was achieved [203].

Besides the applications of energy storage and sensors, nanostructures patterned by laser microfabrication technology for biological applications are receiving increasing attention, especially for the study of adhesive interactions between cells and nanostructured interfaces. Healy et al. fabricated nanocraters in quartz through the pulsed femtosecond laser; then, they studied the effect of spatial distribution and features of the nanocraters on cell migration, morphology, and spatial organization. It demonstrated that this laser surface-patterning approach provided a simple proposal for controlling cell behavior [204].

In addition, Jo et al. reported the writing of integrated circuits on a $2 \mathrm{D}$ semiconductor using a visible laser. In particular, by scanning the laser over metal patterns deposited on $2 \mathrm{H}-\mathrm{MoTe}_{2}$ semiconductor layers, the spatially resolved doping with controlled dopant profiles and concentrations was achieved. This allowed us to directly write various circuitry in designed patterns, including arrays of $n-p-n$ $(\mathrm{p}-\mathrm{n}-\mathrm{p})$ bipolar junction transistors (BJTs) and $\mathrm{p}-\mathrm{n}$ diode discs [205]. Zheng et al. [206] developed a new optothermoplasmonic nanolithography (OTNL) technique. By virtue of the plasmon-enhanced light absorption and localized photothermal effect in deposited Au nanoparticles, the ondemand, low-power and desired patterning of 2D materials (graphene and $\mathrm{MoS}_{2}$ monolayers) was achieved through a continuous-wave laser irradiation (Fig. 14c). It demonstrated that thermal oxidation for graphene patterns and sublimation for $\mathrm{MoS}_{2}$ patterns under the laser-induced temperature field can lead to direct etching of the corresponding atomic layers.

\subsection{Electrocatalytic Materials and Electrodes Fabricated by Laser Technology}

High efficiency of the electrolyzer system is dependent on the electrocatalytic materials with high activity. It is noted that the surface structure and the surface area play an important role in improving the activity of electrocatalytic electrode materials for hydrogen evolution reaction (HER), oxygen evolution reaction (OER) or oxygen reduction reaction (a)

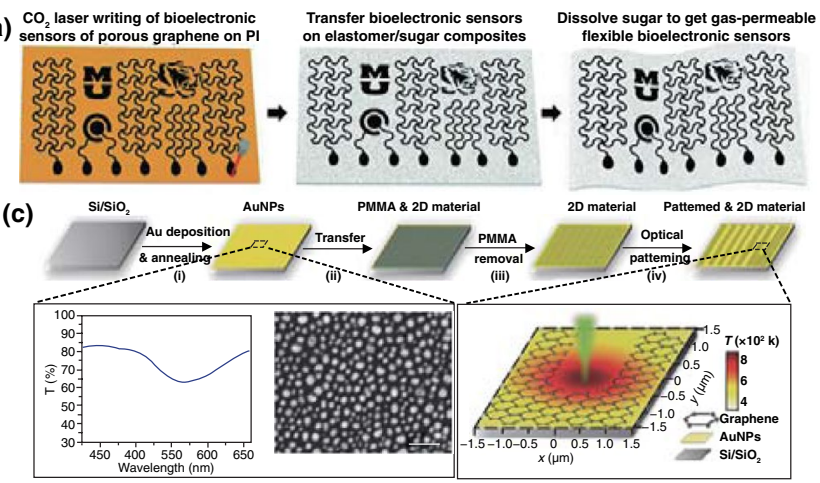

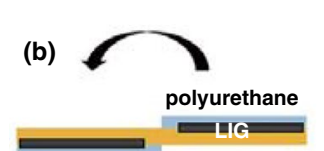

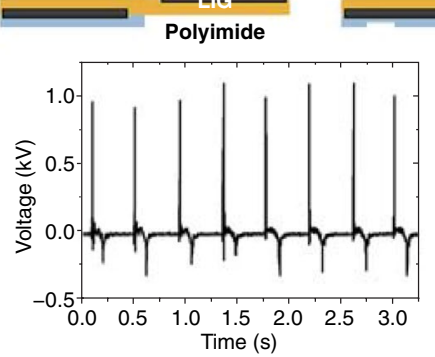

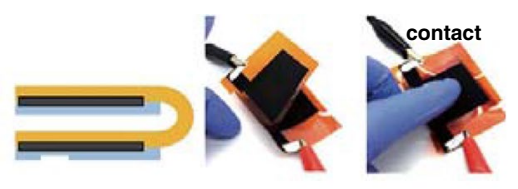

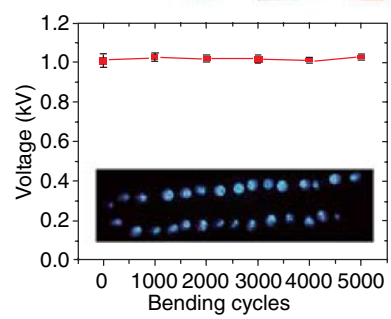

Fig. 14 a Schematic illustration of the fabrication process for bioelectronic sensing systems [199]. b Performance of a flexible metal-free TENG [200]. c Schematic flowchart of OTNL process for 2D materials patterning [206] 
(ORR). Various techniques have been used to construct the surface structure of electrocatalytic electrodes [207-209], especially by using the template synthesis [209]. However, the removal of the template was tedious, and the laser microfabrication technique provided an alternative method to construct different surface microstructures of electrocatalysts. With regards to the relationship between the high HER performance and laser microfabrication technology, it can be attributed to two factors. On the one hand, powder-like electrocatalysts prepared by laser ablation in liquid usually possess the high electrocatalytic activity due to the laserinduced defects and the large specific surface area for exposing more active sites on the electrocatalysts. On the other hand, for the 3D electrocatalytic electrodes fabricated by the laser microfabrication technique, the high performance can be attributed to the different surface microstructures constructed by laser. During the laser microfabrication process, the hydrophilic surface, the large specific surface area for exposing more active sites and even the formation of a more active nanomaterials can be achieved, which are all preferable to the improvement of the electrocatalytic performance.

\subsubsection{Electrocatalytic Hydrogen Evolution Reaction (HER)}

Electrocatalysts with high activity and durability for HER are crucial for the practical demands of electrochemical water splitting. The laser synthesis and microfabrication techniques provide a new avenue toward fabricating nanostructures with novel properties due to the strong quenching effect [210]. As mentioned in Sect. 2.2.2, Du et al. reported a novel active Ag electrocatalyst [145] and RuAu singleatom alloy electrocatalyst [111], which was fabricated by laser ablation in liquid. The HER electrocatalytic activities outperformed $\mathrm{Pt} / \mathrm{C}$. As reported, the Ag nanoparticle electrocatalyst exhibited an extremely high activity for HER (a low overpotential of $32 \mathrm{mV}$ at $10 \mathrm{~mA} \mathrm{~cm}^{-2}$ and Tafel slope value of $31 \mathrm{mV} \mathrm{dec}^{-1}$ ) in acidic electrolyte, and the transformation from inactive to highly active Ag electrocatalysts was attributed to the improved $\mathrm{H}$ absorption energy regulated by laserinduced stacking faults. The prepared RuAu single-atom alloys also exhibited high stability and low overpotential of $24 \mathrm{mV}$ at the current density of $10 \mathrm{~mA} \mathrm{~cm}^{-2}$ in alkaline media (Fig. 15a-d). The high HER performance was attributed to the following factors: Firstly, the strong hydrogen atoms adsorption by $\mathrm{Ru}$ matrix can be counteracted by $\mathrm{Au}$ with weak hydrogen adsorption. Secondly, the electronic structure of RuAu single-atom alloys can be regulated by the immiscibility between Ru and Au. Lastly, chemically inert $\mathrm{Au}$ favors long-term stability during the reaction.

Non-noble metal electrodes with nanostructures microfabricated by laser were also the candidates for effective electrocatalytic electrodes. Röntzsch et al. reported the surface construction of Ni electrodes through the fs pulse laser for highly active hydrogen evolution, which was realized by enlarging the surface area of Ni [211, 212]. An enhancement of HER activity was achieved and the author confirmed that contributions of the microstructure of the redeposited ablation products and the chemical composition could be neglected for the HER activity, only the morphological surface changes with enlarged surface areas contributed to the HER activity. Also utilizing the ultrashort-pulse laser, the same group reported the laser process-induced micro- and nanostructured Ti surfaces loading Pt by sputter deposition as HER electrode for alkaline water electrolysis [213]. It was demonstrated that the dramatically improved HER performance was ascribed to the significant increase in specific surface area as well as the rapid gas bubble detachment resulted from superhydrophilic and superwetting properties. In addition, Zheng et al. [214] reported a nickel sulfide nanostructures prepared by nanosecond pulsed laser ablation of an aqueous precursor solution under ambient condition. The superb electrochemical performances for electrocatalytic HER and supercapacitors were achieved (Fig. 15e), which exhibited a low overpotential ( $-159 \mathrm{mV}$ vs. RHE at $\left.10 \mathrm{~A} \mathrm{~g}^{-1}\right)$, lower Tafel slope $\left(218 \mathrm{mV} \mathrm{dec}^{-1}\right)$ and longterm durability. Another transition metal sulfide, $\mathrm{MoS}_{2}$ was regarded as one of the most effective substitutes to the noble metal Pt for HER. Thus, the regulation of $\mathrm{MoS}_{2}$ with amorphous or crystalline structures and hybrid structures by laser attracted much attention. Tran et al. [215] investigated the crystallization (c- $\mathrm{MoS}_{2}$ ) of amorphous molybdenum sulfide $\left(\mathrm{a}-\mathrm{MoS}_{x}\right.$ ) induced by laser, which confirmed that a-MoS $x$ had a higher catalytic performance for $\mathrm{H}_{2}$ evolution. This result displayed that defect-rich active sites were beneficial to high activity of the HER catalytic performance. The nanosized amorphous molybdenum sulfide $\left(\mathrm{a}-\mathrm{MoS}_{x}\right)$ with numerous defects and disordered structures by femtosecond laser ablation of ammonium tetrathiomolybdate aqueous solution has been mentioned in Sect. 2.2.2 [132]. It was noteworthy that, large current density of $516 \mathrm{~mA} \mathrm{~cm}^{-2}$ at an overpotential of 

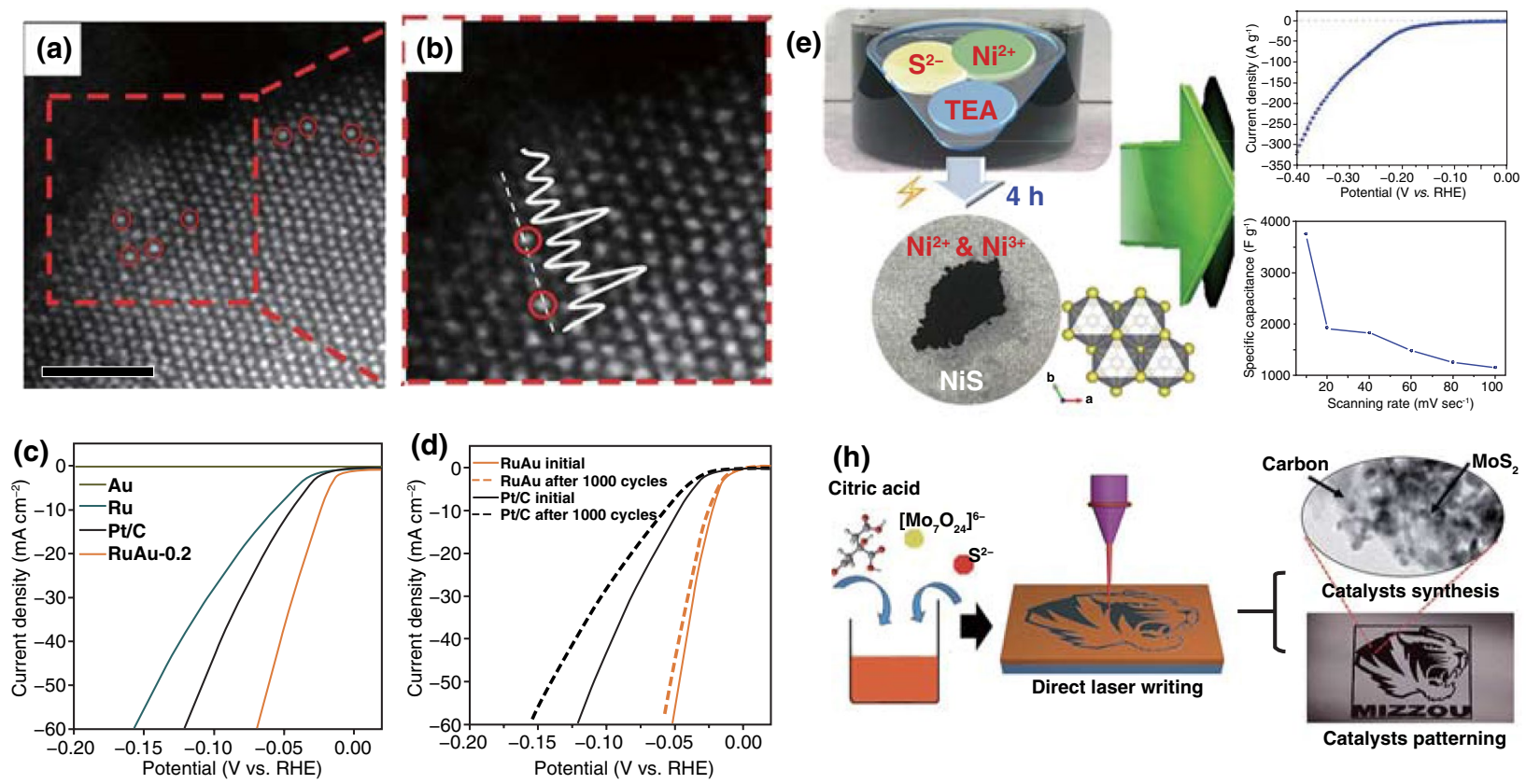

(f)
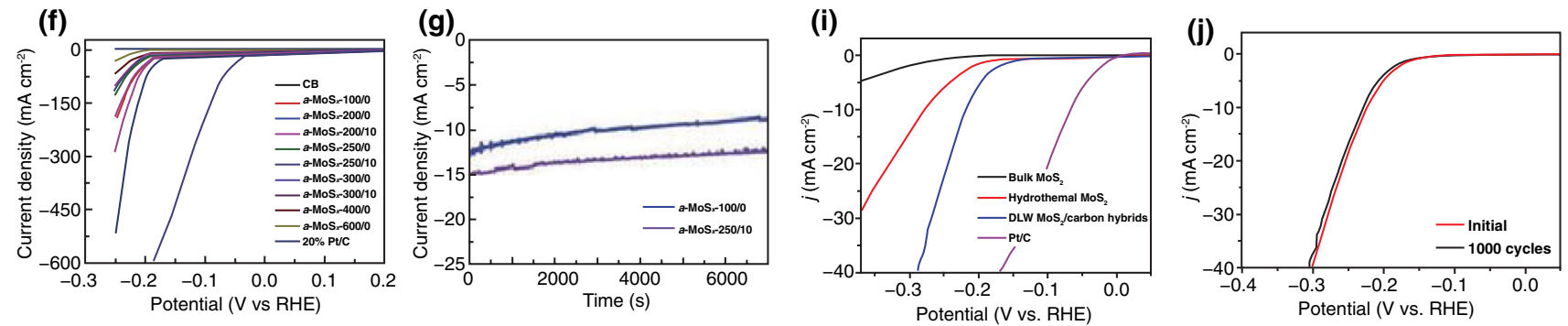

Fig. 15 a Atomic-resolution HAADF-STEM image, Au atoms (marked by red circles) are uniformly distributed throughout the particle. Scale bar: $1 \mathrm{~nm}$. b Magnified image in red dotted rectangle of $\mathbf{a}$, Au atoms were marked with red circles. The white solid curve is the integrated pixel intensity along the white dotted line. HER activity and stability in $1 \mathrm{M} \mathrm{KOH}$ solution. c Linear sweep voltammetry (LSV) polarization curves (iR compensated) at scan rate of $5 \mathrm{mV} \mathrm{s}^{-1} ; \mathbf{d}$ durability test [111]. e Nickel sulfide nanostructures prepared by laser irradiation for efficient electrocatalytic hydrogen evolution reaction and supercapacitors [214]. f Polarization curves of CB, the a-MoS $\mathrm{x}_{\mathrm{x}}$ materials, and 20\% Pt/C catalysts in $0.5 \mathrm{~m} \mathrm{H}_{2} \mathrm{SO}_{4}$. $\mathbf{g}$ Results of the durability tests for the a- $\mathrm{MoS}_{\mathrm{x}}-100 / 0$ and a-MoS $-250 / 10$ materials [132]. $\mathbf{h}$ Scheme of the LDW method in fabricating arbitrary patterns composed of $\mathrm{MoS}_{2} /$ carbon hybrids. i Polarization curves of Pt/C, bulk $\mathrm{MoS}_{2}$, hydrothermal MoS ${ }_{2}$, and laser-induced $\mathrm{MoS}_{2} /$ carbon hybrids. j Durability of laser-induced $\mathrm{MoS}_{2} /$ carbon hybrids [217]

$250 \mathrm{mV}$ could be achieved by using the optimized a-MoS catalysts $(x=2.73)$ (Fig. 15f, g). In addition, Wu et al. [216] also prepared $\mathrm{MoS}_{2}$ quantum dots with defective structure by ultrafast laser ablation. The enhanced HER electrocatalytic performance was achieved on account of the high conductivity, abundant exposed active sites and good hydrophilicity resulted from the laser ablation.

The electrocatalytic performance of $\mathrm{MoS}_{2}$ has also been limited by the poor conductivity. Therefore, the hybrid structure of $\mathrm{MoS}_{2}$ with other conductive materials has been paid attention. Lin et al. [217] presented a laser direct-writing method to synthesize and pattern $\mathrm{MoS}_{2}$ /carbon hybrid materials as HER electrocatalysts under ambient conditions, where small-sized $\mathrm{MoS}_{2}$ NPs anchored on carbon matrix were in situ synthesized and arbitrary patterns of this hybrid structure on substrates could be designed through computercontrolled laser beams. Compared with $\mathrm{MoS}_{2}$ synthesized by conventional hydrothermal method, the laser direct-writing method can not only realize the synthesis of $\mathrm{MoS}_{2}$ in a short period of time, but also perform superior HER activity for laser-induced $\mathrm{MoS}_{2} /$ carbon hybrid materials (Fig. 15h-j). Li et al. [218] prepared Pt-MoS 2 and $\mathrm{Ag}-\mathrm{MoS}_{2}$ composites, which exhibited an enhanced activity for HER. The decorated Pt metal nanoparticles contributed to the high HER activity and was reduced by photogenerated electrons of $\mathrm{MoS}_{2}$ nanosheets induced by the femtosecond laser. 


\subsubsection{Electrocatalytic Oxygen Evolution Reaction (OER)}

The most common OER electrocatalysts are regarded as transition metal oxides and hydroxides. By using laser as the power source under ambient atmosphere, laser ablation synthesis of OER electrocatalysts is facile and feasible. Most of the synthesis methods for these OER electrocatalysts were laser ablation in liquid, as mentioned in Sect. 2.2.2, all of them exhibited excellent OER activity for water oxidation $[219,220]$. For example, $\mathrm{Co}_{3} \mathrm{O}_{4}$ nanoparticles with an overpotential of $314 \mathrm{mV}$ at $0.5 \mathrm{~mA} \mathrm{~cm}^{-2}$ [117], $\mathrm{CoO}-\mathrm{Co}_{2} \mathrm{O}_{3}-\mathrm{Co}(\mathrm{OH})_{2}$ multiphase nanoparticles with an overpotential of $100 \mathrm{mV}$ lower than that of the $\mathrm{CoO}$ submicron precursor particles [221], NiFe layered double hydroxides with a lowest overpotential of $260 \mathrm{mV}$ at $10 \mathrm{~mA} \mathrm{~cm}-2$ [118], CoO nanoclusters/CoFe LDHs hybrid with an overpotential of $254 \mathrm{mV}$ at $10 \mathrm{~mA} \mathrm{~cm}^{-2}$ [222] and oxygen vacancymodified $\mathrm{CoOOH}$ requiring an overpotential of $330 \mathrm{mV}$ to reach $10 \mathrm{~mA} \mathrm{~cm}^{-2}$ [223]. The performance of most of the OER electrocatalysts synthesized by LAL even outperforms $\mathrm{RuO}_{2}$.

Besides the transition metal oxides and hydroxides, Tour et al. [224] used laser microfabrication to prepare oxidized laser-induced graphene (LIG-O) as an efficient metal-free OER electrocatalyst (Fig. 16a). The laser-induced graphene was highly porous to expose more active sites for OER. Furthermore, the oxidation of LIG by $\mathrm{O}_{2}$ plasma to form
LIG-O boosted the activity for OER, exhibiting a low onset potential of $260 \mathrm{mV}$ with a low Tafel slope of $49 \mathrm{mV} \mathrm{dec}^{-1}$ (Fig. 16b, c). The same group also prepared $\mathrm{Co}_{3} \mathrm{O}_{4}$ in graphene [80] and NiFe/LIG catalysts [225] for oxygen electrocatalysis, just by depositing the different metal precursors on a preformed LIG surface followed by laser scribing. On account of the addition of transition metal precursors, the OER activity significantly improved.

\subsubsection{Electrocatalytic Overall Water Splitting}

As depicted above, Tour et al. [226] has made great efforts on oxygen evolution reaction electrocatalysts based on LIG, this group also paid a lot of attention on laser-induced graphene process to fabricate active catalytic electrodes for overall water splitting to generate both $\mathrm{O}_{2}$ and $\mathrm{H}_{2}$. Firstly, they fabricated an overall water splitting device with HER and OER electrocatalytic electrodes on opposing faces of a commercial polyimide (PI) sheet. The HER active species were formed in situ in the LIG forming process by impregnating the PI film in a Pt-ion solution, and the OER active species were formed by subsequent electrodeposition of $\mathrm{CoP} / \mathrm{Co}_{3}\left(\mathrm{PO}_{4}\right)_{2}$ or $\mathrm{Ni}_{x} \mathrm{Fe}_{y}(\mathrm{OH})_{2 x+3 y}$ onto the LIG. As demonstrated, the LIG electrolyzer composed of LIG-Co-P as cathode and LIG-NiFe as anode was employed in $1 \mathrm{M} \mathrm{KOH}$, delivering $1.66 \mathrm{~V}$ at the current density of $10 \mathrm{~mA} \mathrm{~cm}^{-2}$ with
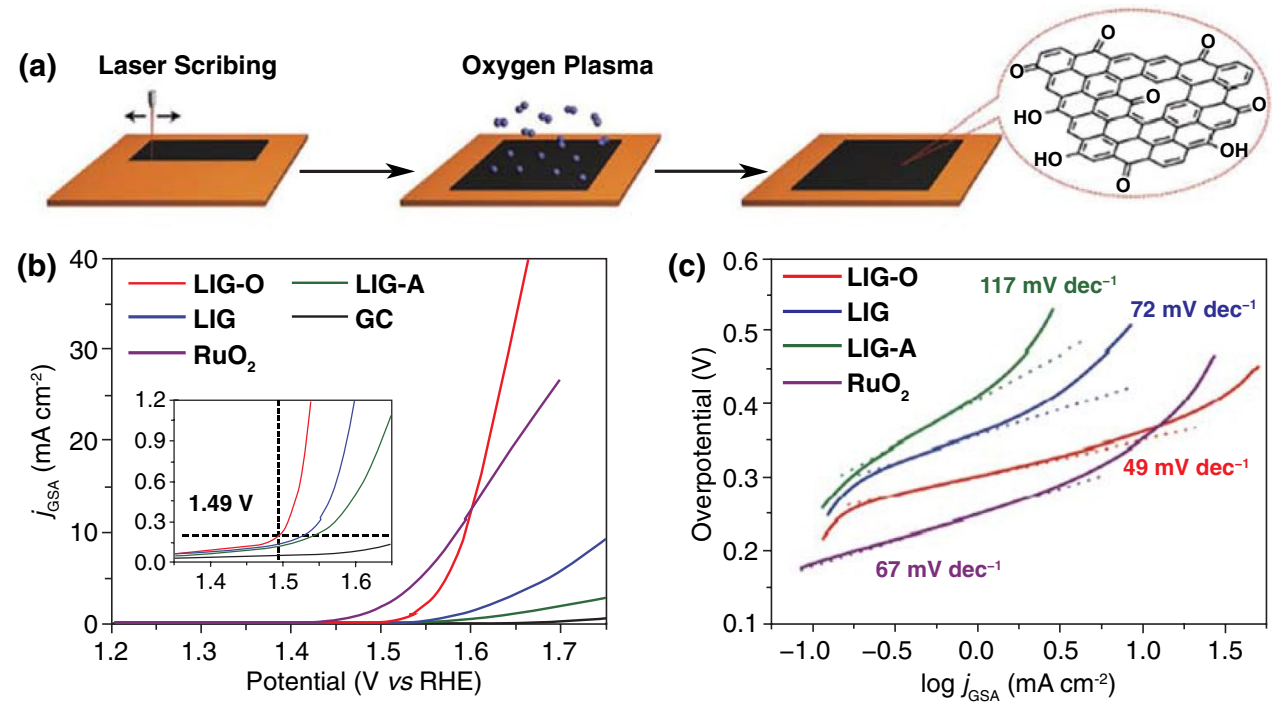

Fig. 16 a Preparation of LIG-O. b LSV curves of LIG-O, LIG, annealed LIG (LIG-A), and a glassy carbon (GC) electrode recorded in $1 \mathrm{~m}$ $\mathrm{KOH}$ at a scan rate of $2 \mathrm{mV} \mathrm{s}^{-1}$. $\mathbf{c}$ Tafel plots calculated from panel $\mathbf{b}$ [224] 
efficient HER and OER activity. In addition, this group used $\mathrm{CO}_{2}$ laser scribing to transform wood into hierarchical porous graphene [227] (Fig. 17a). By varying the electrodeposition materials on the LIG with Co-P or NiFe LDHs, the laser-induced graphene patterned on the wood surfaces could be readily fabricated into HER and OER electrodes for overall water splitting with high reaction activity at low overpotentials (Fig. 17b, c).

Besides the LIG-based electrocatalytic electrode, laserinduced hierarchical oxide nanostructures were also candidates for electrocatalytic overall water splitting. Zhong and $\mathrm{Wu}$ et al. [228] manufactured a series of metal oxides $\left(\mathrm{MO}_{x}, \mathrm{M}=\mathrm{Ti}, \mathrm{Mn}, \mathrm{Fe}, \mathrm{Co}, \mathrm{Ni}, \mathrm{Cu}, \mathrm{Mo}, \mathrm{Ag}, \mathrm{Sn}, \mathrm{W}\right.$, and $\mathrm{NiFe}$ ) with a hierarchical nanostructure on corresponding metal substrates through laser ablation. In particular, the $\mathrm{NiO} / \mathrm{Ni}$ plate electrocatalysts exhibited the HER overpotential of $121 \mathrm{mV}$ at $10 \mathrm{~mA} \mathrm{~cm}^{-2}$, much lower than that of $279 \mathrm{mV}$ for Ni before laser ablation. Meanwhile, a decreased OER overpotential of $294 \mathrm{mV}$ at $10 \mathrm{~mA} \mathrm{~cm}^{-2}$ than $403 \mathrm{mV}$ for Ni suggested the dramatically enhanced OER activity after laser ablation. Yang et al. [229] developed a surface laser modification approach for fabricating $\mathrm{NiCo}_{2} \mathrm{O}_{4-\mathrm{d}}$ with higher $\mathrm{Ni}^{3+} / \mathrm{Ni}^{2+}$ ratio and abundant oxygen vacancies (Vo.*) from $\mathrm{NiCo}_{2} \mathrm{O}_{4}$. The laser-modificated $\mathrm{NiCo}_{2} \mathrm{O}_{4-\mathrm{d}}$ exhibited a higher electrocatalytic activity for overall water splitting compared with the initial $\mathrm{NiCo}_{2} \mathrm{O}_{4}$. Du et al. [119] used laser-synthesized porous $\mathrm{Co}_{0.75} \mathrm{Ni}_{0.25}(\mathrm{OH})_{2}$ nanosheets to catalyze the overall water splitting (Fig. 17d-f), which exhibited a high performance for HER (95 mV@ $\left.10 \mathrm{~mA} \mathrm{~cm}^{-2}\right)$ and OER (235 mV@10 mA cm${ }^{-2}$ ). When using it as both cathode and anode catalysts, an external voltage of only $1.56 \mathrm{~V}$ was needed to reach a current density of $10 \mathrm{~mA} \mathrm{~cm}^{-2}$, much lower than that of commercial Ir/C-Pt/C couple (1.62 V). These works demonstrated that using laser ablation to create novel nanostructures with highly active sites for overall water splitting has great application prospects.

\subsubsection{Electrocatalytic Oxygen Reduction Reaction (ORR)}

As mentioned in Sect. 2.1.2, Tour's group [79] scribed a $\mathrm{CO}_{2}$ laser on a metal-complex containing polyimide film and different metal oxide nanoparticles, $\mathrm{Co}_{3} \mathrm{O}_{4}, \mathrm{MoO}_{2}$, and $\mathrm{Fe}_{3} \mathrm{O}_{4}$ embedded in porous graphene were formed, which were highly active in electrocatalytic ORR. However, it was noted that when the as-prepared metal oxide nanoparticles embedded into porous graphene was applied in ORR, annealing (a)

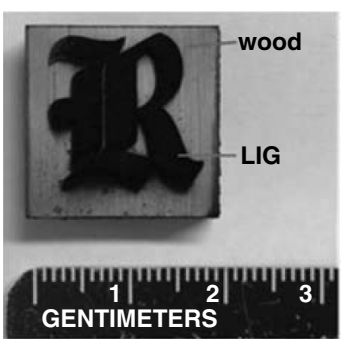

(d)

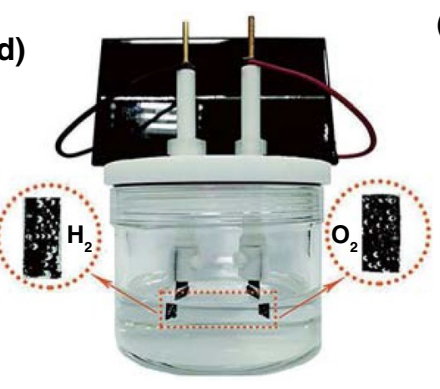

(b) 80

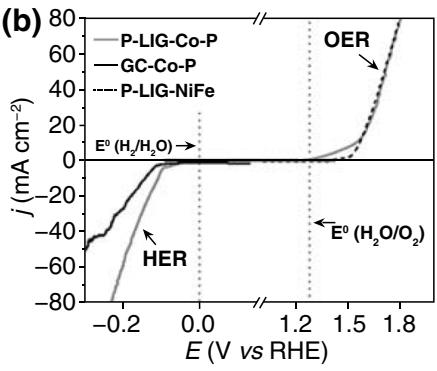

(e)

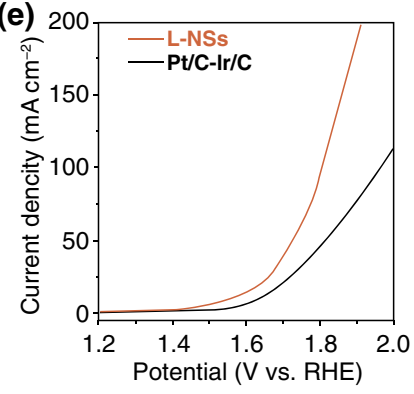

(c)
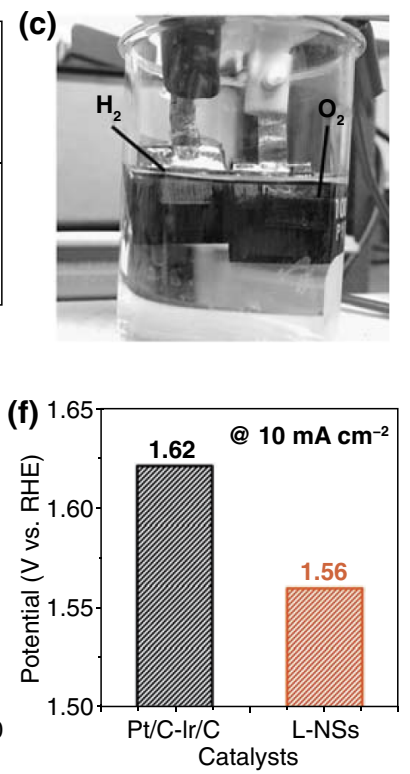

Fig. 17 a A photograph of LIG patterned into a letter R on pine wood. b HER and OER windows (iR compensated) of P-LIG-70 deposited with $\mathrm{Co}-\mathrm{P}$ or $\mathrm{NiFe}$ in $1 \mathrm{M} \mathrm{KOH}$ aqueous solution. $\mathbf{c}$ A photograph shows hydrogen and oxygen bubbling over the P-LIG-Co-P (left electrode) and P-LIG-NiFe (right electrode) surfaces powered by two $1.5 \mathrm{~V}$ batteries in series [227]. d Optical image of overall water splitting driven by a $1.51 \mathrm{~V}$ solar cell. e LSV curves of $\mathrm{Co}_{0.75} \mathrm{Ni}_{0.25}(\mathrm{OH})_{2}$ nanosheets and commercial Pt/C-Ir/C couple in 6 m KOH for overall water splitting. $\mathbf{f}$ Potential values at $10 \mathrm{~mA} \mathrm{~cm} \mathrm{~cm}^{-2}[119]$ 
process at $750{ }^{\circ} \mathrm{C}$ for $30 \mathrm{~min}$ was performed in order to improve the degree of crystallization while maintaining the same crystal phases of metal oxides.

\subsection{Other Applications of Materials Fabricated by Laser Technology}

\subsubsection{Corrosion Protection Application}

Corrosion of metals has been studied for its disadvantages of causing tremendous disasters and economic loss. Because of the unique high conductivity, impermeability and chemical inertness properties, the graphene coating has become a promising choice for anticorrosion application. However, graphene is easily fabricated on copper or nickel substrates while being difficult to grow on carbon steels. Therefore, Zhong et al. grew graphene by laser microfabrication on the solid carbon coating nickel surface [48] and on normal carbon steel by introducing $\mathrm{Ni}$ element into the carbon steel surface [230], which exhibited excellent anticorrosion property. This strategy contained the advantages of fast growth, large-area growth and arbitrary pattern design for graphene synthesis and manufacturing, overcoming the limitation of the CVD method. However, it was noted that both of the wide laser beam size and high laser power density were essential during the graphene synthesis process.

\subsubsection{Hydrophilic and Hydrophobic Applications}

The exciting functionalities of natural superhydrophobic and superhydrophilic surfaces inspired a variety of biomimetic designs. Particularly, the micropatterns combined with wetting states resulted in invigorating applications. By using a fs-laser microstructuring technology, Kostal et al. [231] mimicked the Namib Desert beetle's elytra, the double hierarchical surface structures with superhydrophilic character (water contact angle $<10^{\circ}$ ) on glass were firstly fabricated through laser. After a Teflon coating to change the wetting state from superhydrophilic to superhydrophobic (water contact angle $>150^{\circ}$ ) was applied, selective laser ablation was then utilized to locally expose the superhydrophilic pattern. The fabricated micropatterns exhibited a significantly enhanced fog collection efficiency of $60 \%$ higher than blank glass, it was demonstrated that efficient drop accumulation and fast drop removal contributed to this enhancement. In addition, Chen et al. presented the fs laser on the thermalresponsive shape-memory polymer to fabricate hierarchical micropillars, the laser-induced micropillars exhibited superhydrophobicity performance and the switchable wetting state was achieved [232]. Professor Tour's group changed the different controlled atmospheres of laser-induced graphene process to regulate the wetting state of the LIG surfaces [233]. When varying the atmosphere from oxidizing to reducing condition, a great switch in the water contact angle of the LIG surfaces from $0^{\circ}$ (superhydrophilic, $\mathrm{O}_{2}$ or air) to $>150^{\circ}$ (superhydrophobic, $\mathrm{Ar}$ or $\mathrm{H}_{2}$ ) was observed. The atmosphere-mediated superhydrophobicity of micro/nanostructures by laser processing $\mathrm{Cu}$ and the subsequent adsorption of hydrophobic volatile organics was also reported [152]. In conclusion, the chemical composition and surface morphology of micropatterns contributed to different wetting properties, which had significance for guiding application researches in electrochemical catalysis, energy storage and electronic devices.

\subsubsection{Laser Streaming}

Transforming a laser beam into a mass flow derived additional applications in laser propulsion, microfluidics and laser surgery and cleaning [234]. Wang et al. firstly proposed the optofluidic concept, demonstrating the successful generation of high-speed liquid flow by pulsed laser streaming on a glass window after surface decorating with high-density Au nanoparticles [235]. The optofluidic mechanism was demonstrated that plasmonic nanoparticles generated ultrasonic waves via the photoacoustic effect when a pulsed laser was incident, and then, the ultrasonic waves pushed their surrounding media to generate laser streaming. Then after using the gold-implanted plasmonic quartz plate to replace the glass cuvette with Au nanoparticles, similar photoacoustic laser streaming occurred and the mechanism of the photoacoustic effect and vibration propagation was verified [236]. This laser-driven optofluidic strategy will provide an opportunity for versatile microfluidic applications.

Therefore, the laser microfabrication process, especially the "cold microfabrication" process, allows precise control of the processing sites. Therefore, laser microfabrication realizes mask-free patterning, which benefits for the construction of hierarchical structures on flexible substrates. It is noted that although the laser microfabrication process is 
significantly fast and time saving when line-by-line scanning, the laser punch treatment or point-by-point exposure treatment is time consuming, because that laser process is not a parallel processing technique compared with UV lithography. Alternatively, the use of a patterned laser source or multi-laser beams can substantially enhance the processing efficiency. In summary, the laser technology is expected to contribute to the advancing fabrication of different electronic devices, such as supercapacitors, batteries, sensors, electrocatalytic electrodes and other application systems.

\section{Outlook and Future Challenges}

Laser techniques operating with pulsed or continuous-wave modes covering the wavelength ranges of ultraviolet, visible, and infrared have been employed in synthesis or microfabrication of materials. In terms of the synthesis of nanomaterials by laser, the basic processing principle is that the absorption of laser irradiation causes the photothermal or/ and photochemical effects, which drive the conversion and crystallization of the precursor materials. The demanded thermal or chemical effect can be tuned by varying the laser process parameters, such as the scanning rate, pulse width and laser intensity. Thus, the choice of laser wavelength is related to the light absorption properties of the precursor materials. If photothermal effects predominate during the synthesis process, laser with a long wavelength is essential, such as the $\mathrm{CO}_{2}$ laser, especially for the laser synthesis of carbon materials. In terms of microfabrication of nanostructures by laser technology, two kinds of microfabrication styles are included, one is primarily based on the laser-induced photothermal effect through synthesis of the purpose materials at a localized position to construct the patterned nanostructures. The other is primarily based on the sputtering etching effect to obtain the desired nanostructure pattern. The feature of localized synthesis to construct the patterned nanostructures is similar to that of laser synthesis, and the only difference is that the formation of the pattern is strongly dependent on the laser process parameters, especially the pulse width, while the sputtering etching effect to obtain the desired nanostructured pattern is a so-called cold microfabrication process, which needs highly focused energy to avoid the burrs induced by photothermal effects. Therefore, the ultrafast laser is in ascendancy. Because that the ultrafast laser possesses a high intensity and ultrashort pulse width, thermal side effects are minimized and nonlinear absorption can take place in almost any material. As a result, brittle and transparent materials such as glasses can be processed, and because there is no heat exchange during the ultrafast pulsed laser processing, collateral damage and thermal stress are minimized. Thus, a more precise patterned nanostructure can be obtained.

As an alternative to the conventional annealing treatment, laser processing offers promising advantages. Firstly, this process is significantly fast and time saving. As experimentally verified, laser processing brings the heating and cooling rates of $>106{ }^{\circ} \mathrm{C} \mathrm{s}^{-1}$, which is orders of magnitude higher than that of the conventional thermal treatment. Therefore, rapid fabrication of materials with minimal energy losses becomes possible. Secondly, the laser microfabrication process, especially the "cold microfabrication" process, allows precise control of the processing sites. Therefore, laser microfabrication realizes mask-free patterning, which benefits for the construction of hierarchical structures on flexible substrates. Thirdly, laser processing is adaptable for large size and roll-to-roll manufacturing and compatible with a variety of materials. The roll-to-roll manufacturing can be realized by integrating and digitizing the laser process parameters with computer design and a manufacturing system. Lastly, due to the advantage of precise control of the laser process, the in situ synthesis or in situ sputtering etching, which retaining the precursor morphology after laser processing, can be tailored by tuning the laser focus distance. Hence, laser synthesis and microfabrication are promising protocols for developing nanomaterials and nanostructures for various applications.

In spite of the advantages discussed above, laser processing of nanomaterials still confronted with several limitations. In terms of laser microfabrication for patterning, although this process is significantly fast and time saving when lineby-line scanning, the laser punch treatment or point-by-point exposure treatment is time consuming, because that laser process is not a parallel processing technique compared with UV lithography. In addition, 3D nanostructures are difficult to construct through laser processing. Alternatively, the use of a patterned laser source or multi-laser beams can substantially solve both of the above-mentioned issues. For practical production, the processing efficiency can be enhanced by adapting holographic laser processing or spatial light modulators. In the future, with the rapid development of parallel laser processing techniques or by combining $3 \mathrm{D}$ 
printing program, laser fabrication of 3D nanostructures can be completed in a more efficient manner. In addition, although various nanostructure patterns can be fabricated through the laser process, more nanostructure styles have not been realized compared with those constructed by wet chemical methods. Therefore, in situ transformation from the preconstructed nanostructures through the thermal effect of the unfocused laser is also a potential proposal for expanding the application of laser process.

Laser as a synthetic technique and/or microfabrication technique is not limited to the aforementioned applications. Laser synthesis and microfabrication have great potential for many other development directions. For instance, more compound species can be controllably synthesized by laser ablation under different atmospheres instead of only air or $\mathrm{Ar}$ atmosphere, such as the synthesis of nitrides under the $\mathrm{N}_{2}$ or $\mathrm{NH}_{3}$ atmosphere, synthesis of sulfides under the $\mathrm{H}_{2} \mathrm{~S}$ atmosphere, synthesis of carbides under the $\mathrm{CH}_{4}$ atmosphere and even synthesis under the $\mathrm{CO}_{2}$ atmosphere for oxides or carbides with unique properties. In addition, the limited resolution of the laser process in nanomaterial processing should be improved. By introducing different optical schemes together with the integration with other systems, controlled laser fabrication with higher precision can be achieved. Besides, the combination of laser cold processing and laser thermal synthesis is conducive to the realization of more sophisticated electronics with precise patterns and fine functionalization. In consequence, with the rapid development of laser processing technology, additional nanomaterial-based applications will be explored. With the continuous efforts that are being devoted to this dynamic field, laser as a synthetic technique and/or microfabrication technique will have broad application prospects.

Acknowledgements This work was supported by Taishan Scholars Project Special Funds (tsqn201812083), Natural Science Foundation of Shandong Province (ZR2019YQ20, 2019JMRH0410, ZR2019BB001) and the National Natural Science Foundation of China $(51972147$, 51902132, 52022037).

Open Access This article is licensed under a Creative Commons Attribution 4.0 International License, which permits use, sharing, adaptation, distribution and reproduction in any medium or format, as long as you give appropriate credit to the original author(s) and the source, provide a link to the Creative Commons licence, and indicate if changes were made. The images or other third party material in this article are included in the article's Creative Commons licence, unless indicated otherwise in a credit line to the material. If material is not included in the article's Creative
Commons licence and your intended use is not permitted by statutory regulation or exceeds the permitted use, you will need to obtain permission directly from the copyright holder. To view a copy of this licence, visit http://creativecommons.org/licenses/ by $/ 4.0 /$.

\section{References}

1. H. Wang, D. Tran, J. Qian, F. Ding, D. Losic, $\mathrm{MoS}_{2}$ /graphene composites as promising materials for energy storage and conversion applications. Adv. Mater. Interface 6(20), 1900915 (2019). https://doi.org/10.1002/admi.201900915

2. T.S. Kim, Y. Lee, W. Xu, Y.H. Kim, M. Kim et al., Directprinted nanoscale metal-oxide-wire electronics. Nano Energy 58, 437-446 (2019). https://doi.org/10.1016/j.nanoe n.2019.01.052

3. M.T. Chorsi, E.J. Curry, H.T. Chorsi, R. Das, J. Baroody et al., Piezoelectric biomaterials for sensors and actuators. Adv. Mater. 31(1), 1802084 (2019). https://doi.org/10.1002/ adma.201802084

4. W. Dong, H. Liu, J.K. Behera, L. Lu, R.J.H. Ng et al., Wide bandgap phase change material tuned visible photonics. Adv. Funct. Mater. 29(6), 1806181 (2019). https://doi.org/10.1002/ adfm.201806181

5. D.J. Joe, S. Kim, J.H. Park, D.Y. Park, H.E. Lee et al., Lasermaterial interactions for flexible applications. Adv. Mater. 29(26), 1606586 (2017). https://doi.org/10.1002/adma.20160 6586

6. J. Bian, L. Zhou, X. Wan, C. Zhu, B. Yang et al., Laser transfer, printing, and assembly techniques for flexible electronics. Adv. Electron. Mater. 5(7), 1800900 (2019). https://doi. org/10.1002/aelm.201800900

7. H. Palneedi, J.H. Park, D. Maurya, M. Peddigari, G.T. Hwang et al., Laser irradiation of metal oxide films and nanostructures: applications and advances. Adv. Mater. 30(14), 1705148 (2018). https://doi.org/10.1002/adma.201705148

8. S. Hong, H. Lee, J. Yeo, S.H. Ko, Digital selective laser methods for nanomaterials: from synthesis to processing. Nano Today 11(5), 547-564 (2016). https://doi.org/10.1016/j.nanto d.2016.08.007

9. C. Yang, Y. Huang, H. Cheng, L. Jiang, L. Qu, Rollable, stretchable, and reconfigurable graphene hygroelectric generators. Adv. Mater. 31(2), 1805705 (2019). https://doi. org/10.1002/adma.201805705

10. N.V. Sapra, K.Y. Yang, D. Vercruysse, K.J. Leedle, D.S. Black et al., On-chip integrated laser-driven particle accelerator. Science 367(6473), 79 (2020). https://doi.org/10.1126/ science.aay5734

11. A.A. Sergeev, D.V. Pavlov, A.A. Kuchmizhak, M.V. Lapine, W.K. Yiu et al., Tailoring spontaneous infrared emission of $\mathrm{HgTe}$ quantum dots with laser-printed plasmonic arrays. Light-Sci. Appl. 9(1), 16 (2020). https://doi.org/10.1038/ s41377-020-0247-6

12. K. Gao, B. Wang, L. Tao, B.V. Cunning, Z. Zhang et al., Efficient metal-free electrocatalysts from $\mathrm{N}$-doped carbon 
nanomaterials: mono-doping and co-doping. Adv. Mater. 31(13), 1805121 (2019). https://doi.org/10.1002/adma.20180 5121

13. R. Paul, F. Du, L. Dai, Y. Ding, Z.L. Wang et al., 3D heteroatom-doped carbon nanomaterials as multifunctional metalfree catalysts for integrated energy devices. Adv. Mater. 31(13), 1805598 (2019). https://doi.org/10.1002/adma.20180 5598

14. R. Ye, D.K. James, J.M. Tour, Laser-induced graphene: from discovery to translation. Adv. Mater. 31(1), 1803621 (2019). https://doi.org/10.1002/adma.201803621

15. R.D. Rodriguez, A. Khalelov, P.S. Postnikov, A. Lipovka, E. Dorozhko et al., Beyond graphene oxide: laser engineering functionalized graphene for flexible electronics. Mater. Horiz. 7, 1030 (2020). https://doi.org/10.1039/C9MH01950B

16. R. You, Y.Q. Liu, Y.L. Hao, D.D. Han, Y.L. Zhang et al., Laser fabrication of graphene-based flexible electronics. Adv. Mater. 32, 1901981 (2019). https://doi.org/10.1002/ adma.201901981

17. B. Ye, M. Lee, B. Jeong, J. Kim, D.H. Lee et al., Partially reduced graphene oxide as a support of $\mathrm{Mn}-\mathrm{Ce} / \mathrm{TiO}_{2}$ catalyst for selective catalytic reduction of $\mathrm{NO}_{\mathrm{x}}$ with $\mathrm{NH}_{3}$. Catal. Today 328, 300-306 (2019). https://doi.org/10.1016/j.catto d.2018.12.007

18. K.K.H. De Silva, H.H. Huang, R.K. Joshi, M. Yoshimura, Chemical reduction of graphene oxide using green reductants. Carbon 119, 190-199 (2017). https://doi.org/10.1016/j. carbon.2017.04.025

19. Z. Pan, T. Hisatomi, Q. Wang, S. Chen, A. Iwase et al., Photoreduced graphene oxide as a conductive binder to improve the water splitting activity of photocatalyst sheets. Adv. Funct. Mater. 26(38), 7011-7019 (2016). https://doi. org/10.1002/adfm.201602657

20. R. Kumar, R.K. Singh, D.P. Singh, E. Joanni, R.M. Yadav et al., Laser-assisted synthesis, reduction and micro-patterning of graphene: recent progress and applications. Coord. Chem. Rev. 342, 34-79 (2017). https://doi.org/10.1016/j. ccr.2017.03.021

21. A. Antonelou, L. Sygellou, K. Vrettos, V. Georgakilas, S.N. Yannopoulos, Efficient defect healing and ultralow sheet resistance of laser-assisted reduced graphene oxide at ambient conditions. Carbon 139, 492-499 (2018). https://doi. org/10.1016/j.carbon.2018.07.012

22. B. Xie, Y. Wang, W. Lai, W. Lin, Z. Lin et al., Laser-processed graphene based micro-supercapacitors for ultrathin, rollable, compact and designable energy storage components. Nano Energy 26, 276-285 (2016). https://doi.org/10.1016/j. nanoen.2016.04.045

23. H. Cheng, J. Liu, Y. Zhao, C. Hu, Z. Zhang et al., Graphene fibers with predetermined deformation as moisture-triggered actuators and robots. Angew. Chem. Int. Ed. 52(40), 1048210486 (2013). https://doi.org/10.1002/anie.201304358

24. H. Cheng, M. Ye, F. Zhao, C. Hu, Y. Zhao et al., A general and extremely simple remote approach toward graphene bulks with in situ multifunctionalization. Adv. Mater. 28(17), 3305-3312 (2016). https://doi.org/10.1002/adma.201505431
25. M.F. El-Kady, V. Strong, S. Dubin, R.B. Kaner, Laser scribing of high-performance and flexible graphene-based electrochemical capacitors. Science 335(6074), 1326 (2012). https ://doi.org/10.1126/science.1216744

26. M.F. El-Kady, R.B. Kaner, Scalable fabrication of highpower graphene micro-supercapacitors for flexible and onchip energy storage. Nat. Commun. 4(1), 1475 (2013). https ://doi.org/10.1038/ncomms2446

27. S. Luo, Y. Wang, G. Wang, F. Liu, Y. Zhai et al., Hybrid spray-coating, laser-scribing and ink-dispensing of graphene sensors/arrays with tunable piezoresistivity for in situ monitoring of composites. Carbon 139, 437-444 (2018). https:// doi.org/10.1016/j.carbon.2018.07.014

28. T. Zou, B. Zhao, W. Xin, Y. Wang, B. Wang et al., Highspeed femtosecond laser plasmonic lithography and reduction of graphene oxide for anisotropic photoresponse. LightSci. Appl. 9(1), 69 (2020). https://doi.org/10.1038/s4137 7-020-0311-2

29. D.X. Luong, K. Yang, J. Yoon, S.P. Singh, T. Wang et al., Laser-induced graphene composites as multifunctional surfaces. ACS Nano 13(2), 2579-2586 (2019). https://doi. org/10.1021/acsnano.8b09626

30. M.G. Stanford, J.T. Li, Y. Chen, E.A. McHugh, A. Liopo et al., Self-sterilizing laser-induced graphene bacterial air filter. ACS Nano 13(10), 11912-11920 (2019). https://doi. org/10.1021/acsnano.9b05983

31. C. Thamaraiselvan, J. Wang, D.K. James, P. Narkhede, S.P. Singh et al., Laser-induced graphene and carbon nanotubes as conductive carbon-based materials in environmental technology. Mater. Today 34, 115-131 (2019). https://doi. org/10.1016/j.mattod.2019.08.014

32. J. Lin, Z. Peng, Y. Liu, F. Ruiz-Zepeda, R. Ye et al., Laserinduced porous graphene films from commercial polymers. Nat. Commun. 5(1), 5714 (2014). https://doi.org/10.1038/ ncomms6714

33. Y. Chyan, R. Ye, Y. Li, S.P. Singh, C.J. Arnusch et al., Laserinduced graphene by multiple lasing: toward electronics on cloth, paper, and food. ACS Nano 12(3), 2176-2183 (2018). https://doi.org/10.1021/acsnano.7b08539

34. M.G. Stanford, K. Yang, Y. Chyan, C. Kittrell, J.M. Tour, Laser-induced graphene for flexible and embeddable gas sensors. ACS Nano 13(3), 3474-3482 (2019). https://doi. org/10.1021/acsnano.8b09622

35. Z. Peng, R. Ye, J.A. Mann, D. Zakhidov, Y. Li et al., Flexible boron-doped laser-induced graphene microsupercapacitors. ACS Nano 9(6), 5868-5875 (2015). https://doi.org/10.1021/ acsnano. 5 b00436

36. H. Wang, H. Wang, Y. Wang, X. Su, C. Wang et al., Laser writing of janus graphene/kevlar textile for intelligent protective clothing. ACS Nano 14(3), 3219-3226 (2020). https:// doi.org/10.1021/acsnano.9b08638

37. D.X. Luong, A.K. Subramanian, G.A.L. Silva, J. Yoon, S. Cofer, Laminated object manufacturing of 3D-printed laserinduced graphene foams. Adv. Mater. 30(28), 1707416 (2018). https://doi.org/10.1002/adma.201707416 
38. J. Sha, Y. Li, R. Villegas Salvatierra, T. Wang, P. Dong et al., Three-dimensional printed graphene foams. ACS Nano 11(7), 6860-6867 (2017). https://doi.org/10.1021/acsnano.7b01987

39. R. Ye, X. Han, D.V. Kosynkin, Y. Li, C. Zhang et al., Laserinduced conversion of teflon into fluorinated nanodiamonds or fluorinated graphene. ACS Nano 12(2), 1083-1088 (2018). https://doi.org/10.1021/acsnano.7b05877

40. J. Nasser, L. Groo, L. Zhang, H. Sodano, Laser induced graphene fibers for multifunctional aramid fiber reinforced composite. Carbon 158, 146-156 (2020). https://doi. org/10.1016/j.carbon.2019.11.078

41. Y. Wang, Y. Wang, P. Zhang, F. Liu, S. Luo, Laser-induced freestanding graphene papers: a new route of scalable fabrication with tunable morphologies and properties for multifunctional devices and structures. Small 14(36), 1802350 (2018). https://doi.org/10.1002/smll.201802350

42. W. Zhang, Y. Lei, Q. Jiang, F. Ming, P.M.F.J. Costa et al., 3D laser scribed graphene derived from carbon nanospheres: an ultrahigh-power electrode for supercapacitors. Small Methods 3(5), 1900005 (2019). https://doi.org/10.1002/smtd.20190 0005

43. F. Raimondi, S. Abolhassani, R. Brütsch, F. Geiger, T. Lippert et al., Quantification of polyimide carbonization after laser ablation. J. Appl. Phys. 88(6), 3659-3666 (2000). https ://doi.org/10.1063/1.1289516

44. F. Wang, W. Duan, K. Wang, X. Dong, M. Gao et al., Graphitized hierarchically porous carbon nanosheets derived from bakelite induced by high-repetition picosecond laser. Appl. Surf. Sci. 450, 155-163 (2018). https://doi. org/10.1016/j.apsusc.2018.04.130

45. L.M. Ji, H. Lee, C.H.J. Lim, V.M. Murukeshan, Y. Kim, In direct laser writing of graphene oxide patterns using femtosecond laser pulses with different repetition rates, 2017 Conference on Lasers and Electro-Optics Pacific Rim (CLEOPR), 31 July-4 Aug. 2017.

46. J.B. Park, W. Xiong, Y. Gao, M. Qian, Z.Q. Xie et al., Fast growth of graphene patterns by laser direct writing. Appl. Phys. Lett. 98(12), 123109 (2011). https://doi. org/10.1063/1.3569720

47. J.B. Park, W. Xiong, Z.Q. Xie, Y. Gao, M. Qian et al., Transparent interconnections formed by rapid single-step fabrication of graphene patterns. Appl. Phys. Lett. 99(5), 053103 (2011). https://doi.org/10.1063/1.3622660

48. X. Ye, J. Long, Z. Lin, H. Zhang, H. Zhu et al., Direct laser fabrication of large-area and patterned graphene at room temperature. Carbon 68, 784-790 (2014). https://doi. org/10.1016/j.carbon.2013.11.069

49. S. Lee, M.F. Toney, W. Ko, J.C. Randel, H.J. Jung et al., Laser-synthesized epitaxial graphene. ACS Nano 4(12), 7524-7530 (2010). https://doi.org/10.1021/nn101796e

50. I. Choi, H.Y. Jeong, D.Y. Jung, M. Byun, C.G. Choi et al., Laser-induced solid-phase doped graphene. ACS Nano 8(8), 7671-7677 (2014). https://doi.org/10.1021/nn5032214

51. S.N. Yannopoulos, A. Siokou, N.K. Nasikas, V. Dracopoulos, F. Ravani et al., $\mathrm{CO}_{2}$-laser-induced growth of epitaxial graphene on $6 \mathrm{H}-\mathrm{SiC}(0001)$. Adv. Funct. Mater. 22(1), 113 120 (2012). https://doi.org/10.1002/adfm.201101413

52. F. Stock, F. Antoni, L. Diebold, C. Chowde Gowda et al., UV laser annealing of diamond-like carbon layers obtained by pulsed laser deposition for optical and photovoltaic applications. Appl. Surf. Sci. 464, 562-566 (2019). https://doi. org/10.1016/j.apsusc.2018.09.085

53. L.S. Fan, L. Constantin, D.W. Li, L. Liu, K. Keramatnejad et al., Ultraviolet laser photolysis of hydrocarbons for nondiamond carbon suppression in chemical vapor deposition of diamond films. Light-Sci. Appl. 7(4), 17177-17177 (2018). https://doi.org/10.1038/lsa.2017.177

54. F. Zhang, E. Alhajji, Y. Lei, N. Kurra, H.N. Alshareef, Highly doped 3D graphene Na-Ion battery anode by laser scribing polyimide films in nitrogen ambient. Adv. Energy Mater. 8(23), 1800353 (2018). https://doi.org/10.1002/aenm.20180 0353

55. Y. Huang, L. Zeng, C. Liu, D. Zeng, Z. Liu et al., Laser direct writing of heteroatom ( $\mathrm{N}$ and $\mathrm{S}$ )-doped graphene from a polybenzimidazole ink donor on polyethylene terephthalate polymer and glass substrates. Small 14(44), 1803143 (2018). https://doi.org/10.1002/smll.201803143

56. R. Yuge, S. Bandow, M. Yudasaka, K. Toyama, S. Iijima et al., Boron- and nitrogen-doped single-walled carbon nanohorns with graphite-like thin sheets prepared by $\mathrm{CO}_{2}$ laser ablation method. Carbon 111, 675-680 (2017). https://doi. org/10.1016/j.carbon.2016.10.049

57. W.H. Lee, J.W. Suk, H. Chou, J. Lee, Y. Hao et al., Selectivearea fluorination of graphene with fluoropolymer and laser irradiation. Nano Lett. 12(5), 2374-2378 (2012). https://doi. org/10.1021/nl300346j

58. L. Peng, P. Xiong, L. Ma, Y. Yuan, Y. Zhu et al., Holey twodimensional transition metal oxide nanosheets for efficient energy storage. Nat. Commun. 8(1), 15139 (2017). https:// doi.org/10.1038/ncomms 15139

59. D. Gao, R. Liu, J. Biskupek, U. Kaiser, Y.F. Song et al., Modular design of Noble-Metal-Free mixed metal oxide electrocatalysts for complete water splitting. Angew. Chem. Int. Ed. 58(14), 4644-4648 (2019). https://doi.org/10.1002/ anie. 201900428

60. X. Liu, J. Iocozzia, Y. Wang, X. Cui, Y. Chen et al., Noble metal-metal oxide nanohybrids with tailored nanostructures for efficient solar energy conversion, photocatalysis and environmental remediation. Energy Environ. Sci. 10(2), 402-434 (2017). https://doi.org/10.1039/C6EE02265K

61. R.D.L. Smith, M.S. Prévot, R.D. Fagan, Z. Zhang, P.A. Sedach et al., Photochemical route for accessing amorphous metal oxide materials for water oxidation catalysis. Science 340(6128), 60 (2013). https://doi.org/10.1126/science.12336 38

62. T. Maiyalagan, K.A. Jarvis, S. Therese, P.J. Ferreira, A. Manthiram, Spinel-type lithium cobalt oxide as a bifunctional electrocatalyst for the oxygen evolution and oxygen reduction reactions. Nat. Commun. 5(1), 3949 (2014). https://doi. org/10.1038/ncomms4949 
63. M. Gong, W. Zhou, M.C. Tsai, J. Zhou, M. Guan et al., Nanoscale nickel oxide/nickel heterostructures for active hydrogen evolution electrocatalysis. Nat. Commun. 5(1), 4695 (2014). https://doi.org/10.1038/ncomms5695

64. J. Qi, W. Zhang, R. Xiang, K. Liu, H.Y. Wang et al., Porous nickel-iron oxide as a highly efficient electrocatalyst for oxygen evolution reaction. Adv. Sci. 2(10), 1500199 (2015). https://doi.org/10.1002/advs.201500199

65. L. Wu, Q. Li, C.H. Wu, H. Zhu, A. Mendoza-Garcia et al., Stable cobalt nanoparticles and their monolayer array as an efficient electrocatalyst for oxygen evolution reaction. J. Am. Chem. Soc. 137(22), 7071-7074 (2015). https://doi. org/10.1021/jacs.5b04142

66. Z. Hu, S. Qiu, Y. You, Y. Guo, Y. Guo et al., Hydrothermal synthesis of $\mathrm{NiCeOx}$ nanosheets and its application to the total oxidation of propane. Appl. Catal. B Environ. 225, 110 120 (2018). https://doi.org/10.1016/j.apcatb.2017.08.068

67. K. Jiang, H. Wang, W.B. Cai, H. Wang, Li electrochemical tuning of metal oxide for highly selective $\mathrm{CO}_{2}$ reduction. ACS Nano 11(6), 6451-6458 (2017). https://doi.org/10.1021/ acsnano.7b03029

68. Y. Park, D. Yoon, K. Fukutani, R. Stania, J. Son, Steep-slope threshold switch enabled by pulsed-laser-induced phase transformation. ACS Appl. Mater. Interfaces 11(27), 2422124229 (2019). https://doi.org/10.1021/acsami.9b04015

69. G. Ou, P. Fan, H. Zhang, K. Huang, C. Yang et al., Largescale hierarchical oxide nanostructures for high-performance electrocatalytic water splitting. Nano Energy 35, 207-214 (2017). https://doi.org/10.1016/j.nanoen.2017.03.049

70. H.S. Han, S. Shin, D.H. Kim, I.J. Park, J.S. Kim et al., Boosting the solar water oxidation performance of $\mathrm{a} \mathrm{BiVO}_{4}$ photoanode by crystallographic orientation control. Energy Environ. Sci. 11(5), 1299-1306 (2018). https://doi.org/10.1039/ C8EE00125A

71. J. Sourice, A. Quinsac, Y. Leconte, O. Sublemontier, W. Porcher et al., One-step synthesis of $\mathrm{Si} @ \mathrm{C}$ nanoparticles by laser pyrolysis: High-capacity anode material for lithium-ion batteries. ACS Appl. Mater. Interfaces 7(12), 6637-6644 (2015). https://doi.org/10.1021/am5089742

72. N. Mas, J.L. Hueso, G. Martinez, A. Madrid, R. Mallada et al., Laser-driven direct synthesis of carbon nanodots and application as sensitizers for visible-light photocatalysis. Carbon 156, 453-462 (2020). https://doi.org/10.1016/j.carbo n.2019.09.073

73. K.Y. Wang, L. Feng, T.H. Yan, S. Wu, E. Joseph et al., Rapid generation of hierarchically porous metal-organic frameworks through laser photolysis. Angew. Chem. Int. Ed. 59(28), 11349-11354 (2020). https://doi.org/10.1002/ anie. 202003636

74. L.P. Wang, Y. Leconte, Z. Feng, C. Wei, Y. Zhao et al., Novel preparation of $\mathrm{N}$-doped $\mathrm{SnO}_{2}$ nanoparticles via laser-assisted pyrolysis: demonstration of exceptional lithium storage properties. Adv. Mater. 29(6), 1603286 (2017). https://doi. org/10.1002/adma.201603286

75. J. Zhang, J. Feng, L. Jia, H. Zhang, G. Zhang et al., Laserinduced selective metallization on polymer substrates using organocopper for portable electronics. ACS Appl. Mater. Interfaces 11(14), 13714-13723 (2019). https://doi. org/10.1021/acsami.9b01856

76. A. Basu, K. Roy, N. Sharma, S. Nandi, R. Vaidhyanathan et al., $\mathrm{CO}_{2}$ laser direct written MOF-based metal-decorated and heteroatom-doped porous graphene for flexible all-solidstate microsupercapacitor with extremely high cycling stability. ACS Appl. Mater. Interfaces 8(46), 31841-31848 (2016). https://doi.org/10.1021/acsami.6b10193

77. H. Jiang, S. Jin, C. Wang, R. Ma, Y. Song et al., Nanoscale laser metallurgy and patterning in air using MOFs. J. Am. Chem. Soc. 141(13), 5481-5489 (2019). https://doi. org/10.1021/jacs.9b00355

78. Y. Wu, Z. Huang, H. Jiang, C. Wang, Y. Zhou et al., Facile synthesis of uniform metal carbide nanoparticles from metal-organic frameworks by laser metallurgy. ACS Appl. Mater. Interfaces 11(47), 44573-44581 (2019). https://doi. org/10.1021/acsami.9b13864

79. R. Ye, Z. Peng, T. Wang, Y. Xu, J. Zhang et al., In situ formation of metal oxide nanocrystals embedded in laser-induced graphene. ACS Nano 9(9), 9244-9251 (2015). https://doi. org/10.1021/acsnano.5b04138

80. M. Ren, J. Zhang, J.M. Tour, Laser-induced graphene synthesis of $\mathrm{Co}_{3} \mathrm{O}_{4}$ in graphene for oxygen electrocatalysis and metal-air batteries. Carbon 139, 880-887 (2018). https://doi. org/10.1016/j.carbon.2018.07.051

81. X. Zang, C. Shen, Y. Chu, B. Li, M. Wei et al., Laser-induced molybdenum carbide-graphene composites for 3D foldable paper electronics. Adv. Mater. 30(26), 1800062 (2018). https ://doi.org/10.1002/adma.201800062

82. X. Zang, C. Jian, T. Zhu, Z. Fan, W. Wang et al., Laser-sculptured ultrathin transition metal carbide layers for energy storage and energy harvesting applications. Nat. Commun. 10(1), 3112 (2019). https://doi.org/10.1038/s41467-019-10999-z

83. T. Afaneh, P.K. Sahoo, I.A.P. Nobrega, Y. Xin, H.R. Gutiérrez, Laser-assisted chemical modification of monolayer transition metal dichalcogenides. Adv. Funct. Mater. 28(37), 1802949 (2018). https://doi.org/10.1002/adfm.201802949

84. A. Castellanos-Gomez, M. Barkelid, A.M. Goossens, V.E. Calado, H.S.J. van der Zant et al., Laser-thinning of $\mathrm{MoS}_{2}$ : on demand generation of a single-layer semiconductor. Nano Lett. 12(6), 3187-3192 (2012). https://doi.org/10.1021/nl301 $164 \mathrm{v}$

85. J. Lu, J.H. Lu, H. Liu, B. Liu, K.X. Chan et al., Improved photoelectrical properties of $\mathrm{MoS}_{2}$ films after laser micromachining. ACS Nano 8(6), 6334-6343 (2014). https://doi. org/10.1021/nn501821z

86. J. Li, X. Yang, Y. Liu, B. Huang, R. Wu et al., General synthesis of two-dimensional van der Waals heterostructure arrays. Nature 579(7799), 368-374 (2020). https://doi.org/10.1038/ s41586-020-2098-y

87. K. Savva, B. Višić, R. Popovitz-Biro, E. Stratakis, R. Tenne, Short pulse laser synthesis of transition-metal dichalcogenide nanostructures under ambient conditions. ACS Omega 2(6), 2649-2656 (2017). https://doi.org/10.1021/acsomega.7b004 09 
88. F. Clerici, M. Fontana, S. Bianco, M. Serrapede, F. Perrucci et al., In situ $\mathrm{MoS}_{2}$ decoration of laser-induced graphene as flexible supercapacitor electrodes. ACS Appl. Mater. Interfaces 8(16), 10459-10465 (2016). https://doi.org/10.1021/ acsami.6b00808

89. L. Ge, Q. Hong, H. Li, C. Liu, F. Li, Direct-laser-writing of metal sulfide-graphene nanocomposite photoelectrode toward sensitive photoelectrochemical sensing. Adv. Funct. Mater. 29(38), 1904000 (2019). https://doi.org/10.1002/adfm.20190 4000

90. Y.Z. Chen, H. Medina, T.Y. Su, J.G. Li, K.Y. Cheng et al., Ultrafast and low temperature synthesis of highly crystalline and patternable few-layers tungsten diselenide by laser irradiation assisted selenization process. ACS Nano 9(4), 4346-4353 (2015). https://doi.org/10.1021/acsnano.5b00866

91. S. Rasekh, F.M. Costa, N.M. Ferreira, M.A. Torres, M.A. Madre et al., Use of laser technology to produce high thermoelectric performances in $\mathrm{Bi}_{2} \mathrm{Sr}_{2} \mathrm{Co}_{1.8} \mathrm{O}_{\mathrm{x}}$. Mater. Des. 75, $143-$ 148 (2015). https://doi.org/10.1016/j.matdes.2015.03.005

92. Y. Kinemuchi, M. Mikami, I. Terasaki, W. Shin, Rapid synthesis of thermoelectric compounds by laser melting. Mater. Des. 106, 30-36 (2016). https://doi.org/10.1016/j.matde s.2016.05.093

93. C. Li, M. Liu, H. Ding, L. He, E. Wang et al., A lightly Fedoped $\left(\mathrm{NiS}_{2} / \mathrm{MoS}_{2}\right) /$ carbon nanotube hybrid electrocatalyst film with laser-drilled micropores for stabilized overall water splitting and $\mathrm{pH}$-universal hydrogen evolution reaction. J. Mater. Chem. A 8(34), 17527-17536 (2020). https://doi. org/10.1039/D0TA04586A

94. F. Hao, C.C. Stoumpos, D.H. Cao, R.P.H. Chang, M.G. Kanatzidis, Lead-free solid-state organic-inorganic halide perovskite solar cells. Nat. Photonics 8(6), 489-494 (2014). https://doi.org/10.1038/nphoton.2014.82

95. W.S. Yang, B.W. Park, E.H. Jung, N.J. Jeon, Y.C. Kim et al., Iodide management in formamidinium-lead-halide-based perovskite layers for efficient solar cells. Science 356(6345), 1376 (2017). https://doi.org/10.1126/science.aan2301

96. Y. Huang, Q. Gong, X. Song, K. Feng, K. Nie et al., $\mathrm{Mo}_{2} \mathrm{C}$ nanoparticles dispersed on hierarchical carbon microflowers for efficient electrocatalytic hydrogen evolution. ACS Nano 10, 11337 (2016). https://doi.org/10.1021/acsnano.6b06580

97. T. Jeon, H.M. Jin, S.H. Lee, J.M. Lee, H.I. Park et al., Laser crystallization of organic-inorganic hybrid perovskite solar cells. ACS Nano 10(8), 7907-7914 (2016). https://doi. org/10.1021/acsnano.6b03815

98. P. You, G. Li, G. Tang, J. Cao, F. Yan, Ultrafast laser-annealing of perovskite films for efficient perovskite solar cells. Energy Environ. Sci. 13, 1187-1196 (2020). https://doi. org/10.1039/C9EE02324K

99. I.M. Pinatti, A.F. Gouveia, C. Doñate-Buendía, G. MínguezVega, J. Andrés et al., Femtosecond-laser-irradiation-induced structural organization and crystallinity of $\mathrm{Bi}_{2} \mathrm{WO}_{6}$. Sci. Rep. 10(1), 4613 (2020). https://doi.org/10.1038/s41598-02061524-y

100. D. Zhang, B. Gökce, S. Barcikowski, Laser synthesis and processing of colloids: fundamentals and applications. Chem.
Rev. 117(5), 3990-4103 (2017). https://doi.org/10.1021/acs. chemrev.6b00468

101. S. Ibrahimkutty, P. Wagener, T.D.S. Rolo, D. Karpov, A. Menzel et al., A hierarchical view on material formation during pulsed-laser synthesis of nanoparticles in liquid. Sci. Rep. 5(1), 16313 (2015). https://doi.org/10.1038/srep16313

102. K.Y. Niu, L. Fang, R. Ye, D. Nordlund, M.M. Doeff et al., Tailoring transition-metal hydroxides and oxides by photoninduced reactions. Angew. Chem. Int. Ed. 128(46), 1448414488 (2016). https://doi.org/10.1002/ange.201606775

103. H. Zeng, X.-W. Du, S.C. Singh, S.A. Kulinich, S. Yang et al., Nanomaterials via laser ablation/irradiation in liquid: a review. Adv. Funct. Mater. 22(7), 1333-1353 (2012). https ://doi.org/10.1002/adfm.201102295

104. S. Hebié, Y. Holade, K. Maximova, M. Sentis, P. Delaporte et al., Advanced electrocatalysts on the basis of bare au nanomaterials for biofuel cell applications. ACS Catal. 5(11), 6489-6496 (2015). https://doi.org/10.1021/acscatal.5b01478

105. V. Piotto, L. Litti, M. Meneghetti, Synthesis and shape manipulation of anisotropic gold nanoparticles by laser ablation in solution. J. Phys. Chem. C 124(8), 4820-4826 (2020). https://doi.org/10.1021/acs.jpcc.9b10793

106. G. González-Rubio, T. Milagres de Oliveira, W. Albrecht, P. Díaz-Núñez, J.C. Castro-Palacio et al., Formation of hollow gold nanocrystals by nanosecond laser irradiation. J. Phys. Chem. Lett. 11(3), 670-677 (2020). https://doi.org/10.1021/ acs.jpclett.9b03574

107. I. Vassalini, L. Borgese, M. Mariz, S. Polizzi, G. Aquilanti et al., Enhanced electrocatalytic oxygen evolution in $\mathrm{Au}-$ Fe nanoalloys. Angew. Chem. Int. Ed. 56(23), 6589-6593 (2017). https://doi.org/10.1002/anie.201703387

108. J. Zhang, G. Chen, D. Guay, M. Chaker, D. Ma, Highly active PtAu alloy nanoparticle catalysts for the reduction of 4-nitrophenol. Nanoscale 6(4), 2125-2130 (2014). https:// doi.org/10.1039/C3NR04715F

109. S. Hu, G. Goenaga, C. Melton, T.A. Zawodzinski, D. Mukherjee, $\mathrm{PtCo} / \mathrm{CoOx}$ nanocomposites: bifunctional electrocatalysts for oxygen reduction and evolution reactions synthesized via tandem laser ablation synthesis in solution-galvanic replacement reactions. Appl. Catal. B Environ. 182, 286-296 (2016). https://doi.org/10.1016/j.apcatb.2015.09.035

110. H. Zhang, S. Wu, J. Liu, Y. Cai, C. Liang, Laser irradiationinduced $\mathrm{Au}-\mathrm{ZnO}$ nanospheres with enhanced sensitivity and stability for ethanol sensing. Phys. Chem. Chem. Phys. 18(32), 22503-22508 (2016). https://doi.org/10.1039/C6CP0 $3487 \mathrm{~J}$

111. C.H. Chen, D. Wu, Z. Li, R. Zhang, C.G. Kuai et al., Ruthenium-based single-atom alloy with high electrocatalytic activity for hydrogen evolution. Adv. Energy Mater. 9(20), 1803913 (2019). https://doi.org/10.1002/aenm.201803913

112. Z. Li, Y. Feng, Y.L. Liang, C.Q. Cheng, C.K. Dong et al., Stable rhodium (IV) oxide for alkaline hydrogen evolution reaction. Adv. Mater. 32(25), 1908521 (2020). https://doi. org/10.1002/adma.201908521

113. T. Zhang, Y. Bai, Y. Sun, L. Hang, X. Li et al., Laser-irradiation induced synthesis of spongy AuAgPt alloy nanospheres 
with high-index facets, rich grain boundaries and subtle lattice distortion for enhanced electrocatalytic activity. J. Mater. Chem. A 6(28), 13735-13742 (2018). https://doi. org/10.1039/C8TA04087G

114. S. Pan, X. Zhang, W. Lu, S.F. Yu, Plasmon-engineered anti-replacement synthesis of naked $\mathrm{Cu}$ nanoclusters with ultrahigh electrocatalytic activity. J. Mater. Chem. A 6(38), 18687-18693 (2018). https://doi.org/10.1039/C8TA06789A

115. W. Zheng, Y. Zhang, K. Niu, T. Liu, K. Bustillo et al., Selective nitrogen doping of graphene oxide by laser irradiation for enhanced hydrogen evolution activity. Chem. Commun. 54(97), 13726-13729 (2018). https://doi.org/10.1039/C8CC0 $7725 \mathrm{H}$

116. L. Liao, Q. Zhang, Z. Su, Z. Zhao, Y. Wang et al., Efficient solar water-splitting using a nanocrystalline $\mathrm{CoO}$ photocatalyst. Nat. Nanotechnol. 9(1), 69-73 (2014). https://doi. org/10.1038/nnano.2013.272

117. J.D. Blakemore, H.B. Gray, J.R. Winkler, A.M. Müller, $\mathrm{Co}_{3} \mathrm{O}_{4}$ nanoparticle water-oxidation catalysts made by pulsed-laser ablation in liquids. ACS Catal. 3(11), 2497-2500 (2013). https://doi.org/10.1021/cs400639b

118. B.M. Hunter, J.D. Blakemore, M. Deimund, H.B. Gray, J.R. Winkler et al., Highly active mixed-metal nanosheet water oxidation catalysts made by pulsed-laser ablation in liquids. J. Am. Chem. Soc. 136(38), 13118-13121 (2014). https://doi. org/10.1021/ja506087h

119. X. Wang, Z. Li, D.Y. Wu, G.R. Shen, C. Zou et al., Porous cobalt-nickel hydroxide nanosheets with active cobalt ions for overall water splitting. Small 15(8), 1804832 (2019). https ://doi.org/10.1002/smll.201804832

120. H. Lee, D.A. Reddy, Y. Kim, S.Y. Chun, R. Ma et al., Drastic improvement of 1D-CdS solar-driven photocatalytic hydrogen evolution rate by integrating with nife layered double hydroxide nanosheets synthesized by liquid-phase pulsedlaser ablation. ACS Sustain. Chem. Eng. 6(12), 16734-16743 (2018). https://doi.org/10.1021/acssuschemeng.8b04000

121. D.K. Lee, D. Lee, M.A. Lumley, K.S. Choi, Progress on ternary oxide-based photoanodes for use in photoelectrochemical cells for solar water splitting. Chem. Soc. Rev. 48(7), 2126-2157 (2019). https://doi.org/10.1039/C8CS00761F

122. H. Liu, P. Jin, Y.M. Xue, C. Dong, X. Li et al., Photochemical synthesis of ultrafine cubic boron nitride nanoparticles under ambient conditions. Angew. Chem. Int. Ed. 54(24), 7051-7054 (2015). https://doi.org/10.1002/anie.201502023

123. M. Rui, X. Li, L. Gan, T. Zhai, H. Zeng, Ternary oxide nanocrystals: universal laser-hydrothermal synthesis, optoelectronic and electrochemical applications. Adv. Funct. Mater. 26(28), 5051-5060 (2016). https://doi.org/10.1002/ adfm.201600785

124. Y. Dong, S. Wang, Y. Zou, S. Liu, Z. Zhu et al., Zinc stannate nanocrystal-based ultrarapid-response UV photodetectors. Adv. Mater. Technol. 3(6), 1800085 (2018). https://doi. org/10.1002/admt.201800085

125. Z. Lin, J. Li, Z. Zheng, J. Yan, P. Liu et al., Electronic reconstruction of $\alpha-\mathrm{Ag}_{2} \mathrm{WO}_{4}$ nanorods for visible-light photocatalysis. ACS Nano 9(7), 7256-7265 (2015). https:// doi.org/10.1021/acsnano.5b02077

126. Z. Lin, W. Li, G. Yang, Hydrogen-interstitial $\mathrm{CuWO}_{4}$ nanomesh: a single-component full spectrum-active photocatalyst for hydrogen evolution. Appl. Catal. B Environ. 227, 35-43 (2018). https://doi.org/10.1016/j.apcatb.2018.01.021

127. J. Jian, Y. Xu, X. Yang, W. Liu, M. Fu et al., Embedding laser generated nanocrystals in $\mathrm{BiVO}_{4}$ photoanode for efficient photoelectrochemical water splitting. Nat. Commun. 10(1), 2609 (2019). https://doi.org/10.1038/s41467-019-10543-z

128. L. Zhou, H. Zhang, H. Bao, G. Liu, Y. Li et al., Onion-structured spherical $\mathrm{MoS}_{2}$ nanoparticles induced by laser ablation in water and liquid droplets' radial solidification/oriented growth mechanism. J. Phys. Chem. C 121(41), 23233-23239 (2017). https://doi.org/10.1021/acs.jpcc.7b07784

129. Z.W. Gao, M. Liu, W. Zheng, X. Zhang, L.Y.S. Lee, Surface engineering of $\mathrm{MoS}_{2}$ via laser-induced exfoliation in protic solvents. Small 15(44), 1903791 (2019). https://doi. org/10.1002/smll.201903791

130. W. Gong, Q. Yuan, C. Chen, Y. Lv, Y. Lin et al., Liberating N-CNTs confined highly dispersed Co- $\mathrm{N}_{\mathrm{x}}$ sites for selective hydrogenation of quinolines. Adv. Mater. 31(49), 1906051 (2019). https://doi.org/10.1002/adma.201906051

131. H. Liu, X.H. Zhang, Y.X. Li, X. Li, C.K. Dong et al., Conductive boron nitride as promising catalyst support for the oxygen evolution reaction. Adv. Energy Mater. 10(25), 1902521 (2020). https://doi.org/10.1002/aenm.201902521

132. B. Li, L. Jiang, X. Li, Z. Cheng, P. Ran et al., Controllable synthesis of nanosized amorphous $\mathrm{MoS}_{\mathrm{x}}$ using temporally shaped femtosecond laser for highly efficient electrochemical hydrogen production. Adv. Funct. Mater. 29(1), 1806229 (2019). https://doi.org/10.1002/adfm.201806229

133. X. Zhou, W. Guo, Y. Zhu, P. Peng, The laser writing of highly conductive and anti-oxidative copper structures in liquid. Nanoscale 12(2), 563-571 (2020). https://doi.org/10.1039/ C9NR07248A

134. S. Wu, J. Liu, D. Liang, H. Sun, Y. Ye et al., Photo-excited in situ loading of Pt clusters onto rGO immobilized $\mathrm{SnO}_{2}$ with excellent catalytic performance toward methanol oxidation. Nano Energy 26, 699-707 (2016). https://doi. org/10.1016/j.nanoen.2016.06.038

135. Y. Peng, J. Cao, J. Yang, W. Yang, C. Zhang et al., Laser assisted solution synthesis of high performance graphene supported electrocatalysts. Adv. Funct. Mater. 30(32), 2001756 (2020). https://doi.org/10.1002/adfm.202001756

136. J. Yeo, S. Hong, M. Wanit, H.W. Kang, D. Lee et al., Rapid, one-step, digital selective growth of $\mathrm{ZnO}$ nanowires on 3D structures using laser induced hydrothermal growth. Adv. Funct. Mater. 23(26), 3316-3323 (2013). https://doi. org/10.1002/adfm.201203863

137. K. Kwon, J. Shim, J.O. Lee, K. Choi, K. Yu, Localized laserbased photohydrothermal synthesis of functionalized metaloxides. Adv. Funct. Mater. 25(15), 2222-2229 (2015). https ://doi.org/10.1002/adfm.201404215

138. J. Yeo, S. Hong, G. Kim, H. Lee, Y.D. Suh et al., Laserinduced hydrothermal growth of heterogeneous metal-oxide 
nanowire on flexible substrate by laser absorption layer design. ACS Nano 9(6), 6059-6068 (2015). https://doi. org/10.1021/acsnano.5b01125

139. P. Guo, X. Yang, Q. Ye, J. Zhang, H. Wang et al., Lasergenerated nanocrystals in perovskite: universal embedding of ligand-free and sub-10 nm nanocrystals in solution-processed metal halide perovskite films for effectively modulated optoelectronic performance. Adv. Energy Mater. 9(35), 1901341 (2019). https://doi.org/10.1002/aenm.201901341

140. K.H. Ibrahim, M. Irannejad, M. Hajialamdari, A. Ramadhan, K.P. Musselman et al., A novel femtosecond laser-assisted method for the synthesis of reduced graphene oxide gels and thin films with tunable properties. Adv. Mater. Inter. 3(14), 1500864 (2016). https://doi.org/10.1002/admi.201500864

141. D. Zhang, B. Gökce, S. Barcikowski, Laser synthesis and processing of colloids: fundamentals and applications. Chem. Rev. 117, 3990-4103 (2017). https://doi.org/10.1021/acs. chemrev.6b00468

142. Y. Zhou, C.K. Dong, L.L. Han, J. Yang, X.W. Du, Top-down preparation of active cobalt oxide catalyst. ACS Catal. 6(10), 6699-6703 (2016). https://doi.org/10.1021/acscatal.6b02416

143. L. Li, L. Yu, Z. Lin, G. Yang, Reduced $\mathrm{TiO}_{2}$-graphene oxide heterostructure as broad spectrum-driven efficient watersplitting photocatalysts. ACS Appl. Mater. Interfaces 8(13), 8536-8545 (2016). https://doi.org/10.1021/acsami.6b00966

144. K. Ibrahim, I. Novodchuk, K. Mistry, M. Singh, C. Ling et al., Laser-directed assembly of nanorods of 2D materials. Small 15(46), 1904415 (2019). https://doi.org/10.1002/smll.20190 4415

145. Z. Li, J.Y. Fu, Y. Feng, C.K. Dong, H. Liu et al., A silver catalyst activated by stacking faults for the hydrogen evolution reaction. Nat. Catal. 2(12), 1107-1114 (2019). https:// doi.org/10.1038/s41929-019-0365-9

146. E.H. Penilla, L.F. Devia-Cruz, A.T. Wieg, P. Martinez-Torres, N. Cuando-Espitia et al., Ultrafast laser welding of ceramics. Science 365(6455), 803 (2019). https://doi.org/10.1126/scien ce.aaw6699

147. H. Luo, C. Wang, C. Linghu, K. Yu, C. Wang et al., Laserdriven programmable non-contact transfer printing of objects onto arbitrary receivers via an active elastomeric micro-structured stamp. Natl. Sci. Rev. 7(2), 296-304 (2019). https://doi. org/10.1093/nsr/nwz109

148. C. Chen, Y. Kuang, L. Hu, Challenges and opportunities for solar evaporation. Joule 3(3), 683-718 (2019). https://doi. org/10.1016/j.joule.2018.12.023

149. M. Gao, L. Zhu, C.K. Peh, G.W. Ho, Solar absorber material and system designs for photothermal water vaporization towards clean water and energy production. Energy Environ. Sci. 12(3), 841-864 (2019). https://doi.org/10.1039/C8EE0 $1146 \mathrm{~J}$

150. G. Liu, J. Xu, K. Wang, Solar water evaporation by black photothermal sheets. Nano Energy 41, 269-284 (2017). https ://doi.org/10.1016/j.nanoen.2017.09.005

151. C.C. Chuang, H.C. Chu, S.B. Huang, W.S. Chang, H.Y. Tuan, Laser-induced plasmonic heating in copper nanowire fabric as a photothermal catalytic reactor. Chem. Eng. J. 379, 122285 (2020). https://doi.org/10.1016/j.cej.2019.122285

152. X. Yan, Z. Huang, S. Sett, J. Oh, H. Cha et al., Atmospheremediated superhydrophobicity of rationally designed micro/ nanostructured surfaces. ACS Nano 13(4), 4160-4173 (2019). https://doi.org/10.1021/acsnano.8b09106

153. S.A. Jalil, B. Lai, M. ElKabbash, J. Zhang, E.M. Garcell et al., Spectral absorption control of femtosecond laser-treated metals and application in solar-thermal devices. Light-Sci. Appl. 9(1), 14 (2020). https://doi.org/10.1038/s41377-020-0242-y

154. P. Fan, B. Bai, J. Long, D. Jiang, G. Jin et al., Broadband high-performance infrared antireflection nanowires facilely grown on ultrafast laser structured $\mathrm{Cu}$ surface. Nano Lett. 15(9), 5988-5994 (2015). https://doi.org/10.1021/acs.nanol ett.5b02141

155. P. Fan, H. Wu, M. Zhong, H. Zhang, B. Bai et al., Largescale cauliflower-shaped hierarchical copper nanostructures for efficient photothermal conversion. Nanoscale 8(30), 14617-14624 (2016). https://doi.org/10.1039/C6NR03662G

156. P. Fan, B. Bai, M. Zhong, H. Zhang, J. Long et al., General strategy toward dual-scale-controlled metallic micro-nano hybrid structures with ultralow reflectance. ACS Nano 11(7), 7401-7408 (2017). https://doi.org/10.1021/acsnano.7b03673

157. P. Zhang, Q. Liao, H. Yao, H. Cheng, Y. Huang et al., Threedimensional water evaporation on a macroporous vertically aligned graphene pillar array under one sun. J. Mater. Chem. A 6(31), 15303-15309 (2018). https://doi.org/10.1039/ C8TA05412F

158. J. Li, Y. Liu, L. Lin, M. Wang, T. Jiang et al., Optical nanomanipulation on solid substrates via optothermally-gated photon nudging. Nat. Commun. 10(1), 5672 (2019). https:// doi.org/10.1038/s41467-019-13676-3

159. Z.W. Seh, K.D. Fredrickson, B. Anasori, J. Kibsgaard, A.L. Strickler et al., Two-dimensional molybdenum carbide (MXene) as an efficient electrocatalyst for hydrogen evolution. ACS Energy Lett. 1, 589 (2016). https://doi.org/10.1021/ acsenergylett.6b00247

160. J. Liang, C. Jiang, W. Wu, Toward fiber-, paper-, and foambased flexible solid-state supercapacitors: electrode materials and device designs. Nanoscale 11(15), 7041-7061 (2019). https://doi.org/10.1039/C8NR10301A

161. L. Liu, Y. Feng, W. Wu, Recent progress in printed flexible solid-state supercapacitors for portable and wearable energy storage. J. Power Sources 410-411, 69-77 (2019). https://doi. org/10.1016/j.jpowsour.2018.11.012

162. W. Wu, Stretchable electronics: functional materials, fabrication strategies and applications. Scie. Technol. Adv. Mater. 20(1), 187-224 (2019). https://doi.org/10.1080/14686 996.2018.1549460

163. W. Gao, N. Singh, L. Song, Z. Liu, A.L.M. Reddy et al., Direct laser writing of micro-supercapacitors on hydrated graphite oxide films. Nat. Nanotechnol. 6(8), 496-500 (2011). https://doi.org/10.1038/nnano.2011.110

164. N. Kamboj, T. Purkait, M. Das, S. Sarkar, K.S. Hazra et al., Ultralong cycle life and outstanding capacitive performance of a $10.8 \mathrm{~V}$ metal free micro-supercapacitor with highly 
conducting and robust laser-irradiated graphene for an integrated storage device. Energy Environ. Sci. 12(8), 2507-2517 (2019). https://doi.org/10.1039/C9EE01458F

165. J. Cai, C. Lv, A. Watanabe, Laser direct writing of high-performance flexible all-solid-state carbon micro-supercapacitors for an on-chip self-powered photodetection system. Nano Energy 30, 790-800 (2016). https://doi.org/10.1016/j.nanoe n.2016.09.017

166. W. He, R. Ma, D.J. Kang, High-performance, flexible planar microsupercapacitors based on crosslinked polyaniline using laser printing lithography. Carbon 161, 117-122 (2020). https ://doi.org/10.1016/j.carbon.2020.01.047

167. A. Lamberti, F. Clerici, M. Fontana, L. Scaltrito, A highly stretchable supercapacitor using laser-induced graphene electrodes onto elastomeric substrate. Adv. Energy Mater. 6(10), 1600050 (2016). https://doi.org/10.1002/aenm.201600050

168. J. Ye, H. Tan, S. Wu, K. Ni, F. Pan et al., Direct laser writing of graphene made from chemical vapor deposition for flexible, integratable micro-supercapacitors with ultrahigh power output. Adv. Mater. 30(27), 1801384 (2018). https:// doi.org/10.1002/adma.201801384

169. J. Gao, C. Shao, S. Shao, F. Wan, C. Gao et al., Laser-assisted large-scale fabrication of all-solid-state asymmetrical microsupercapacitor array. Small 14(37), 1801809 (2018). https:// doi.org/10.1002/smll.201801809

170. J. Lee, J.Y. Seok, S. Son, M. Yang, B. Kang, High-energy, flexible micro-supercapacitors by one-step laser fabrication of a self-generated nanoporous metal/oxide electrode. J. Mater. Chem. A 5(47), 24585-24593 (2017). https://doi. org/10.1039/C7TA07960E

171. J.Y. Hwang, M.F. El-Kady, Y. Wang, L. Wang, Y. Shao et al., Direct preparation and processing of graphene $/ \mathrm{RuO}_{2}$ nanocomposite electrodes for high-performance capacitive energy storage. Nano Energy 18, 57-70 (2015). https://doi. org/10.1016/j.nanoen.2015.09.009

172. S. Yang, Y. Li, J. Sun, B. Cao, Laser induced oxygen-deficient $\mathrm{TiO}_{2}$ /graphene hybrid for high-performance supercapacitor. J. Power Sources 431, 220-225 (2019). https://doi. org/10.1016/j.jpowsour.2019.05.016

173. W. Wang, L. Lu, Y. Xie, W. Yuan, Z. Wan et al., A highly stretchable microsupercapacitor using laser-induced graphene $/ \mathrm{NiO} / \mathrm{Co}_{3} \mathrm{O}_{4}$ electrodes on a biodegradable waterborne polyurethane substrate. Adv. Mater. Technol. 5(2), 1900903 (2020). https://doi.org/10.1002/admt.201900903

174. L. Li, J. Zhang, Z. Peng, Y. Li, C. Gao et al., High-performance pseudocapacitive microsupercapacitors from laserinduced graphene. Adv. Mater. 28(5), 838-845 (2016). https ://doi.org/10.1002/adma.201503333

175. H. Wu, W. Zhang, S. Kandambeth, O. Shekhah, M. Eddaoudi et al., Conductive metal-organic frameworks selectively grown on laser-scribed graphene for electrochemical microsupercapacitors. Adv. Energy Mater. 9(21), 1900482 (2019). https://doi.org/10.1002/aenm.201900482

176. H.C. Huang, C.J. Chung, C.T. Hsieh, P.L. Kuo, H. Teng, Laser fabrication of all-solid-state microsupercapacitors with ultrahigh energy and power based on hierarchical pore carbon. Nano Energy 21, 90-105 (2016). https://doi. org/10.1016/j.nanoen.2015.12.012

177. Q. Li, Q. Wang, L. Li, L. Yang, Y. Wang et al., Femtosecond laser-etched MXene microsupercapacitors with double-side configuration via arbitrary on- and through-substrate connections. Adv. Energy Mater. 10(24), 2000470 (2020). https:// doi.org/10.1002/aenm.202000470

178. M. Ren, J. Zhang, C. Zhang, M.G. Stanford, Y. Chyan et al., Quasi-solid-state $\mathrm{Li}-\mathrm{O}_{2}$ batteries with laser-induced graphene cathode catalysts. ACS Appl. Energy Mater. 3(2), 1702-1709 (2020). https://doi.org/10.1021/acsaem.9b02182

179. Z. Veliscek, L.S. Perse, R. Dominko, E. Kelder, M. Gaberscek, Preparation, characterisation and optimisation of lithium battery anodes consisting of silicon synthesised using laser assisted chemical vapour pyrolysis. J. Power Sources 273, 380-388 (2015). https://doi.org/10.1016/j.jpows our.2014.09.111

180. D. Munaò, M. Valvo, J. van Erven, E.M. Kelder, J. Hassoun et al., Silicon-based nanocomposite for advanced thin film anodes in lithium-ion batteries. J. Mater. Chem. 22(4), 15561561 (2012). https://doi.org/10.1039/C1JM13565A

181. C. Zhou, K. Zhang, M. Hong, Y. Yang, N. Hu et al., Laserinduced $\mathrm{MnO} / \mathrm{Mn} 3 \mathrm{O} 4 / \mathrm{N}$-doped-graphene hybrid as binderfree anodes for lithium ion batteries. Chem. Eng. J. 385, 123720 (2020). https://doi.org/10.1016/j.cej.2019.123720

182. B. Zhang, M. Deschamps, M.R. Ammar, E. RaymundoPiñero, L. Hennet et al., Laser synthesis of hard carbon for anodes in Na-ion battery. Adv. Mater. Technol. 2(3), 1600227 (2017). https://doi.org/10.1002/admt.201600227

183. T. Han, A. Nag, N. Afsarimanesh, S.C. Mukhopadhyay, S. Kundu et al., Laser-assisted printed flexible sensors: a review. Sensors 19(6), 1462 (2019). https://doi.org/10.3390/s1906 1462

184. X. Wang, Z. Liu, T. Zhang, Flexible sensing electronics for wearable/attachable health monitoring. Small 13(25), 1602790 (2017). https://doi.org/10.1002/smll.201602790

185. R. Rahimi, M. Ochoa, W. Yu, B. Ziaie, Highly stretchable and sensitive unidirectional strain sensor via laser carbonization. ACS Appl. Mater. Interfaces 7(8), 4463-4470 (2015). https ://doi.org/10.1021/am509087u

186. L.Q. Tao, H. Tian, Y. Liu, Z.Y. Ju, Y. Pang et al., An intelligent artificial throat with sound-sensing ability based on laser induced graphene. Nat. Commun. 8(1), 14579 (2017). https://doi.org/10.1038/ncomms14579

187. B.K.B. Deka, A. Hazarika, J. Kim, H.E. Jeong, Y.B. Park et al., Fabrication of the piezoresistive sensor using the continuous laser-induced nanostructure growth for structural health monitoring. Carbon 152, 376-387 (2019). https://doi. org/10.1016/j.carbon.2019.06.015

188. O.A. Araromi, S. Rosset, H.R. Shea, High-resolution, largearea fabrication of compliant electrodes via laser ablation for robust, stretchable dielectric elastomer actuators and sensors. ACS Appl. Mater. Interfaces 7(32), 18046-18053 (2015). https://doi.org/10.1021/acsami.5b04975

189. A. Nag, S.C. Mukhopadhyay, J. Kosel, Flexible carbon nanotube nanocomposite sensor for multiple physiological 
parameter monitoring. Sens. Actuat. A-Phys. 251, 148-155 (2016). https://doi.org/10.1016/j.sna.2016.10.023

190. A. Nag, S.C. Mukhopadhyay, J. Kosel, Tactile sensing from laser-ablated metallized PET films. IEEE Sens. J. 17(1), 7-13 (2016). https://doi.org/10.1109/JSEN.2016.2617878

191. S. Son, J.E. Park, J. Lee, M. Yang, B. Kang, Laser-assisted fabrication of single-layer flexible touch sensor. Sci. Rep. 6(1), 34629 (2016). https://doi.org/10.1038/srep34629

192. S. Bai, S. Zhang, W. Zhou, D. Ma, Y. Ma et al., Laser-assisted reduction of highly conductive circuits based on copper nitrate for flexible printed sensors. Nano-Micro Lett. 9(4), 42 (2017). https://doi.org/10.1007/s40820-017-0139-3

193. S.Y. Yu, G. Schrodj, K. Mougin, J. Dentzer, J.P. Malval et al., Direct laser writing of crystallized $\mathrm{TiO}_{2}$ and $\mathrm{TiO}_{2} /$ carbon microstructures with tunable conductive properties. Adv. Mater. 30(51), 1805093 (2018). https://doi.org/10.1002/ adma. 201805093

194. G. Dubourg, M. Radović, Multifunctional screen-printed $\mathrm{TiO}_{2}$ nanoparticles tuned by laser irradiation for a flexible and scalable UV detector and room-temperature ethanol sensor. ACS Appl. Mater. Interfaces 11(6), 6257-6266 (2019). https://doi.org/10.1021/acsami.8b19976

195. D. Wu, Q. Peng, S. Wu, G. Wang, L. Deng et al., A simple graphene $\mathrm{NH}_{3}$ gas sensor via laser direct writing. Sensors 18(12), 4405 (2018). https://doi.org/10.3390/s18124405

196. R. Park, H. Kim, S. Lone, S. Jeon, W.Y. Kwon et al., Onestep laser patterned highly uniform reduced graphene oxide thin films for circuit-enabled tattoo and flexible humidity sensor application. Sensors 18(6), 1857 (2018). https://doi. org/10.3390/s18061857

197. Q.A. Drmosh, Z.H. Yamani, A.H. Hendi, M.A. Gondal, R.A. Moqbel et al., A novel approach to fabricating a ternary rGO/ $\mathrm{ZnO} / \mathrm{Pt}$ system for high-performance hydrogen sensor at low operating temperatures. Appl. Surf. Sci. 464, 616-626 (2019). https://doi.org/10.1016/j.apsusc.2018.09.128

198. T.L. Chang, C.Y. Chou, C.P. Wang, T.C. Teng, H.C. Han, Picosecond laser-direct fabrication of graphene-based electrodes for a gas sensor module with wireless circuits. Microelectron. Eng. 210, 19-26 (2019). https://doi.org/10.1016/j. mee.2019.03.003

199. B. Sun, R.N. McCay, S. Goswami, Y. Xu, C. Zhang et al., Gas-permeable, multifunctional on-skin electronics based on laser-induced porous graphene and sugar-templated elastomer sponges. Adv. Mater. 30(50), 1804327 (2018). https://doi. org/10.1002/adma.201804327

200. M.G. Stanford, J.T. Li, Y. Chyan, Z. Wang, W. Wang et al., Laser-induced graphene triboelectric nanogenerators. ACS Nano 13(6), 7166-7174 (2019). https://doi.org/10.1021/acsna no. 9 b02596

201. J. Huang, X. Fu, G. Liu, S. Xu, X. Li et al., Micro/nano-structures-enhanced triboelectric nanogenerators by femtosecond laser direct writing. Nano Energy 62, 638-644 (2019). https ://doi.org/10.1016/j.nanoen.2019.05.081

202. Y. Zhang, N. Li, Y. Xiang, D. Wang, P. Zhang et al., A flexible non-enzymatic glucose sensor based on copper nanoparticles anchored on laser-induced graphene. Carbon 156, 506-513 (2020). https://doi.org/10.1016/j.carbon.2019.10.006

203. D. Yin, J. Feng, R. Ma, Y.F. Liu, Y.L. Zhang et al., Efficient and mechanically robust stretchable organic lightemitting devices by a laser-programmable buckling process. Nat. Commun. 7(1), 11573 (2016). https://doi.org/10.1038/ ncomms 11573

204. H. Jeon, S. Koo, W.M. Reese, P. Loskill, C.P. Grigoropoulos et al., Directing cell migration and organization via nanocrater-patterned cell-repellent interfaces. Nat. Mater. 14(9), 918-923 (2015). https://doi.org/10.1038/nmat4342

205. S.Y. Seo, J. Park, J. Park, K. Song, S. Cha et al., Writing monolithic integrated circuits on a two-dimensional semiconductor with a scanning light probe. Nat. Electron. 1(9), 512-517 (2018). https://doi.org/10.1038/s41928-018-0129-6

206. L. Lin, J. Li, W. Li, M.N. Yogeesh, J. Shi et al., Optothermoplasmonic nanolithography for on-demand patterning of 2D materials. Adv. Funct. Mater. 28(41), 1803990 (2018). https ://doi.org/10.1002/adfm.201803990

207. P. Zhang, L. Li, D. Nordlund, H. Chen, L. Fan et al., Dendritic core-shell nickel-iron-copper metal/metal oxide electrode for efficient electrocatalytic water oxidation. Nat. Commun. 9(1), 381 (2018). https://doi.org/10.1038/s41467-017-02429-9

208. J. Zhang, T. Wang, P. Liu, Z. Liao, S. Liu et al., Efficient hydrogen production on $\mathrm{MoNi}_{4}$ electrocatalysts with fast water dissociation kinetics. Nat. Commun. 8, 15437 (2017). https://doi.org/10.1038/ncomms 15437

209. S. Zhuo, Y. Shi, L. Liu, R. Li, L. Shi et al., Dual-template engineering of triple-layered nanoarray electrode of metal chalcogenides sandwiched with hydrogen-substituted graphdiyne. Nat. Commun. 9(1), 3132 (2018). https://doi. org/10.1038/s41467-018-05474-0

210. X. Mo, K.C. Chan, E.C.M. Tse, A scalable laser-assisted method to produce active and robust graphene-supported nanoparticle electrocatalysts. Chem. Mater. 31(19), 8230-8238 (2019). https://doi.org/10.1021/acs.chemmater.9b03669

211. T. Rauscher, C.I. Müller, A. Gabler, T. Gimpel, M. Köhring et al., Femtosecond-laser structuring of Ni electrodes for highly active hydrogen evolution. Electrochim. Acta 247, 1130-1139 (2017). https://doi.org/10.1016/j.elect acta.2017.07.074

212. A. Gabler, C.I. Müller, T. Rauscher, M. Köhring, B. Kieback et al., Ultrashort pulse laser-structured nickel surfaces as hydrogen evolution electrodes for alkaline water electrolysis. Int. J. Hydrogen Energy 42(16), 10826-10833 (2017). https ://doi.org/10.1016/j.ijhydene.2017.02.006

213. A. Gabler, C.I. Müller, T. Rauscher, T. Gimpel, R. Hahn et al., Ultrashort-pulse laser structured titanium surfaces with sputter-coated platinum catalyst as hydrogen evolution electrodes for alkaline water electrolysis. Int. J. Hydrogen Energy 43(15), 7216-7226 (2018). https://doi.org/10.1016/j. ijhydene.2018.02.130

214. T.F. Hung, Z.W. Yin, S.B. Betzler, W. Zheng, J. Yang et al., Nickel sulfide nanostructures prepared by laser irradiation for efficient electrocatalytic hydrogen evolution reaction and 
supercapacitors. Chem. Eng. J. 367, 115-122 (2019). https:// doi.org/10.1016/j.cej.2019.02.136

215. D.N. Nguyen, L.N. Nguyen, P.D. Nguyen, T.V. Thu, A.D. Nguyen et al., Crystallization of amorphous molybdenum sulfide induced by electron or laser beam and its effect on $\mathrm{H}_{2}$-evolving activities. J. Phys. Chem. C 120(50), 2878928794 (2016). https://doi.org/10.1021/acs.jpcc.6b08817

216. G. Ou, P. Fan, X. Ke, Y. Xu, K. Huang et al., Defective molybdenum sulfide quantum dots as highly active hydrogen evolution electrocatalysts. Nano Res. 11(2), 751-761 (2018). https://doi.org/10.1007/s12274-017-1684-2

217. H. Deng, C. Zhang, Y. Xie, T. Tumlin, L. Giri et al., Laser induced $\mathrm{MoS}_{2}$ /carbon hybrids for hydrogen evolution reaction catalysts. J. Mater. Chem. A 4(18), 6824-6830 (2016). https://doi.org/10.1039/C5TA09322H

218. P. Zuo, L. Jiang, X. Li, B. Li, P. Ran et al., Metal (Ag, Pt)$\mathrm{MoS}_{2}$ hybrids greenly prepared through photochemical reduction of femtosecond laser pulses for SERS and HER. ACS Sustain. Chem. Eng. 6(6), 7704-7714 (2018). https:// doi.org/10.1021/acssuschemeng.8b00579

219. G.O.S. Santos, L.R.A. Silva, Y.G.S. Alves, R.S. Silva, K.I.B. Eguiluz et al., Enhanced stability and electrocatalytic properties of $\mathrm{Ti} / \mathrm{Ru}_{x} \mathrm{Ir}_{1-x} \mathrm{O}_{2}$ anodes produced by a new laser process. Chem. Eng. J. 355, 439-447 (2019). https://doi.org/10.1016/j. cej.2018.08.145

220. M. Cai, R. Pan, W. Liu, X. Luo, C. Chen et al., Laser-assisted doping and architecture engineering of $\mathrm{Fe}_{3} \mathrm{O}_{4}$ nanoparticles for highly enhanced oxygen evolution reaction. Chemsuschem 12(15), 3562-3570 (2019). https://doi.org/10.1002/ cssc. 201901020

221. T. Nishi, Y. Hayasaka, T.M. Suzuki, S. Sato, N. Isomura et al., Electrochemical water oxidation catalysed by $\mathrm{CoO}-\mathrm{Co}_{2} \mathrm{O}_{3}-$ $\mathrm{Co}(\mathrm{OH})_{2}$ multiphase-nanoparticles prepared by femtosecond laser ablation in water. ChemistrySelect 3(17), 4979-4984 (2018). https://doi.org/10.1002/slct.201800943

222. Z.W. Gao, T. Ma, X.M. Chen, H. Liu, L. Cui et al., Strongly coupled $\mathrm{CoO}$ nanoclusters/CoFe LDHs hybrid as a synergistic catalyst for electrochemical water oxidation. Small 14(17), 1800195 (2018). https://doi.org/10.1002/smll.201800195

223. C. Meng, M. Lin, X. Sun, X. Chen, X. Chen et al., Laser synthesis of oxygen vacancy-modified $\mathrm{CoOOH}$ for highly efficient oxygen evolution. Chem. Commun. 55(20), 2904-2907 (2019). https://doi.org/10.1039/C8CC08951E

224. J. Zhang, M. Ren, L. Wang, Y. Li, B.I. Yakobson et al., Oxidized laser-induced graphene for efficient oxygen electrocatalysis. Adv. Mater. 30(21), 1707319 (2018). https://doi. org/10.1002/adma.201707319

225. J. Zhang, M. Ren, Y. Li, J.M. Tour, In situ synthesis of efficient water oxidation catalysts in laser-induced graphene. ACS Energy Lett. 3(3), 677-683 (2018). https://doi. org/10.1021/acsenergylett.8b00042
226. J. Zhang, C. Zhang, J. Sha, H. Fei, Y. Li et al., Efficient watersplitting electrodes based on laser-induced graphene. ACS Appl. Mater. Interfaces 9(32), 26840-26847 (2017). https:// doi.org/10.1021/acsami.7b06727

227. R. Ye, Y. Chyan, J. Zhang, Y. Li, X. Han et al., Laser-induced graphene formation on wood. Adv. Mater. 29(37), 1702211 (2017). https://doi.org/10.1002/adma.201702211

228. J. Jia, T. Xiong, L. Zhao, F. Wang, H. Liu et al., Ultrathin $\mathrm{N}$-Doped $\mathrm{Mo}_{2} \mathrm{C}$ nanosheets with exposed active sites as efficient electrocatalyst for hydrogen evolution reactions. ACS Nano 11(12), 12509-12518 (2017). https://doi.org/10.1021/ acsnano.7b06607

229. Y. Liu, P. Liu, W. Qin, X. Wu, G. Yang, Laser modificationinduced $\mathrm{NiCo}_{2} \mathrm{O}_{4-\delta}$ with high exterior $\mathrm{Ni}^{3+} / \mathrm{Ni}^{2+}$ ratio and substantial oxygen vacancies for electrocatalysis. Electrochim. Acta 297, 623-632 (2019). https://doi.org/10.1016/j. electacta.2018.11.111

230. X. Ye, Z. Lin, H. Zhang, H. Zhu, Z. Liu et al., Protecting carbon steel from corrosion by laser in situ grown graphene films. Carbon 94, 326-334 (2015). https://doi.org/10.1016/j. carbon.2015.06.080

231. E. Kostal, S. Stroj, S. Kasemann, V. Matylitsky, M. Domke, Fabrication of biomimetic fog-collecting superhydrophilicsuperhydrophobic surface micropatterns using femtosecond lasers. Langmuir 34(9), 2933-2941 (2018). https://doi. org/10.1021/acs.langmuir.7b03699

232. X. Bai, Q. Yang, Y. Fang, J. Zhang, J. Yong et al., Superhydrophobicity-memory surfaces prepared by a femtosecond laser. Chem. Eng. J. 383, 123143 (2020). https://doi. org/10.1016/j.cej.2019.123143

233. Y. Li, D.X. Luong, J. Zhang, Y.R. Tarkunde, C. Kittrell et al., Laser-Induced graphene in controlled atmospheres: from superhydrophilic to superhydrophobic surfaces. Adv. Mater. 29(27), 1700496 (2017). https://doi.org/10.1002/adma.20170 0496

234. B.N. Shivananju, L. Zhou, Y. Yin, W. Yu, B. Shabbir et al., Probing the dynamic structural changes of DNA using ultrafast laser pulse in graphene-based optofluidic device. InfoMat 1-11, 1 (2020). https://doi.org/10.1002/inf2.12114

235. Y. Wang, Q. Zhang, Z. Zhu, F. Lin, J. Deng et al., Laser streaming: Turning a laser beam into a flow of liquid. Sci. Adv. 3(9), e1700555 (2017). https://doi.org/10.1126/sciad v. 1700555

236. S. Yue, F. Lin, Q. Zhang, N. Epie, S. Dong et al., Goldimplanted plasmonic quartz plate as a launch pad for laser-driven photoacoustic microfluidic pumps. Proc. Natl. Acad. Sci. 116(14), 6580 (2019). https://doi.org/10.1073/ pnas. 1818911116 